\title{
Childhood and adolescent depression : the role of environmental adversities, of the serotonin transporter gene and of their interaction, in a developmental perspective
}

Citation for published version (APA):

Nobile, M. (2012). Childhood and adolescent depression : the role of environmental adversities, of the serotonin transporter gene and of their interaction, in a developmental perspective. [Doctoral Thesis, Maastricht University]. Maastricht University. https://doi.org/10.26481/dis.20121011mn

Document status and date:

Published: 01/01/2012

DOI:

10.26481/dis.20121011mn

Document Version:

Publisher's PDF, also known as Version of record

Please check the document version of this publication:

- A submitted manuscript is the version of the article upon submission and before peer-review. There can be important differences between the submitted version and the official published version of record. People interested in the research are advised to contact the author for the final version of the publication, or visit the DOI to the publisher's website.

- The final author version and the galley proof are versions of the publication after peer review.

- The final published version features the final layout of the paper including the volume, issue and page numbers.

Link to publication

\footnotetext{
General rights rights.

- You may freely distribute the URL identifying the publication in the public portal. please follow below link for the End User Agreement:

www.umlib.nl/taverne-license

Take down policy

If you believe that this document breaches copyright please contact us at:

repository@maastrichtuniversity.nl

providing details and we will investigate your claim.
}

Copyright and moral rights for the publications made accessible in the public portal are retained by the authors and/or other copyright owners and it is a condition of accessing publications that users recognise and abide by the legal requirements associated with these

- Users may download and print one copy of any publication from the public portal for the purpose of private study or research.

- You may not further distribute the material or use it for any profit-making activity or commercial gain

If the publication is distributed under the terms of Article 25fa of the Dutch Copyright Act, indicated by the "Taverne" license above, 


\section{Childhood and Adolescent Depression}

The Role of Environmental Adversities, of the Serotonin Transporter Gene and of their Interaction, in a Developmental Perspective 
ISBN 978-88-907619-0-4

Copyright $\odot$ Maria Nobile, Maastricht 2012

All rights riserved. No part of this publication may be reproduced, stored in a retrieval system, or transmitted in any form or by any means without the prior permission from the proprietor.

Printed in Italy by Grafiche Boffi - Giussano 


\section{Childhood and Adolescent Depression}

The Role of Environmental Adversities, of the Serotonin Transporter Gene and of their Interaction, in a Developmental Perspective

\section{DISSERTATION}

to obtain the degree of

Doctor at the Maastricht University, on the authority of the Rector Magnificus,

Prof. dr. L.L.G. Soete

in accordance with the decision of the Board of Deans,

to be defended in public

on Thursday, the $11^{\text {th }}$ October 2012, at 2.00 p.m.

by

Maria Nobile 
Supervisor

Prof. dr. E.J.L. Griez

Co-supervisor

Prof. dr. G. Perna, University of Miami, USA

\section{Assessment Committee}

Prof. dr. F.R.J. Verhey, chairman

Prof. dr. T. van Amelsvoort

Prof. dr. S. Claes

Prof. dr. I. Germeys

Dr. K. Schruers 


\section{To my Father}

"The Child is Father of the Man"

W. Wordsworth

"Nothing in life is to be feared, it is only to be understood. Now is the time to understand more, so that we may fear less."

M. Curie 



\section{CONTENTS}

CHAPTER 1 : INTRODUCTION

- Childhood and adolescent depression

- The role of environmental adversities

- The role of genetic factors

- The gene environment interaction hypothesis

- Molecular genetic studies of gene-environment interactions: The case of serotonin transporter gene

- The role of time

- Overview

CHAPTER 2: Psychopathology and adversities from early to late adolescence: a general population follow-up study with the CBCL DSM-Oriented Scale

CHAPTER 3: Effects of Serotonin Transporter Promoter Genotype on Platelet Serotonin Transporter Functionality in Depressed Children and adolescents

CHAPTER 4: A case-control and family-based association study of the 5-HTTLPR in pediatric-onset depressive disorder

CHAPTER 5: The influence of family structure, and the TPH2 G-703T and 5-HTTLPR serotonergic genes upon affective problems in children aged $10-14$ years-

CHAPTER 6: Socio-economic status moderates the genetic contribution of the dopamine receptor D4 and 5-HTTLPR polymorphisms to externalization in preadolescence

CHAPTER 7: The moderation by the serotonin transporter gene on the continuity/discontinuity of internalizing problems throughout adolescence and the role of family structure

CHAPTER 8: Summary and concluding remarks 



\section{CHAPTER 1}

\section{INTRODUCTION}

\section{Childhood and adolescent depression}

In the past three decades, depression research in children and adolescents has moved from adult clinical descriptions and theories to the development of an increasingly sophisticated understanding of these disorders based on a developmental psychopathology framework. Developmental psychopathology has more and more finely identified the clinical and epidemiological features of depression in youngsters. In particular, systematic empirical studies have started to characterize the longitudinal course of major depressive disorder and common patterns of comorbid psychopathology, identifying several core patterns of convergence and divergence of depressive presentations across the lifespan. Furthermore, much is known about the familial and psychological context in which early-onset depression develops; in addition, specific interactions between genetic risk and environmental risk factors are beginning to be identified even though many basic questions remain in this specific area, underlining the need for researchers and clinicians to account for the unique developmental aspects of depressive disorders beginning early in life.

The diagnosis of dysthymic disorder and major depressive disorder is based on similar criteria for children, adolescents and adults with two important exceptions. First, the Diagnostic and Statistical Manual of Mental Disorders $4^{\text {th }}$ edition with text revision (DSM-IV TR) has allowed the substitution of irritability for depressed mood in children and adolescents; second, the duration criterion for dysthymic disorder is one instead of two years. Even though the clinical syndrome of depression is substantially similar among children, adolescents and adults, there are some significant developmental differences. (Brent \& Weersing, 2008; Rao \& Chen 2009). Very young patients are more likely to express distress and negative affect by externalizing behaviour problems and somatic complaints, probably because of their still immature language capabilities. On the other hand, vegetative symptoms (e.g.; weight loss or gain, insomnia or hypersomnia) and endogenous-type symptoms (e.g., melancholia, psychotic symptoms and 
suicidal attempts, particularly those involving high lethality) seem to increase with age (Angold \& Costello, 1993; Birmaher et al., 2004). Although the reasons for these developmental variations in depressive symptoms are not known, maturational effects on emotional and behavioural regulation and cognitive function might contribute to these differences.

Depression can also present itself as a subthreshold, subsyndromal, or subclinical condition. In this case, even if DSM-IV TR criteria are not satisfied, the child or adolescent may experience depressive symptoms such as negative self-esteem, sadness or lack of energy, that are more severe and numerous than the norm in his or her reference groups. In children and adolescents subsyndromal or mild depressive symptoms have been shown to increase risk for later major depressive episodes and functional impairment (Gotlib et al., 1995; Lewinsohn et al., 1998, 2002). In this case, elevated symptom states are better investigated by rating scales or questionnaires rather than semi-structured clinical interviews (Angold et al., 1993, 2002)

Prevalence estimates of unipolar depression vary with the time-period of reference and method of assessment. Risk of major depression increases almost exponentially across development. According to epidemiological studies, the prevalence rates of major depressive disorder is approximately $2 \%$ in young children, roughly $4 \%$ in young adolescents, and at least $16 \%$ to $25 \%$ in older adolescents (Lewinsohn et al., 2002, Costello et al., 2002). These prevalence estimates of late- adolescent depression are comparable to the lifetime rates reported in adults, suggesting that the rates of depression begin to plateau by early adult life. Furthermore, these data suggest that, for a substantial proportion of adult cases, the onset occurred during adolescence. During childhood, rates are higher in boys than girls, but during adolescence and after puberty, prevalence rates for girls become approximately twice those for boys (Costello et al., 2011; Lewinsohn et al. 2002).

Longitudinal clinical studies using standardized diagnostic criteria report that mood disorders which begin between the ages 7 and 18 are often episodic (7 to 9 months), but a sizeable amount (up to 20\%) has a more protracted chronic course (more than 18 months) (Kovacs, 1996). Furthermore, children with a diagnosis of major depression are more likely than non- depressed to become depressed in the future (Kovacs, 1996), and dysthymic disorder is often a precursor of later recurrent mood disorder. Consistently, major depressive, manic or hypomanic episodes occur with a frequency significantly higher than chance at some point during the natural course of the dysthymic disorder ( $80 \%$ of dysthymic children) with a median interval between the illness and the first depressive or manic 
episode of 2 to 3 years. When monitored into adulthood, approximately half of depressed adolescents from community sample have major depression in adulthood (Lewinsohn et al., 2002) and about half of depressed young adults had their first episode as a child or adolescent (Newman et al., 1996). During childhood and adolescence, the functional impairments that usually characterize depression can interfere with the achievement of key developmental milestones (e.g. academic achievement, changes in family relationships, establishing peer relationship). Psychosocial disturbances and academic declines as well as social, emotional and cognitive impairments are common (Kovacs, 1996; Cataldo 2005). Interpersonal dysfunction is often characterized by low self-esteem, spending considerable time alone, and eliciting overt negative reactions from peers and adults (e.g. Kovacs \& Lohr, 1995; Messer \& Gross, 1994). In a community-based sample of adolescents, lifetime dysthymic disorder was more frequently associated with psychosocial difficulties at onset (i.e. no sport activities, poor relationships with siblings and problems with parents) (Flament et al., 2001). Depressed children and adolescents frequently experience impairments in relationships with peers, which is in turn a risk factor for lower functioning, especially during such a critical period of development. Intellectual problems are frequently marked by attentional difficulties that interfere with other cognitive tasks on standardized intelligence and neuropsychological tests (e.g. Cataldo et al., 2005) and on academic performance. In addition, negative outcomes of severe depression often include substance use (Rao et al.,1995), suicide attempts (Kovacs et al.,1993), and employment incapacity (Harrington et al.,1990). Adolescents with long-lasting depression in particular have poorer psychosocial outcome and more limited social interaction when they become adults.

\section{The role of environmental adversities}

Environmental adversities play a prominent role in most theories of depression and a clear empirical link exists between stress and depression in children and adolescents (Garber, 2006; Grant et al., 2004; Hammen, 2005), where 'stress' refers to environmental circumstances that pose challenge for children's development. Stress may occur either as an acute event or a chronic adversity, and as a major life event or as minor accumulated events. Stressful events may be normative (e.g. school transition) or pathological (e.g. abuse), and may be dependent on, or independent of, an individual's attitude. Although no single or specific type of environmental adversities leads to depression, certain types of stressful events have been found to be associated with depression: child abuse/neglect (especially for girls), socioeconomic disadvantage, personal 
disappointment, failures and losses, and interpersonal problems, negative family relationship and parental divorce, poor social support (e.g. friendship quality) (for a review see Rao \& Chen, 2009).

Developmental models of psychopathology also suggest a transactional perspective in which stress exposure contributes to depressive symptoms and in turn depressed children and adolescents contribute to negative events through their own behaviour (Hammen, 2006). Longitudinal studies have shown support to the stress-generation model, particularly with regards to interpersonal relationships (Hammen, 2006; Rudolph \& TroopGordon, 2010). Factors that might contribute to the generation of psychosocial adversities (stress) include temperament and personality, lack of interpersonal competence and comorbid psychopathology. This model highlights the 'vicious cycle' that can occur between stress and depression especially during adolescence.

Although environmental risk factor clearly plays a role in childhood and adolescent depression, individuals vary in their response to stress-, and how they respond to stress can affect their future adjusting and emotional well-being. Heterogeneity of response characterizes all known environmental risk factors, including even the most overwhelming trauma. Such response heterogeneity is associated with pre-existing individual differences in temperament, personality, cognition and autonomic physiology, all of which are known to be under genetic influences (Plomin et al., 2001). An innate vulnerability/resilience model implies that exposures to environmental adversities are important, but insufficient in the causal pattern of emotional disorder.

As we will see hereinafter, the hypothesis of genetic moderation implies that differences between individuals, originating in the DNA sequence, bring about differences between individuals in their resilience or vulnerability to the environmental causes of many psychopathological conditions.

\section{The role of genetic factors}

Family studies have examined the extent to which depressive disorder clusters in families.

A large amount of studies have established that parental depression predicts offspring depression. In particular, children of depressed parents are 3 times more likely than non psychiatric controls to develop major depressive disorder, with lifetime risk up to 45 percent (Kaminski \& Garber, 2002; Rice, 2009). In addition, family history appears to be essential for predicting recurrence (Wickramaratne et al., 2000). Multi-generational studies identify patterns of increasingly severe and earlier age of onset 
across successive generations in families with recurrent unipolar (Ohara et al., -1998) or bipolar disorder (Mclnnis et al., 1993; Nylander et al.,1994). However, it needs to be borne in mind that greater familial loading could arise from environmental and genetic effects. In fact, it is highly likely that important non-inherited effects are at work in the generational transmission of depression. For instance, depression interferes with a parent's ability to provide a supportive family environment for a child; rates of hostility towards children, inconsistent parenting, and family and marital conflict are all increased in families in which a parent is depressed (Downey \& Coyne, 1990; Goodman \& Gotlib, 1999).

Family studies provide an estimate of upper limit of heritable effects, as members of the same family can be similar since they share genes and environment.

On the basis of these data, showing a clear evidence of familial transmission of depression, the genetic etiology of childhood onset depression has been extensively investigated by twin and adoption studies. Twin studies involve apportioning variations to genetic, shared environmental and non-shared environmental influences.

Most twin studies of childhood and adolescent depression have been based on nonclinical samples and have examined the genetic and environmental etiology of depressive symptoms as opposed to depressive disorder. In fact, only one twin study of depressive disorder has been carried out in young people (for a review see Rice, 2009). However, good evidence indicates that depression in young people can be examined dimensionally (Angold et al., 2002; Lewinsohn et al., 2002).

Most twin studies find evidence for a significant genetic component to depressive symptomatology. Most heritability estimates (i.e. the proportion of variation due to genetic factors) range from $30 \%$ to $50 \%$. However, wide variation exists across different studies (ranging from $11 \%$ to $72 \%$ ) (Rice et al., 2002).

Recently, in a sample of twins belonging to the general population-based Italian Twin Registry, the heritability estimate for affective problems, as assessed by the CBCL DSM Oriented Scale (DOS), was reported to be moderate: $63 \%$ (54\%-71\%) (Spatola et al., 2007)

Some variation is to be expected due to the fact that heritability estimates are specific to the population being studied. However, with respect to childhood and adolescent depression, some of the variation seems to be attributable to differences between informants who report on symptoms, as well as heterogeneity in etiology according to child sex and age.

Genetic influences have been found to vary with age and sex. Shared environmental influences may be more important in younger children and 
these influences may be replaced by new genetic and unique environmental influences as children grow older. Adolescent onset depression symptomatology seems to have a greater heritable component than child onset depressive symptomatology, especially in girls (Silberg et al., 1999). However, the finding of developmentally-mediated differential heritability of depression may be due to the relatively low number of younger children in the investigated samples, or to an increase in the number of behaviour-dependent life events that emerge in adolescence (Rice et al., 2003; Todd, 2002)

As a consequence $50 \%-70 \%$ variance is explained by shared and nonshared environmental influence, underling the critical role of environmental adversities briefly described earlier.

Progress in molecular genetics technique has made it possible to directly investigate the effect of a host of genes potentially involved in ethiopathogenesis of early-onset depression.

In 'candidate gene' genetic studies the investigated genes were usually chosen because of their involvement in neurotransmissions circuits, or in the 'stress response' and related processes such as neurogenesis, since malfunctions in these biological pathways are most commonly hypothesized to play a role in the development of youngster depression (Belmaker \& Agam, 2008).

Few, if any, of the genes identified in candidate gene association studies of childhood and adolescent depression have survived the test of replication (Middeldorp et al., 2007, 2010), and to date none of genome wide association studies (GWAS) has focused particularly on child and adolescent depression (McGuffin et al., 2005).

There may be several reasons for this lack of definite results. One potential reason is that the disorder is too heterogeneous since it is defined by symptom cluster (i.e. phenotype problem); even if this factor is likely to contribute to the complexity of the analysis, it is unlikely to be the major reason as the diagnosis itself is clearly familial and, therefore, affected individuals would be expected to share alleles. Another possible reason is that the clear familiality has led to an overestimated genetic risk in relation to the shared family environmental risk. This could be a partial explanation as to why the quantification of genetic load is performed through twin and adoption studies, each of which has its own problems and biases (Tishler \& Carey, 2007). Another possible reason for the lack of consistent observation is that to find and quantify the genetic risk loci, relevant environmental risk factors should be factored in. 


\section{The gene environment interaction hypothesis:}

The gene-environment interaction hypothesis assumes that environmental pathogens cause disorder, and that genes influence susceptibility to pathogens. In contrast to main-effect studies, there is no necessary expectation of a direct gene-to-behaviour association in the absence of the environmental pathogen. The gene-environment interaction hypothesis has emerged out of two observations: first, that mental disorders have environmental causes; second, that people show heterogeneity in their response to those causes (Moffitt et al., 2005).

For years, quantitative behavioural genetics have been concerned with partitioning population variance of that due to genetics from that due to environmental influences. The implication has been that the two were separate and it was assumed that gene-environment interactions were usually of so little importance that they could safely be ignored. Furthermore, quantification of heritability, on its own, was singularly unhelpful in the elucidation of causal processes and mechanisms; in most cases the heritability accounted for only about half the population variance, and there has been increasing evidence of gene-environment correlations and interactions, raising questions about the supposed separateness of $G$ and $E$ (Rutter, 2007).

Four main types of gene environment interplay can occur: epigenetic effects of environment on genes; variations in heritability according to environmental circumstances; gene-environment correlations; geneenvironment interactions.

Environment can have a direct effect on genes through a process termed epigenesis (Jaenisch \& Bird, 2003). This kind of gene-environment interplay involves the environmentally induced chemical changes responsible for methylation and acetylation influences on gene expression. This mechanism could be involved in rearing influences in early childhood. Large variations in heritability over time and place are demonstrated clearly and there are different models accounting for these variations. Considering that heritability is a context-specific, population-specific measure, heritability will go down when there is a massive environmentally mediated risk effect. Conversely it will go up in the context of a major genetic risk. For example, some studies (Johnson et al., 2009) reported that heritability of cognitive functioning was significantly lower in children with a very low birth weight in relation to gestational age than those with a normal (or above average) birth weight. According to this model such variation of heritability could reflect just a relative variation. According to the environmental constraints/opportunities model, the genetically influenced individual differences will increase heritability if good environmental 
opportunities mean that they have a greater chance to make a difference, and that heritability will be lower if there are environmental constraints that impede the possibility of genetically influenced individual initiatives making much difference.

Gene-environment correlations (rGE) concern genetic influences on individual variations in people's exposure to particular sorts of environments. This may come about through either the parent's gene or the child's gene and it can be classified as 'passive', 'active' or 'evocative' rGE (Plomin et al., 1977). 'Passive' refers to the effects of parental genes on parental behaviours that help shape the rearing environments which they provide for their children. The rGE comes about when there is a positive correlation between passing on 'risky' genes and providing a 'risky' rearing environment. 'Active' rGE refers to the effects of the child's genes on those child behaviours that serve to select or shape the environment experienced.

'Evocative' refers to the effects of the child's genes on those child behaviours that serve to influence interpersonal interactions and influence other people's reaction to the child.

A new generation of twin studies using structural equation modelling have examined the impact of rGE. Twin studies have selected environmental factors associated with depression, such as stressful life events and family dysfunction, and tested for rGE. Several twin studies have found evidence for rGE between stressful life events and depression (Silberg et al.,1999; Eaves et al., 2003). That is, there appears to be genetic correlation between stressful life events and depression, meaning that the genes that influence depression also influence exposure to certain types of stressful events. Furthermore, rGE with life events could account for the differences in the genetic etiology of depressive symptoms between children and adolescents. Rice and colleagues (2003) found that adolescents reported more stressful life events than children and that rGE was greater in adolescents than children. Another important environmental stressor for which rGE may exist is family negativity, which includes exposure to anger, hostility, and conflict. Evidence for rGE with adverse family factors, including parental negativity and punitive discipline with adolescent depression, has been reported (Neiderheiser et al., 1999; Lau \& Eley, 2008).

Two main points deserve attention. First, part of the genetic influences on child psychopathology derive from the genetic effects on individual differences in the likelihood of children experiencing a risky or protective environment. Second, part of the risk associated with adverse environments is genetically rather than environmentally-mediated. 
Gene-environment interactions occur when the effect of exposure to an environment pathogen is conditional on his or her genotype. This approach 'paradigm' is based on different theoretical assumptions and, on the basis of the findings of Caspi and colleagues (2003), on biological data.

First, there is the basic underlying evolutionary concept of natural selection. This argues that genes are involved in the adaptation of organisms to their environment, that all organisms in a species will not respond to environmental conditions in the same way, and that this withinspecies variation in response involves individual differences in genetic endowment. In short, genetic variation in response to the environment is the raw material for natural selection.

Second, both human and animal studies are quite consistent in revealing great variability in individuals' behavioural responses to all manner of environmental hazards (Rutter, 2007). A heterogeneity in response characterizes even the most overwhelming of traumas, including all known environmental risk factors for psychopathology. To suppose that such response heterogeneity is not influenced by genes would require some assumption that although genes influence all other areas of biological and psychological function, responsiveness to the environment is uniquely outside the sphere of genetic influence (Moffitt et al., 2005; Rutter, 2007). Up to now, there has been relatively little direct study of genetic influences on susceptibility to particular environments, but there is the beginning of evidence of their operation (Kotb et al., 2002; Uhart et al., 2004). It is also the case that research guided by resilience concepts shows that individual variation in response to environmental hazards is associated with preexisting individual differences in temperament, personality, cognitive functioning and psychophysiology, all of which are known to be under a degree of genetic influence (Rutter, 2007). Finally, there is a rapidly growing body of evidence of its importance in somatic medicine (Moffitt et al., 2005; Rutter, 2007).

Although $G \times E$ interaction may be involved in any multifactorial mental disorder, it is perhaps most likely when certain criteria apply. There should be evidence of important substantial environmentally-mediated risks but, equally, there should be marked heterogeneity in individuals' vulnerability to such risks with respect to the probability of their developing the disorder in question. In addition, there should be evidence of not only a substantial genetic effect but also indications that such risks may operate in relation to indirect risk pathways rather than through a direct connection with a particular psychiatric condition. The level of heritability is not a major consideration but gene-environment interaction may be more probable 
when there is substantial discordance within monozygotic pairs.

The second source for anticipating the likelihood of $G \times E$ interaction is the evidence from twin and adoptee studies.

Childhood onset depressive disorders fulfil these criteria.

As regards quantitative findings, genetically sensitive designs have shown various environmentally-mediated effects from specific risk environments for anxiety/depression both in adults and youngsters (for a review see Rutter, 2005, Rice 2009). Specifically for early-onset depression, Silberg and colleagues (2001) used a twin design to examine the depressioninducing effects of stressful life events. Attention was confined to life events (LE) not showing rGE and focusing on adolescent twin girls in the Virginia Twin Study of Adolescent Development. The findings showed a significant increase in heritability in the presence of LE, an increase that was entirely due to the presence of $G \times E$ interaction. The phenotypic analysis showed no effect of LE on anxiety or depression in the absence of a genetic risk, but a significant effect in its presence. On the other hand, genetic factors did have a significant effect in the absence of LE, indicating that there must have been effects on susceptibility to depression and anxiety that operated other than through susceptibility to risk environments (or alternatively that the range of risk environments that were operative were not included in those studied in the investigation). Eley and colleagues (2004) used longitudinal family data from two ongoing genetic studies (with a combined sample of 1,818 adolescent offspring) to examine the possible interplay between familial vulnerability (as indexed by questionnaire measures of anxiety, depression and neuroticism) and three environmental variables (parental education, social adversity, and negative life events) as predictors of a self-report questionnaire measure of adolescent depression one year later. Here, a significant interaction between low parental education and familial vulnerability was found.

These same two studies were later used by Lau and Eley (2008) to test for possible $G \times E$ interaction, using a twin and sibling design. Negative life events and maternal punitive discipline were used as environmental risk indices, both of which involved some genetic influence, using an appropriate model to take into account the rGE. These results are also in accordance with a recent family study that reported that separation life events more strongly predicted the first onset of MDD in young people with a family history of MDD (Zimmerman et al 2009). Examining a different environmental stressor, Rice and colleagues (2006) found evidence for G $x E$ interaction with family conflict and depressive symptoms. Specifically, individuals at genetic risk for depression showed higher depressive symptoms in the presence of family conflict, and the genetic variance of 
depressive symptoms was increased at higher levels of family conflict. Although the quantitative genetic findings on $G \times E$ interaction are quite limited, they are consistent in pointing to the likelihood of $G \times E$ interaction, as do the other findings on the mode of operation of genetic and environmental effects on childhood-onset anxiety and depression.

\section{Molecular genetics studies of gene-environment interactions: the case of serotonin transporter gene}

In recent years, $G \times E$ interaction involving specific gene polymorphisms has been identified both in animals and humans. Replications and positive metaanalysis indicate that measuring environment improves the reliability of genetic research. The fact that these gene-environment interactions are often not accompanied by direct gene-illness associations suggest why 'candidate gene' and 'genome wide' association studies may not detect genes involved in the pathogenesis of depression. In these studies, particular focus has been placed on the interaction of a polymorphism in the Serotonin Transporter gene (5-HTTLPR) and environmental adversity in the causation of depression.

Serotonergic $(5-\mathrm{HT})$ neurotransmission contributes to many physiological functions, including regulation of appetite, sleep, aspects of cognition (memory and learning) and the regulation of mood. The most prescribed drugs in depression are drugs which alter serotonin levels (including SSRIs, tricyclic antidepressant, and MAOI), although the mechanisms underlying their delayed efficacy, which clearly result from adaptive consequences following repeated administration are not completely understood.

The principal function of the serotonin transporter (5-HTT) is to remove serotonin from the synapse, returning it to the presynaptic neuron where the neurotransmitter can be degraded or re-released at a later time. The serotonin transporter gene maps to chromosome 17.

In 1996, it was reported that a repeat length polymorphism in the promoter region of the human serotonin transporter gene (SLC6A4; also known as 5-HTTLPR) regulates gene expression in vitro. Furthermore, individuals carrying one or two copies of the relatively low-expressing short (S) allele of the serotonin transporter linked polymorphic region (5-HTTLPR) exhibit elevated neuroticism, a personality trait involved in the propensity to depression $(L)$. It has been suggested that this polymorphism contributes to dysregulation of serotonergic neurotransmission (Lesch et al., 1996). In 2002, functional magnetic resonance imaging (fMRI) studies showed that the $S$ allele is associated with exaggerated amygdala response to 
environmental threat. This finding suggests that the $S$ allele may influence risk for emotional problems by biasing the response of a key brain region mediating behavioural and physiologic arousal to environmental challenges (Hariri et al., 2002).

In 2003, Caspi and colleagues, using a prospective longitudinal design, reported that carriers of the $S$ allele, transcriptionally less active, exhibit elevated depressive symptoms, diagnosable depression, and suicidality after experiencing stressful life events and childhood maltreatment in a large birth cohort (Caspi et al., 2003).

These three papers, and those following, have generated evidence for validity of the construct of genetically driven individual differences in stress sensitivity and, consequently, the 5-HTTLPR has become the most investigated genetic variant in psychiatry, psychology, and neuroscience.

\section{The role of time: how do responses to trauma vary with development?}

Time is another crucial factor, both in terms of window vulnerability, when brain regions might be maximally sensitive to environmental influences, and in the cascade of maturational events that lead to the unfolding of depression. For example, chronic exposure to stress hormones, whether it occurs during the prenatal period, infancy, childhood or adolescence has an impact on brain structures involved in cognition and mental health. However, the specific effects on the brain, behaviour and cognition emerge as a function of the timing and the duration of the exposure, and some also depend on the interaction between gene effects and previous exposure to environmental adversities (for a review see Lupien, 2009). The effects of chronic or repeated exposure to stress (or a single exposure to severe stress) at different stages of life could depend on the brain area that is developing at the time of exposure. From birth to 2 years of age the hippocampus is developing; therefore it might be the brain area that is most vulnerable to the effects of very early adversities. The exposure to stress from birth to late childhood might lead to changes in amygdala volume as this brain region continues to develop until the late 20 's. During adolescence the hippocampus is fully organized, the amygdala is still developing and there is an important increase in frontal volume. Consequently, stress exposure during this period should have major effects on the frontal cortex; by contrast, the hippocampus, which develops mainly in the first year of life, might be less affected. Interestingly, studies in human adolescents show that adolescents are highly vulnerable to stress possibly because of a protracted glucocorticoid response to stress that persists in adulthood (potentiation/incubation effect). They also 
suggest that the adolescent period is associated with heightened basal and stress-induced activity of the HPA axis (Gunnar et al., 2009). This could be related to the dramatic changes in sex steroids that influences HPA axis activity. As mentioned above, various forms of psychopathology including depression increase in prevalence in adolescence and period of heightened stress often precede the first episode of these disorders. Furthermore, adolescence is also a period in which the long-lasting effects of earlier exposure to stress (maternal separation, maltreatment, low socioeconomic status or parental divorce) become evident.

Taking these considerations as a whole, a life-course approach seems ideal for understanding determinants of developmental depression: causation in depression appears to be multifactorial, including interaction between genes and stressful life events, or between early life trauma and later stress in life; timing of onset and remission vary widely, indicating different trajectories of symptoms over time. Time-sensitive modelling techniques that are able to incorporate multiple interacting factors across time, such as structural equation models, will be critical in understanding the complexity of causal and influencing factors from early development to later stages of life. 


\section{OVERVIEW}

Chapter 1 provides a brief introduction to the concept of childhood and adolescence depression. The role of environmental adversities and of genetic factors in the etiology of early depression are revised, taking into consideration both their single effects and their possible interaction, with a special focus on the effect of the serotonin transporter gene (5-HTTLPR) and adversities. The role of time as a crucial factor, both in terms of window vulnerability and in the cascade of maturational events that lead to the emergence of depressive symptomatology, is briefly discussed.

In Chapter 2 we evaluate the continuity and discontinuity of behavioural problems (including affective problems) from early to late adolescence while taking into account the multiple covariation of psychopathological traits and the complex role of recent adversities. Our results suggest that a higher number of stressful life events during adolescence predicted higher depression problems longitudinally, confirming the importance of adversities in contributing to internalizing problems in youth. Furthermore, our data suggest that the best predictor of affective problems in late adolescence is the presence of high affective problems in preadolescence, showing that homotypic evolution of psychopathology should be expected in the first place, when considering the transition from earlyto late-adolescence. Nevertheless, adolescent Affective Problems were also significantly predicted by Somatic and Oppositional Defiant Problems in pre-adolescence thus confirming the constructs of equifinality (i.e. diversity of pathways leading to a common outcome) for developmental affective problems. Further analysis revealed that recent SLEs partially mediated the heterotypic progression of Oppositional Defiant Problems towards the development of Affective Problems.

In Chapter 3 we investigate possible associations between serotonin transporter promoter (5-HTTLPR), genotypic variants (LL, Ls, and ss) and differential regulation of platelet 5-HTT functionality parameters in a group of drug-naive depressed children and adolescents and healthy controls. We found that depressed children had lower serotonin dissociation rate (Vmax) and lower serotonin dissociation constant (Km). Control subjects with LL genotype had significantly higher Vmax than control subjects with Ls and ss genotype. Control subjects with LL genotype also had significantly higher Vmax than their depressed homologs. In contrast, Vmax was not significantly different between depressed and nondepressed subjects the latter of whom carried the other 2 genotypes. The 
5-HTT promoter genotype, diagnoses, or their interaction had no effect on the other serotonin parameters. These data suggest that LL genotype has a substantial effect on the decrease of $V$ max during a depressive episode.

In Chapter 4 we investigate the possible association between childhoodand early-adolescent-onset DSM-IV depressive disorders (including major depression and dysthymia) and the serotonin transporter promoter polymorphism (5-HTTLPR) locus. An excess of the ss genotype and of the s-allele was found among children with Depressive Disorder. The family-based results suggested that the s-allele was preferentially transmitted to depressed children. These data further support a role for the 5-HTTLPR locus in childhood and adolescence Depressive Disorder.

In Chapter 5 we explore the role of the 5-HTTLPR both alone and in interaction with another serotonergic polymorphism, that is the Tryptophane hydroxylase 2 (TPH2- G703T), upon adolescent depressive symptoms in a general population sample of 607 Italian children aged 1014 years when a psychosocial moderator (i.e. family structure) is taken into account. We found that belonging to 'one-parent' families, the 5HTTLPR 'short' alleles and the TPH2 G-703T ' $G$ variant' were associated - both alone and in apparent gene-by-environment interaction - with higher Affective Problems scores. As predicted by quantitative genetics theory, both polymorphisms contributed with a small effect size, while 'family structure' had a moderate effect size. We found no gene $x$ gene interaction. These results were confirmed as relatively specific after having taken into consideration other environmental variables (SES), a broader psychometric construct (Internalisation), and an alternative definition of the 5-HTTLPR (LA/LG). These data suggest that a putative hazard factor impinging on individual risk at the family-wide level, namely family structure, appears to moderate the effect of two pivotal serotonergic genes in heightening risk for Affective Problems in children.

In Chapter 6, by contrast, we explore the role of the 5-HTTLPR alone and in interaction with the dopamine receptor D4 (DRD4) upon adolescence externalizing problems when a societal moderator (i.e. parental socioeconomic status, SES) is taken into account. We found evidence, based on both one locus and two-loci genotype analyses, that DRD4 long and 5-HTTLPR long alleles in interaction are associated with higher aggressive behaviour scores. These data add evidence to the hypothesis (Benjamin et al. 2002) that the long alleles of DRD4 and the short alleles of 5-HTTLPR oppose each other's effects, in that the DRD4 
long alleles promote approach and extraverted behaviours, whereas the short alleles of 5-HTTLPR promote avoidance behaviours (antagonistic interaction mechanism). We also found that the co-presence of the identified alleles of the DRD4 and 5-HTTLPR genes with low SES multiplies the risk for aggressive behaviours. Consistent with studies that showed the effects of societal moderators on the heritability of externalized behaviours across different segments of the population, these data suggest that diminished social constraints associated with low parental SES may act as enhancers of the genetic influence of specific DRD4 and 5-HTTLPR alleles over aggressive behaviours in preadolescence.

Finally, in Chapter 7, in order to explore the effect of the serotonin transporter gene in interaction with family structure on the continuity/discontinuity of internalizing problems throughout adolescence, we evaluate the moderation of genetic assessment on the effects environmental variables (i.e. socioeconomic status and family structure) in a five-year follow-up general population study. Based on Structural Equation Modelling we found that the pathway between internalizing problems and family structure at the first wave was positive and significant $(\beta=0.24, p<0.01)$ only for genotype S-allele carriers. Furthermore, based on the results of the Lagrange multiplier test, the two groups (LL vs S-allele carriers genotype) showed a significant difference in the pathway between internalizing problems at first and second wave $\left(\mathrm{X}^{2}=3.89, p<.05\right)$, suggesting that the direct impact of internalizing problems at first wave on internalizing problems at second wave was greater for the S-allele carriers group. Data from this longitudinal study suggest that the 5-HTTLPR polymorphism plays an important role in determining the stability of this psychopathological trait throughout a developmental period (i.e. adolescents) during which internalizing problems increase. A moderating role of 5-HTTLPR on the effect of family status in determining the presence of internalizing problems was found only during early adolescence. 


\section{REFERENCES}

Angold, A., \& Costello, E. J. (1993). Depressive comorbidity in children and adolescents: Empirical, theoretical, and methodological issues. The American Journal of Psychiatry, 150(12), 1779-1791.

Angold, A., Erkanli, A., Silberg, J., Eaves, L., \& Costello, E. J. (2002). Depression scale scores in 8-17-year-olds: Effects of age and gender. Journal of Child Psychology and Psychiatry, and Allied Disciplines, 43(8), 1052-1063.

Belmaker, R. H., \& Agam, G. (2008). Major depressive disorder. The New England Journal of Medicine, 358(1), 55-68.

Benjamin, J., Ebstein, R. P., \& Lesch, K. P. (1998). Genes for personality traits: Implications for psychopathology. The International Journal of Neuropsychopharmacology / Official Scientific Journal of the Collegium Internationale Neuropsychopharmacologicum (CINP), 1(2), 153-168.

Birmaher, B., Williamson, D. E., Dahl, R. E., Axelson, D. A., Kaufman, J., Dorn, L. D., et al. (2004). Clinical presentation and course of depression in youth: Does onset in childhood differ from onset in adolescence? Journal of the American Academy of Child and Adolescent Psychiatry, 43(1), 6370.

Brent, D. \&. W.,V.R. (2008). Rutter's child and adolescent psychiatry. In M. Rutter (Ed.), Child and adolescent psychiatry (5th ed., pp. 1230). Oxford: Blackwell.

Caspi, A., Sugden, K., Moffitt, T. E., Taylor, A., Craig, I. W., Harrington, H., et al. (2003). Influence of life stress on depression: Moderation by a polymorphism in the 5-HTT gene. Science (New York, N.Y.), 301(5631), 386-389.

Cataldo, M. G., Nobile, M., Lorusso, M. L., Battaglia, M., \& Molteni, M. (2005). Impulsivity in depressed children and adolescents: A comparison between behavioral and neuropsychological data. Psychiatry Research, 136(2-3), 123-133.

Costello, E. J., Copeland, W., \& Angold, A. (2011). Trends in psychopathology across the adolescent years: What changes when children become adolescents, and when adolescents become adults? Journal of Child Psychology and Psychiatry, and Allied Disciplines, 52(10), 1015-1025.

Costello, E. J., Pine, D. S., Hammen, C., March, J. S., Plotsky, P. M., 
Weissman, M. M., et al. (2002). Development and natural history of mood disorders. Biological Psychiatry, 52(6), 529-542.

Downey, G., \& Coyne, J. C. (1990). Children of depressed parents: An integrative review. Psychological Bulletin, 108(1), 50-76.

Eaves, L., Silberg, J., \& Erkanli, A. (2003). Resolving multiple epigenetic pathways to adolescent depression. Journal of Child Psychology and Psychiatry, and Allied Disciplines, 44(7), 1006-1014.

Eley, T. C., Sugden, K., Corsico, A., Gregory, A. M., Sham, P., McGuffin, P., et al. (2004). Gene-environment interaction analysis of serotonin system markers with adolescent depression. Molecular Psychiatry, 9(10), 908-915.

Flament, M. F., Cohen, D., Choquet, M., Jeammet, P., \& Ledoux, S. (2001). Phenomenology, psychosocial correlates, and treatment seeking in major depression and dysthymia of adolescence. Journal of the American Academy of Child and Adolescent Psychiatry, 40(9), 1070-1078.

Garber, J. (2006). Depression in children and adolescents: Linking risk research and prevention. American Journal of Preventive Medicine, 31(6 Suppl 1), S104-25.

Goodman, S. H., \& Gotlib, I. H. (1999). Risk for psychopathology in the children of depressed mothers: A developmental model for understanding mechanisms of transmission. Psychological Review, 106(3), 458-490.

Gotlib, I. H., Lewinsohn, P. M., \& Seeley, J. R. (1995). Symptoms versus a diagnosis of depression: Differences in psychosocial functioning. Journal of Consulting and Clinical Psychology, 63(1), 90-100.

Grant, K. E., Compas, B. E., Thurm, A. E., McMahon, S. D., \& Gipson, P. Y. (2004). Stressors and child and adolescent psychopathology: Measurement issues and prospective effects. Journal of Clinical Child and Adolescent Psychology 33(2), 412-425.

Gunnar, M. R., Frenn, K., Wewerka, S. S., \& Van Ryzin, M. J. (2009). Moderate versus severe early life stress: Associations with stress reactivity and regulation in 10-12-year-old children. Psychoneuroendocrinology, 34(1), 62-75.

Hammen, C. (2005). Stress and depression. Annual Review of Clinical Psychology, 1, 293-319.

Hammen, C. (2006). Stress generation in depression: Reflections on 
origins, research, and future directions. Journal of Clinical Psychology, 62(9), 1065-1082.

Hariri, A. R., Mattay, V. S., Tessitore, A., Kolachana, B., Fera, F., Goldman, D., et al. (2002). Serotonin transporter genetic variation and the response of the human amygdala. Science (New York, N.Y.), 297(5580), 400-403.

Harrington, R., Fudge, H., Rutter, M., Pickles, A., \& Hill, J. (1990). Adult outcomes of childhood and adolescent depression. I. psychiatric status. Archives of General Psychiatry, 47(5), 465-473.

Jaenisch, R., \& Bird, A. (2003). Epigenetic regulation of gene expression: How the genome integrates intrinsic and environmental signals. Nature Genetics, 33 Suppl, 245-254.

Johnson, S., Fawke, J., Hennessy, E., Rowell, V., Thomas, S., Wolke, D., et al. (2009). Neurodevelopmental disability through 11 years of age in children born before 26 weeks of gestation. Pediatrics, 124(2), e249-57.

Kaminski, K. M., \& Garber, J. (2002). Depressive spectrum disorders in high-risk adolescents: Episode duration and predictors of time to recovery. Journal of the American Academy of Child and Adolescent Psychiatry, 41(4), 410-418.

Kotb, M., Norrby-Teglund, A., McGeer, A., El-Sherbini, H., Dorak, M. T., Khurshid, A., et al. (2002). An immunogenetic and molecular basis for differences in outcomes of invasive group A streptococcal infections. Nature Medicine, 8(12), 1398-1404.

Kovacs, M. (1996). Presentation and course of major depressive disorder during childhood and later years of the life span. Journal of the American Academy of Child and Adolescent Psychiatry, 35(6), 705-715.

Kovacs, M., Goldston, D., \& Gatsonis, C. (1993). Suicidal behaviors and childhood-onset depressive disorders: A longitudinal investigation. Journal of the American Academy of Child and Adolescent Psychiatry, 32(1), 8-20.

Kovacs, M., \& Lohr, W. D. (1995). Research on psychotherapy with children and adolescents: An overview of evolving trends and current issues. Journal of Abnormal Child Psychology, 23(1), 11-30.

Lau, J. Y., \& Eley, T. C. (2008). Disentangling gene-environment correlations and interactions on adolescent depressive symptoms. Journal of Child Psychology and Psychiatry, and Allied Disciplines, 49(2), 142-150.

Lesch, K. P., Bengel, D., Heils, A., Sabol, S. Z., Greenberg, B. D., Petri, 
S., et al. (1996). Association of anxiety-related traits with a polymorphism in the serotonin transporter gene regulatory region. Science (New York, N.Y.), 274(5292), 1527-1531.

Lewinsohn, P. M., Rohde, P., \& Seeley, J. R. (1998). Major depressive disorder in older adolescents: Prevalence, risk factors, and clinical implications. Clinical Psychology Review, 18(7), 765-794.

Lewinsohn, P. M., Seeley, J. R., Buckley, M. E., \& Klein, D. N. (2002). Bipolar disorder in adolescence and young adulthood. Child and Adolescent Psychiatric Clinics of North America, 11(3), 461-75, vii.

Lewinsohn, P. M., Solomon, A., Seeley, J. R., \& Zeiss, A. (2000). Clinical implications of "subthreshold" depressive symptoms. Journal of Abnormal Psychology, 109(2), 345-351.

Lupien, S. J., McEwen, B. S., Gunnar, M. R., \& Heim, C. (2009). Effects of stress throughout the lifespan on the brain, behaviour and cognition. Nature Reviews. Neuroscience, 10(6), 434-445.

McGuffin, P., Knight, J., Breen, G., Brewster, S., Boyd, P. R., Craddock, N., et al. (2005). Whole genome linkage scan of recurrent depressive disorder from the depression network study. Human Molecular Genetics, 14(22), 3337-3345.

McInnis, M. G., McMahon, F. J., Chase, G. A., Simpson, S. G., Ross, C. A., \& DePaulo, J. R.,Jr. (1993). Anticipation in bipolar affective disorder. American Journal of Human Genetics, 53(2), 385-390.

Messer, S. C., \& Gross, A. M. (1994). Childhood depression and aggression: A covariance structure analysis. Behaviour Research and Therapy, 32(6), 663-677.

Moffitt, T. E., Caspi, A., \& Rutter, M. (2005). Strategy for investigating interactions between measured genes and measured environments. Archives of General Psychiatry, 62(5), 473-481.

Neiderhiser, J. M., Reiss, D., Hetherington, E. M., \& Plomin, R. (1999). Relationships between parenting and adolescent adjustment over time: Genetic and environmental contributions. Developmental Psychology, 35(3), 680-692.

Newman, D. L., Moffitt, T. E., Caspi, A., Magdol, L., Silva, P. A., \& Stanton, W. R. (1996). Psychiatric disorder in a birth cohort of young adults: Prevalence, comorbidity, clinical significance, and new case incidence from ages 11 to 21 . Journal of Consulting and Clinical Psychology, 64(3), 552-562. 
Nylander, P. O., Engstrom, C., Chotai, J., Wahlstrom, J., \& Adolfsson, R. (1994). Anticipation in swedish families with bipolar affective disorder. Journal of Medical Genetics, 31(9), 686-689.

Ohara, K., Suzuki, Y., Ushimi, Y., Yoshida, K., \& Ohara, K. (1998). Anticipation and imprinting in japanese familial mood disorders. Psychiatry Research, 79(3), 191-198.

Plomin, R., DeFries, J. C., \& Loehlin, J. C. (1977). Genotype-environment interaction and correlation in the analysis of human behavior. Psychological Bulletin, 84(2), 309-322.

Plomin R. (Ed.), Behavioral genetics (4th ed.). New York; Basingstoke: Worth Publishers; W.H. Freeman.

Rao, U., \& Chen, L. A. (2009). Characteristics, correlates, and outcomes of childhood and adolescent depressive disorders. Dialogues in Clinical Neuroscience, 11(1), 45-62.

Rao, U., Ryan, N. D., Birmaher, B., Dahl, R. E., Williamson, D. E., Kaufman, J., et al. (1995). Unipolar depression in adolescents: Clinical outcome in adulthood. Journal of the American Academy of Child and Adolescent Psychiatry, 34(5), 566-578.

Rice, F., Harold, G. T., \& Thapar, A. (2003). Negative life events as an account of age-related differences in the genetic aetiology of depression in childhood and adolescence. Journal of Child Psychology and Psychiatry, and Allied Disciplines, 44(7), 977-987.

Rudolph, K. D., \& Troop-Gordon, W. (2010). Personal-accentuation and contextual-amplification models of pubertal timing: Predicting youth depression. Development and Psychopathology, 22(2), 433-451.

Rutter, M. (2005). Environmentally mediated risks for psychopathology: Research strategies and findings. Journal of the American Academy of Child and Adolescent Psychiatry, 44(1), 3-18.

Rutter, M. (2007). Gene-environment interdependence. Developmental Science, 10(1), 12-18.

Silberg, J., Pickles, A., Rutter, M., Hewitt, J., Simonoff, E., Maes, H., et al. (1999). The influence of genetic factors and life stress on depression among adolescent girls. Archives of General Psychiatry, 56(3), 225-232.

Silberg, J., Rutter, M., Neale, M., \& Eaves, L. (2001). Genetic moderation of environmental risk for depression and anxiety in adolescent girls. The 
British Journal of Psychiatry: The Journal of Mental Science, 179, 116-121.

Spatola, C. A., Fagnani, C., Pesenti-Gritti, P., Ogliari, A., Stazi, M. A., \& Battaglia, M. (2007). A general population twin study of the CBCL/6-18 DSM-oriented scales. Journal of the American Academy of Child and Adolescent Psychiatry, 46(5), 619-627.

Tishler, P. V., \& Carey, V. J. (2007). Can comparison of MZ- and DZ-twin concordance rates be used invariably to estimate heritability? Twin Research and Human Genetics: The Official Journal of the International Society for Twin Studies, 10(5), 712-717.

Todd, R. D. (2002). Genetics of early onset bipolar affective disorder: Are we making progress? Current Psychiatry Reports, 4(2), 141-145.

Uhart, M., McCaul, M. E., Oswald, L. M., Choi, L., \& Wand, G. S. (2004). GABRA6 gene polymorphism and an attenuated stress response. Molecular Psychiatry, 9(11), 998-1006.

Wickramaratne, P. J., Greenwald, S., \& Weissman, M. M. (2000). Psychiatric disorders in the relatives of probands with prepubertal-onset or adolescent-onset major depression. Journal of the American Academy of Child and Adolescent Psychiatry, 39(11), 1396-1405.

Zimmerman, R., Pal, D. K., Tin, A., Ahsan, H., \& Greenberg, D. A. (2009). Methods for assessing familial aggregation: Family history measures and confounding in the standard cohort, reconstructed cohort and case-control designs. Human Heredity, 68(3), 201-208. 


\section{CHAPTER 2}

\section{Psychopathology and adversities from early to late adolescence: a general population follow-up study with the CBCL DSM-Oriented Scale}

Maria Nobile, Paola Colombo, Monica Bellina, Massimo Molteni, Daniela Simone, Francesco Nardocci, Ombretta Carlet and Marco Battaglia

Epidemiology and Psychiatric Sciences: Published online: 11 aprile 2012; DOI: http://dx.doi.org/10.1017/S2045796012000145 


\section{ABSTRACT}

Aims. Adolescence is a critical, turning point that lies between childhood and adulthood, when the burden of mental disorder may still be prevented. The aim of this study was to evaluate the continuity and discontinuity of behavioural problems in adolescence while taking into account the multiple covariation of psychopathological traits and the complex role of recent stressful life events (SLEs).

Methods. This is a five-year follow-up investigation of emotional and behavioural problems assessed by the newly-developed CBCL DSMOriented Scales (DOSs) in 420 general population subjects aged 15-19 years.

Results. The DOSs showed good stability, even when multiple covariation was taken into account. Longitudinal data showed that homotypic evolution of psychopathology was to be expected in the first place. Equifinality and multifinality were also found. Oppositional Defiant Problems emerged to be polyvalent predictors of both internalizing and externalizing problems. Furthermore, Oppositional Defiant Problems predicted more SLEs, which in turn predicted more Depression, Anxiety and Oppositional Defiant Problems. Mediational analyses confirmed the role of SLEs in partially accounting for the continuity of Oppositional Defiant Problems and for the heterotypic progression towards Affective Problems.

Conclusions. These data underscore early adolescence behavioural problems as an important focus for primary and secondary intervention. 


\section{INTRODUCTION}

Behavioural problems in childhood have been connected to psychiatric disorders and poor psychosocial functioning in adulthood (Caspi et al., 1996; Hofstra et al., 2002; Hatch et al., 2010), but only a relatively small number of studies have investigated the connections between adolescence, development, and psychopathology. In particular, information on the continuity of psychopathology in the transition from preadolescence to adolescence remains scarce. Epidemiologists agree in recognizing that in this critical turning point between childhood and adulthood (Hofstra et al., 2002) the burden of mental disorder may still be prevented by welldesigned interventions based on empirical research (de Girolamo et al., 2012). The potential role of adversities in precipitating and maintaining both internalizing and externalizing disorders in adolescence has also been recognized (Haggerty et al., 1994, Bot et al., 2011). More recently, adversities have been conceptualized within a gene- environment interplay framework, which suggests that adversities not only perpetuate existing disorders but may also be consequences of existing disorders (Mash \& Barkley, 1996).

Studies of the longitudinal consistency of psychopathology across adolescence must therefore take into account three key theoretical and practical issues, namely the co-variation of different forms of psychopathology, the reciprocal effects of adversities and psychopathology, and the costs and benefits of different strategies for conducting longitudinal research. The first issue refers to the moderateto-high reciprocal co-variation between different forms of psychopathology. This should be taken into account when trying to make reliable predictions in time for both homotypic and heterotypic continuity (Copeland et al., 2009a) . Homotypic prediction refers to a psychopathological trait predicting itself over time; heterotypic prediction refers to different psychopathological traits predicting one another. Failure to adequately consider the multiple co-variation of diagnoses (Angold et al., 1999) may limit the meaning of measured pairwise associations of childhood and adolescence disorders. The reason for this is that apparent homotypic and heterotypic continuities between any two diagnoses could in fact be explained by uncontrolled 'third' variables. In a similar way, when looking at the influence of stressful life events (SLEs) upon specific diagnoses (e.g. depression/anxiety), lack of consideration for the effect exerted by SLEs upon other, co-varying forms of psychopathology, would limit the meaning of the estimated associations between adversities and the psychopathological dimension under study. As a matter of fact, few studies 
only analyzed the effects of life events upon a range of mental health dimensions taken into account simultaneously (Copeland et al., 2009b). Available studies typically focused on one, or two, narrow-band domains (depression and anxiety), or broadband problems domain (e.g. internalizing, externalizing and total problems) (Essex et al.,2006; AmoneP'Olak et al.,2009).

The second issue refers to the possible reciprocal effects of adversities and psychopathology. The fact that many stressful agents -such as SLEshave a complex causal architecture that encompasses genetic determinants further complicates the picture and often requires sophisticated conceptualizations and computational approaches (Rutter et al., 2006). This brings about the complex issue of gene-environment interplay (and gene-environment correlation), and adds substantial support to the idea that psychopathology can both be caused by, and cause, SLEs (Plomin et al., 1977). While these causal chains can become very complex and hard to prove even within the context of large, well-designed behavioural genetic studies (Rutter et al., 2006), contemporary longitudinal epidemiological studies cannot ignore the dual nature that SLEs can assume in developmental psychopathology. As a consequence, epidemiological studies need now to consider adversities and psychopathology in their reciprocal influence over time, rather than within the context of unidirectional causal chains (from stressors to psychopathology) only. Specifically, while associational studies of stressors and developmental psychopathology - the former in both moderational and mediational roles - are available (Grant et al., 2006), data are needed on the mediational role of life stressors in sustaining the continuity of a broad spectrum of emotional and behavioural problems in adolescence. The few available studies of this kind looked at the mediational role of SLE in the reciprocal cycle of stress-generation in anxiety and depression (Hammen, 2006). For instance, in a two-year follow-up study Rudolph, Flynn, Abaied, Groot, and Thompson (Rudolph et al., 2009) supported a reciprocal cycle of interpersonal stress and depression among girls (but not boys) aged 10-14.

The third issue is related to more practical and economic considerations. It is clear that longitudinal general population studies of youth based upon direct psychiatric interviews are a gold standard for the field. By these designs one can address the homotypic and heterotypic patterns of prediction while accounting for multiple covariation of comorbidities (Costello et al., 1996; Ford et al., 2003). These research designs also enable the study of the role of SLEs on stability and change in psychopathology, but unfortunately they are extremely costly. Inasmuch 
as we are currently facing a contrast between a global need for better health and budgetary restrictions for research, general population longitudinal studies based upon paper-and-pencil instruments can contribute substantially to the field within more affordable budgetary limits. One of the difficulties that have hampered this type of investigation, however, has been the lack of widely-adopted questionnaires that could be referred to currently employed diagnostic systems, such as the DSMIV or the ICD-10, for the developmental age. In an attempt to overcome this limitation, Achenbach and Rescorla (2001) developed a new scoring system based on consensus between clinicians that allows better correspondence between the vastly adopted CBCL scale and the currently employed DSM-IV diagnostic criteria. The six different CBCL DSM-oriented scales (DOSs) include Affective, Anxiety, Somatic, Attention Deficit/Hyperactivity, Oppositional-Defiant, and Conduct Problems.

Here we show the results of a five-year follow-up investigation of a broad range of emotional and behavioural problems measured with the DOSs among the general population-based PrISMA (Progetto Italiano Salute Mentale Adolescenti) sample (Frigerio et al., 2006; Frigerio et al., 2009). Our first aim was to assess the continuity and discontinuity of DOSs between 10-14 years and 15-19 years while taking into account the reciprocal covariation of scales. The second aim was to investigate the differential association between SLEs and DOSs while taking diagnostic covariation into account. The third aim was to test the mediational role of SLEs in sustaining the continuity of psychopathology during this time interval. 


\section{METHODS}

\section{Subjects}

This study is a five year follow-up of the PrISMA project, which started in 2003, with the purpose of assessing the prevalence of mental disorders in preadolescents (10-14 years) living in Italian urban areas, and of analysing the demographic and biological correlates of emotional and behavioural problems (Frigerio et al., 2006; Nobile et al., 2007; Frigerio et al., 2009; Nobile et al., 2009; Nobile et al., 2010). The original study population consisted of 3,418 Italian preadolescents aged 10-14 years selected through public and private schools. At the time of the PrISMA 1st wave (W1) study participants were attending the $6^{\text {th }}$ to $8^{\text {th }}$ grade and were living in 7 urban areas encompassing 5 small-to-average-size urban areas, and 2 metropolitan areas (the cities of Rome and Milan).

Three research groups out of the 7 originally involved in the PrISMA W1 study, and whose participants had been sampled from the 3 small-toaverage-size urban areas of Lecco $(n=435)$, Conegliano $(n=426)$, and Rimini ( $n=344)$, continued the PrISMA study by setting a follow-up phase (W2). Participants in the W1 study were invited by mail and/or by telephone to the W2 study after 5 years. Of the 1205 adolescents who were candidates in the W2, 32.9\% $(n=398)$ were no longer available due to change of address, incomplete mail/phone data, or relocation. Questionnaires were thus sent in sealed envelopes to the families of the remaining 808 adolescents, with 420 subjects (52\%: 49.3\% boys, $50.7 \%$ girls, aged 15-19) accepting participation in the study. Because only about half of the potential families participated in the follow up, attrition analyses were conducted to compare participants with non-participants, as described below.

\section{Procedures}

The study protocols were approved by the 'Eugenio Medea' Scientific Institute Ethical Committee. Parents' and adolescents' (when required) written informed consent was obtained for all participants.

\section{Emotional and Behavioural assessment}

The CBCL/6-18 is an empirically-based checklist of social competence and behavioural problems filled out by parents of children and adolescents aged 6-18 years (Achenbach \& Rescorla, 2001). According to the Achenbach System of Empirically Based Assessment (ASEBA) CBCL/6- 
18 items can be scored to obtain the following DSM-Oriented Scales (DOSs): Affective Problems, Anxiety Problems, Somatic Problems, Attention Deficit/Hyperactivity Problems, Oppositional Defiant Problems and Conduct Problems. Although the DOSs are not directly equivalent to any clinical diagnosis, they satisfactorily predict DSM-IV diagnoses (Lengua et al., 2001; Krol et al., 2006; Spatola et al.,2007; Ferdinand, 2008). In the present sample DOSs at $W 1$ and $W 2$ showed acceptable internal reliability (Affective Problems: $W 1-\alpha=0.65, W 2-\alpha=0.71$; Anxiety Problems: W1- $\alpha=0.64$, W2- $\alpha=0.68$; Attention Deficit/Hyperactivity Problems: W1 $\alpha=0.80$, W2 $-\alpha=0.77$; Oppositional Defiant Problems: W1$\alpha=0.67, W 2-\alpha=0.76$; Conduct Problems W1 $-\alpha=0.68$, W2 $-\alpha=0.83$ ) with the exception of Somatic Problems (W1- $\alpha=0.46, W 2-\alpha=0.50)$.

\section{Socio-demographic form}

The individual and family characteristics of the sample were gathered by an 'ad hoc' form filled in by parents. This was an expanded version of the questionnaires originally employed during the PrISMA W1 assessment that encompassed questions on socio-demographic data, child's education, possible contacts with the health services and family socio-economic status (SES) (Frigerio et al., 2006). A section bearing a list of 14 stressful life events was added to the W2 questionnaire: it was mainly based on a list of 11 psychologically-threatening events for children, as developed and adopted by Meltzer, Gatward, Corbin, Goodman and Ford (2003), to which we added 3 items (namely: child has been bullied; child has been victim of violence, child has been victim of sexual harassment) based on evidence from previous work on emotionality in adolescents (brown et al., 1987; Grant et al., 2006). The original stressful life events include: parent had separated or broken up in a steady relationship; child had a serious illness which required a stay in hospital; parent had a severe physical or mental illness or serious accident; child had been in a serious accident or badly hurt in an accident; parent, brother or sister death; grandparent death; close friend death; pet death; child had broken off close friendship or steady relationship; parent had a major financial crisis; parent had a problem with the police involving a court appearance (Meltzer et al., 2003). Parents were asked if their children had ever experienced any of these adversities; response categories were 'yes' or 'no'; when any such adversity was endorsed, parents were asked to report age at first occurrence. We considered the number of life stressors without taking into account their perceived severity. For the present study we defined 'recent SLEs' as all those adversities that had occurred after the first evaluation at W1, therefore chronic SLEs (such as the chronic illness of a relative) 
which had begun prior to the first evaluation at W1 were not considered. Likewise, SLEs where age at first occurrence was not reported were not included in the analyses.

\section{Data Analyses}

Attrition analysis were conduct to test socio-demographic and clinical differences between participants and non-participants in the W2 phase. Specifically, we analysed all the DOSs scores and age at W1 by ANOVA, and gender, father's and mother's education level and family structure at W1 by $\chi^{2}$.To study the continuity and discontinuity of psychopathology from early- (W1) to late-adolescence (W2), we used the following indicators:

- Changes in mean DOS scores: changes in mean score were calculated on the basis of mean and standard-deviations (SD) of the six DOSs raw scores measured at W1 and W2. Repeated-measure ANOVA was employed to detect significant differences between scores at W1 and W2, with 'gender' as a between-subjects' factor. Effects sizes were categorized according to Cohen's criteria: eta square $<0.06=$ small; $0.06-0.14=$ medium, $>0.14=$ large effect size (Cohen, 1988).

- Stability: Pearson's correlation coefficient was calculated between DOS raw scores at $W 1$ and $W 2$, to index the degree of stability of behavioural/emotional problems. We used Cohen's criteria to evaluate the magnitude of Pearson's correlation coefficients as follows: small $(r=0.10-$ 0.29), medium ( $r=0.30-0.49)$, or large $(r \geq 0.50)$ (Cohen, 1988).

- Predictors: to determine whether DOS scores at W1 predicted scores at W2, all predictors were entered simultaneously and then backwards stepwise selection was used to remove non-significant predictors from the model (criterion for entrance: $p<.05$; criterion for removal $p>=.1$; likelihood ratio test.). Gender was included as an additional predictor. The Wald statistic was used to test the significance $(p<.05)$ of independent variables, whereas model $f$ tests, were used to test the significance $(p<$ .05 ) of any full regression models. The number of tests in this study may suggest the need for a correction for chance findings for multiple tests, such as a Bonferroni procedure. However, the probability of chance findings in the logistic regression analyses was minimized by applying significance tests for the full regression models.

- Mediational role of SLEs having occurred after the first evaluation: to test the possible mediational role of SLEs we followed the classic steps for the establishment of mediation recommended by Baron and Kenny (1986). A mediator is a variable that conceptually and statistically accounts for the relation between a predictor and a criterion variable, so that: (a) the predictor is significantly related to the criterion, (b) the predictor is 
significantly related to the mediator, (c) the mediator is related to the criterion, and (d) the variance accounted for in the criterion, by the predictor, decreases when the mediator is controlled (Baron \& Kenny, 1986). Accordingly, step a) was resolved by the multiple backward stepwise linear regression analysis described at the end of the previous paragraph (predictors). Step $b$ ) was addressed by regressing the number of recent SLEs on each DOS at W1. The relation between SLEs (mediator) and psychopathology at W2 (criterion) was tested by setting a regression of the 6 DOSs at W2 on the number of recent SLEs (step c). In order to obtain results that could be specifically informative for each DOS, in every regression carried out, other DOS scales at W1 -as well as gender- were included as covariates.

We assessed the presence of mediation (step d) by determining the degree of attenuation that was observed in the relation between DOS at W1 and DOS at W2, as a result of adding SLEs as a covariate to the regression model. The attenuation in the relation between DOS at W1 and DOS at W2 was scaled as the percentage decrease relative to the regression coefficient for psychopathology at $W 1$. To asses statistical significance of each conditional indirect effects we then applied bootstrapping method to obtain $95 \%$ confidence intervals $[\mathrm{Cl}]$ for the observed indirect effect (Preacher \& Hayes, 2008). Confidence intervals based on bias corrected bootstrapping has been shown to be the most accurate method of assessing mediated effect. Bootstrapping can be used to generate an approximation of the sampling distribution in order to obtain $\mathrm{Cl}$ that are more accurate than $\mathrm{Cl}$ using standard methods, while making no assumption about the shape of the sampling distribution (e.g. Sobel test assumes normality of the sampling distribution). If zero is outside of the upper and lower limits, then the parameter being estimated is deemed statistically different from zero at the alpha level corresponding to the $\mathrm{Cl}$ (e.g 0.05 for a $95 \% \mathrm{Cl}$ ) (Preacher \& Hayes, 2008).

To place the same weight on information throughout different time measurements and to ensure that all variables in the regression and mediation models would be comparable, we standardized DOSs and recent SLEs to a mean of zero and SD of 1 ( $z$ scores) (Kraemer \& Blasey, 2004). For all regression analyses, the Tolerance Index and the Variance Inflation Factor (VIF) were computed to index collinearity. All analyses were conducted by PASW Statistics, version 18.0, with an alpha $p$-value $=0.05$. 


\section{RESULTS}

\section{Attrition results}

The demographic characteristics of the study group are shown in Table 1. No significant differences were found for scores at all the DOSs, age, gender, and father's education level at W1 between participants and nonparticipants in the W2 phase. Significant differences were found for mother's education level $\left(\chi^{2}=8.55 ; p=0.003\right)$, SES $\left(\chi^{2}=5.71 ; p=0.017\right)$ and family structure $\left(\chi^{2}=7.51 ; p=0.006\right)$ however, with lower level of mother's education, lower SES and more single-parent families among non-participants.

\section{Changes in mean DOS scores}

Complete emotional, behavioural and sociodemographic data were available for 382 subjects (196 boys and 186 girls) at W1 and W2. Table 2 shows the mean DOS raw scores in male and female participants at W1 and W2. Both Anxiety and Attention Deficit/Hyperactivity Problems scores decreased significantly $\left(\eta^{2}=0.04\right.$ and $\left.\eta^{2}=0.08 ; p<0.001\right)$. ADHD also showed a linear effect of gender (male, $\eta^{2}=0.03, p=0.001$ ), and both ADHD and Anxiety DOS yielded significant time $x$ gender interactions $\left(\eta^{2}=0.01\right.$, $p=0.001$ and $\eta^{2}=0.03, p=0.03$, respectively), sustained by a more marked decrease of scores in time among boys. There was, on the contrary, a significant increase in time of the mean scores for Affective $\left(\eta^{2}=0.03\right.$, $p=0.001)$ and Somatic Problems $\left(\eta^{2}=0.03, p<0.001\right)$, with a significant time $x$ gender interaction $\left(\eta^{2}=0.02, p=0.016\right.$ and $\eta^{2}=0.02, p=0.004$, respectively) sustained by a more marked increase of scores in time among girls. There was also a significant increase in time for the mean scores of Conduct Problems $\left(\eta^{2}=0.02, p=0.006\right)$, but no significant time $x$ gender interaction. There was a significant effect of gender on Somatic Problems $\left(\eta^{2}=0.02, p=0.010\right)$ with higher scores for girls, Attention Deficit/Hyperactivity $\left(\eta^{2}=0.03, p=0.001\right)$ and Conduct Problems $\left(\eta^{2}=0.02\right.$, $p=0.012$ ) with higher scores for boys. There were no significant effects of time, gender or time $x$ gender interaction on Oppositional Defiant Problems score. Effect sizes were medium for the effect of time on Attention Deficit/Hyperactivity Problems, and small for all the other significant effects.

\section{Stability}

Across DOSs, the zero order correlation coefficients were medium and significant (all: $p<0.001)$ for Affective $(r=0.39)$, Anxiety $(r=0.42)$, Somatic $(r=0.32)$, Oppositional Defiant $(r=0.48)$ and Conduct Problems $(r=0.43)$, and larger and more significant for Attention Deficit/Hyperactivity Problems $(r=0.55 ; p<0.001)$. 


\section{Predictors of psychopathology}

Table 3 shows the results (reported as standardized beta coefficient) of the backward stepwise linear regression model to predict psychopathology in adolescence. For all DOS, the score at W1 was the most consistent and significant predictor of the W2 score with $\beta$ s ranging from .26 for Conduct Problems to .47 for Oppositional Defiant Problems; $p<0.001-$, which is a clear indication in favour of homotypy across all the newly established DSM-IV CBCL scales. Moreover, Affective Problems at W2 were significantly predicted by Somatic $(\beta=0.13 ; p=0.014)$ and Oppositional Defiant Problems $(\beta=0.16 ; p=0.002)$ at $W 1$, Anxiety Problems at $W 2$ were predicted by Affective Problems $(\beta=0.12 ; p=0.029)$ at $W 1$, Attention Deficit/ Hyperactivity Problems at W2 were significantly predicted by Affective $(\beta=0.10 ; p=0.033)$ and Oppositional Defiant Problems $(\beta=0.12 ; p=0.028)$ at $W 1$, Conduct Problems at $W 2$ were significantly predicted by Oppositional Defiant Problems $(\beta=0.25 ; p<0.001)$ at $W 1$.

Gender was a significant predictor for Anxiety $(\beta=0.19 ; p<0.001)$ and Somatic Problems $(\beta=0.17 ; p<0.001)$. None of the independent variables showed serious collinearity effects: Tolerance Index scores ranged from 0.590 to 1 and VIF scores ranged from 1 to 1.694 . All the full regression models were significant $(F$ ranged from 23.08, d.f. $=7.379, p<0.001-$ for Affective Problems- to 62.42, d.f.=7.379, $p<0.001$ - for Attention Deficit/Hyperactivity Problems). The proportion of explained variance for the models ranged from $R^{2}=0.13$ (for Somatic Problems) to $R^{2}=0.33$ (for Attention Deficit/Hyperactivity Problems).

\section{Mediational analysis}

By regression analysis we found that the number of SLEs during the W1W2 time frame was predicted by Affective Problems $(\beta=0.15 ; p=0.002)$, Anxiety Problems $(\beta=0.13, p=0.007)$, Attention Deficit/Hyperactivity Problems $(\beta=0.17, p=0.001)$, Oppositional Defiant Problems $(\beta=0.21$, $p<0.001)$ and Conduct Problems $(\beta=0.12, p=0.015)$. This means that all DOSs except for Somatic Problems predicted SLEs to be more likely to occur in the W1-W2 time frame. However, when a stepwise multiple regression analysis was set to evaluate possible significant predictors of recent SLEs (step b) (with all the DOSs at W1 entered simultaneously in the regression, with gender as covariate and with backwards stepwise selection used to remove non-significant predictors from the model), the only significant predictor was the Oppositional Defiant Problems scale $(\beta=0.20 ; p<0.001$; full model $F: 2,873$, d.f. $=6,209, p=0.01)$. This means that the effect of different problem behaviours at $\mathrm{W} 1$ in heightening the probability of occurrence of recent SLEs could be more parsimoniously 
confined to the effect of Oppositional Defiant Problems only.

We set a second multiple regression analysis to resolve step c) of Baron and Kenny (1986) mediation approach by regressing all the W2 DOSs on the number of recent SLEs (while partialling out the effects of the DOSs measured at $\mathrm{W} 1$ and gender). This analysis showed that the number of recent SLEs predicted higher scores in Affective Problems $(\beta=0.23$; $p<0.001)$, Anxiety Problems $(\beta=0.14 ; p=0.002)$, and Oppositional Defiant Problems $(\beta=0.15 ; p=0.001)$.

The only paths satisfying all the Baron Kenny a), b), and c) criteria for mediation were the relation between Oppositional Defiant Problems at W1 and Affective Problems at W2, and the relation between Oppositional Defiant Problems at W1 and the homotypic Oppositional Defiant Problems scale at W2. Therefore the last (d) step for the mediational analysis of recent SLEs included only these two paths. The inclusion of recent SLEs as a mediator significantly reduced the association between Oppositional Defiant Problems at W1 and Affective Problems (Fig. 1a) and Oppositional Defiant Problems (Fig. 1b) at W2: regression coefficients decreased by $26 \%$ for Affective Problems and by $6 \%$ for Oppositional defiant Problems. The bootstrap results showed significant mediation for both outcomes, with 95\% Cl: $9 \%-53 \%$ for Affective Problems and 95\% Cl: $1 \%-15 \%$ for Oppositional Defiant Problems. The proportion of explained variance for the model that included SLEs increased from $R^{2}=0.189$ to $R^{2}=0.223$ and from $R^{2}=0.235$ to $R^{2}=0.246$, respectively. 


\section{DISCUSSION}

This is the first study with the CBCL DSM-oriented scales (DOSs) to evaluate the continuity and discontinuity of behavioural problems from early- to late-adolescence while taking into account the multiple covariation of psychopathological traits and the possible influence of adversities. We found that the 5-year stability of the DOSs is, overall, satisfactory, as the size of the six DOSs' autocorrelations between W1 and W2 range from 'medium' to 'large'. The highest stability indexes were found for Attention Deficit/Hyperactivity and Oppositional Defiant Problems ( $r=0.55$ and $r=0.48$, respectively). This replicates the finding of higher stability for externalizing than internalizing problems (Stanger et al., 1992; Verhulst \& Van der Ende, 1995; Hofstra, 2000). We also detected a moderate but significant decrease in Attention Deficit/Hyperactivity Problems (mostly in boys) and a small but significant increase in Affective and Somatic Problems (mostly in girls) and in Conduct Problems (both in boys and girls) in time. This age effect replicates similar tendencies that have been described by previous interview- and questionnaire-based studies (Roza, 2003; Spencer, 2007), and further support the validity of the DOSs.

In a model taking into account the multiple covariation of the DOSs, we found that for all the six scales the best predictor at W2 was the score at the same scale at the first evaluation. This confirms the stability of the DOSs, and shows that homotypic evolution of psychopathology should be expected in the first place, when considering the transition from early- to late-adolescence. In supporting the psychometric stability and homotypic evolution of psychopathology, our data show that the DOSs yield long-term stability figures that are close to those obtained over a 6-year period in an epidemiological sample of Dutch children originally aged 4-11 years (Verhulst and Van der Ende, 1992) and in an American national sample of children originally aged 4-12 years (Achenbach et al., 1995) assessed with the 'classical' $\mathrm{CBCL}$ scales, while allowing for a more immediate reference to the DSM nosology.

Not only does our multivariate approach allow us to draw robust enough conclusions on homotypic stability and prediction but by multiple stepwise regressions we also found that most DOSs at W2 were predicted by more than one DOS at W1. Likewise, one DOS score at W1 often predicted several DOS scores at W2, albeit the size of heterotypic correlations were invariably smaller than the autocorrelations. These findings confirm the constructs of multifinality (i.e. dispersion of outcomes) and equifinality (i.e. diversity of pathways leading to a common outcome) described by Cicchetti (1990) for most developmental psychopathological traits. Within 
this landscape, however, specific developmental trajectories are clearly more probable than others. This can be best appreciated in the externalizing domain. The clearest example of multifinality is provided by Oppositional Defiant Problems predicting Affective, Conduct and, to a lesser extent, Attention Deficit/Hyperactivity Problems. In contrast, Conduct Problems at first wave predicted only the respective homotypic scale, suggesting two different developmental patterns for these two externalizing domains, and striking similarity with the results of the interview-based analyses of the GSMS sample by Copeland et al. (2009a) and with the results of the Canadian National Longitudinal Study of Youth mainly based on mother reported questionnaires (Boylan, 2010). Therefore, these data suggest oppositional defiant problems as being part of a developmental pathway towards a host of internalizing and externalizing problems in lateadolescence (and probably young adulthood) over and above the comorbidity with, or the evolution towards, Conduct Problems.

Our second, major aim was to explore the complex relationship between adversities and psychopathology. We found that higher Affective, Anxiety, Oppositional Defiant and Conduct Problems scores predicted a higher number of SLEs in adolescence in a univariate approach. Controlling for other psychopathologies, i.e. the full spectrum of DOS, Oppositional Defiant Problems was the only dimension still able to predict a significantly higher number of SLEs, suggesting that this specific form of externalization constitutes a relatively robust predictor of adversities in youth. Unsurprisingly, a higher number of recent SLEs predicted higher scores on most DOSs longitudinally, confirming the importance of adversities in contributing to both internalizing and externalizing problems in youth (Cicchetti, 1990; Haggerty et al., 1994). Mediational analysis revealed that recent SLEs partially accounted for not only the continuity of Oppositional Defiant Problems in time, but also for the heterotypic progression towards the development of Affective Problems. Our data confirmed longitudinally the cross sectional findings of Rowe et al. (2006), i.e. that adversities support the association between oppositionality and depressed mood in youth. Moreover, our follow-up perspective allowed us to investigate and to confirm the existence of a reciprocal cycle of stress generation in maintaining specific developmental trajectories across externalizing and internalizing domains. These data may inform on the mechanisms underlying the continuity/etiology of both Oppositional Defiant and Depression Problems from early- to late-adolescence: recent adversities in adolescence may contribute to the etiology/maintenance of these disturbances playing a very complex role as they could be antecedent of psychopathology, but they also in part result from psychopathology and, 
according to the analyses of indirect effect, they partially mediate the perpetuation of Oppositional Defiant Problems over time and their evolution towards Affective Problems.

There are several limitations in this study. While the psychometric variables did not affect agreement to participate in the study, non-participants were more likely to belong to socially disadvantaged backgrounds, as suggested by the excess of lower mother's education level, lower SES, and singleparent families. The sample may thus not be fully representative of a general population. However, the fact that non-participant adolescents did not differ from participants in terms of behavioural problems suggests that loss from analysis of those subjects is unlikely to have introduced a major bias. In the second wave of this study the only sources on behavioural problems of adolescents were behaviour checklists filled in by parents. Other sources of information such as the adolescents themselves and their teachers could have been desirable. However, all the DOSs-parent versions were found to satisfactorily predict the corresponding DSM-IV diagnoses (Lengua et al., 2001; Krol et al., 2006; Ferdinand, 2008). The use of 'repeated' measures obtained by the same informants (i.e. parents) in time could suffer from shared method variance and inflate the estimates of stability of behaviour. Finally, the addition of a broader spectrum of adversities as well as of indicators of protective factors would have been desirable to build a more complete picture of risks and adaptation. Similarly, standardized information on treatment and help-seeking at follow-up would have been desirable in order to evaluate their impact on the problems reported at the DOSs. 


\section{CONCLUSION}

We found good stability of the newly-developed DOSs through adolescence, and considerable homotypic continuity both for Internalizing (Depression, Anxiety and Somatic Problems) and externalizing (Attention Deficit/Hyperactivity, Oppositional Defiant and Conduct Problems) DOSs. Parent-reported Oppositional Defiant Problems emerged to be a polyvalent predictor of both internalizing and externalizing problems in lateadolescence. These data suggest oppositional defiant problems as being part of a developmental pathway towards a host of problems in lateadolescence (and probably young adulthood) over and above the comorbidity with, or the evolution towards, Conduct Problems.

Furthermore, we found that Oppositional Defiant Problems predict more SLEs, which in turn predict Depression and Oppositional Defiant Problems longitudinally. This chain of risk appears to deserve particular attention, although it should not be thought of as deterministic. For instance, if environmental reinforcements are disrupted, recovery and adaptation become likely.

More broadly, our data underscore early adolescence behavioural problems as an important focus for primary and secondary intervention. Primary prevention strategies emphasizing social (and educational) intervention may reduce the likelihood of persistence of behavioural problems (especially Depression and Oppositional Defiant Problems) from early- to late-adolescence and, perhaps, to early adult years. As far as secondary prevention is concerned, the CBCL DOS could be adopted in programs aimed at identifying and treating general population individuals at increased risk of developing emotional/behavioural problems.

\section{Acknowledgements.}

This study is a part of the Progetto Italiano Salute Mentale Adolescenti (PrISMA) project. PrISMA has been financially supported by various grants from the Italian National Institute of Health and from the Italian 'Centro per il Controllo e la prevenzione delle Malattie' (CCM). The authors thank Mss Teresa Di Fiandra, Margherita Fossati and Chiara Steffenini for their valuable technical support, and the study families and participants for taking part to the study. 
Table 1. Sociodemographic characteristics of the study sample at W2 $(N=420)$

\section{Characteristics}

Gender, Female (n, \%)

$213(50.7)$

Age $($ mean $\pm \mathrm{sd})$

$17.71 \pm 0.93$

Family Characteristics

Single parent $(n, \%)$ $44(10.7)$

Mother education $<10$ years $(n, \%)$ $160(38.5)$

Father education $<10$ years $(n, \%)$ $171(41.1)$

SES Low (n, \%) $46(11.3)$

Stressful life events (mean \pm SD)

$0.70 \pm 0.97$ 
CHAPTER 2

\begin{tabular}{|c|c|c|c|c|c|c|c|}
\hline 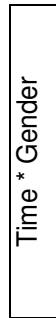 & 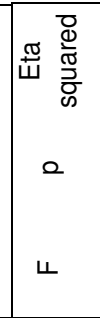 & 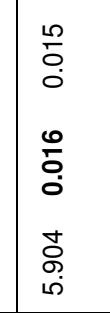 & $\begin{array}{l}\hat{\delta} \\
0 \\
0 \\
\bar{o} \\
0 \\
0 \\
\hat{0} \\
0 \\
0 \\
0\end{array}$ & 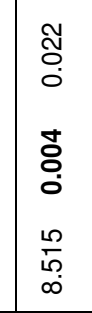 & 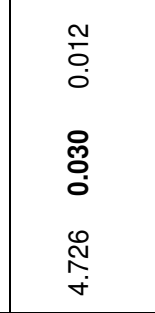 & $\begin{array}{l}0 \\
0 \\
0 \\
\infty \\
m \\
0 \\
0 \\
\infty \\
\stackrel{\sim}{7} \\
\text { N. }\end{array}$ & 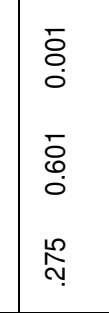 \\
\hline 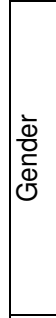 & 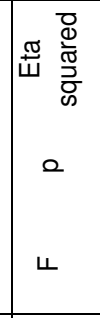 & 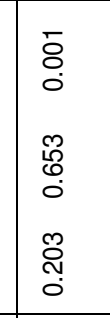 & 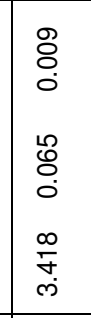 & $\begin{array}{l}\hat{y} \\
0 \\
0 \\
0 \\
0 \\
0 \\
0 \\
0 \\
0 \\
0 \\
0 \\
0\end{array}$ & 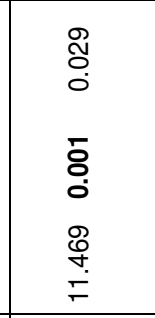 & 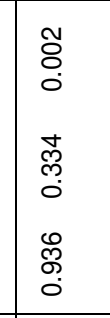 & 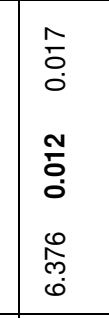 \\
\hline$\underset{\underline{E}}{\stackrel{\oplus}{E}}$ & 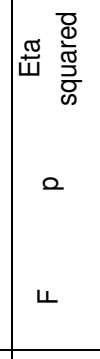 & 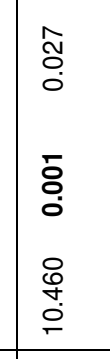 & 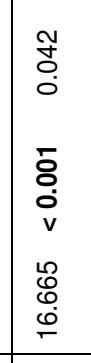 & 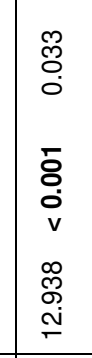 & 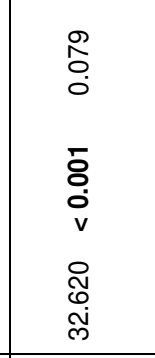 & 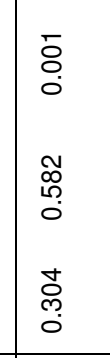 & 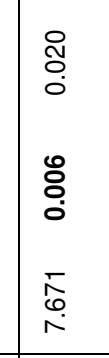 \\
\hline$\tilde{\xi}$ & 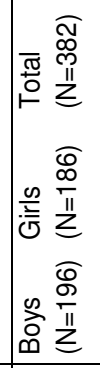 & 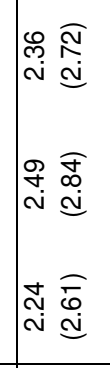 & 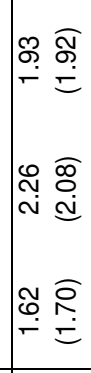 & 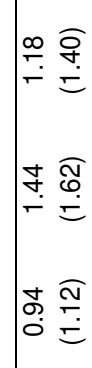 & 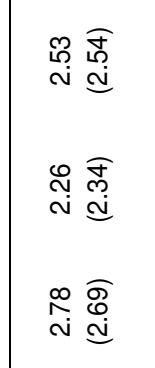 & 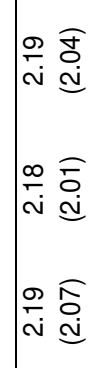 & 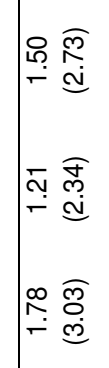 \\
\hline$\sum$ & 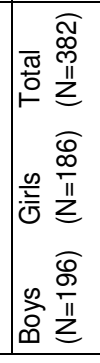 & 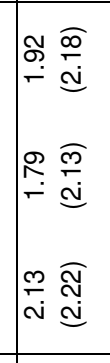 & 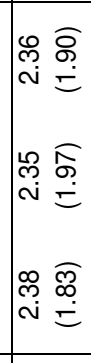 & 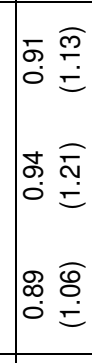 & 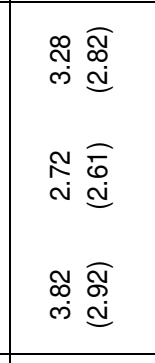 & 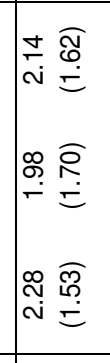 & 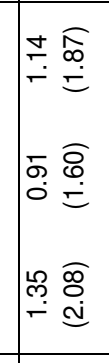 \\
\hline $\begin{array}{l}0 \\
0 \\
0 \\
0 \\
0 \\
0\end{array}$ & 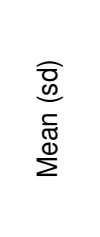 & 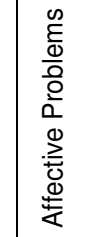 & 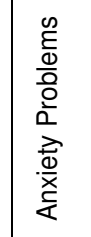 & 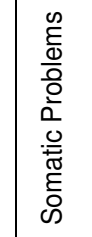 & 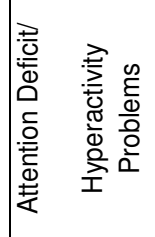 & 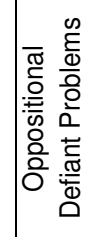 & 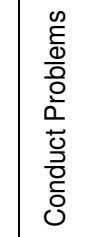 \\
\hline
\end{tabular}


PSYCHOPATHOLOGY AND ADVERSITIES IN ADOLESCENCE

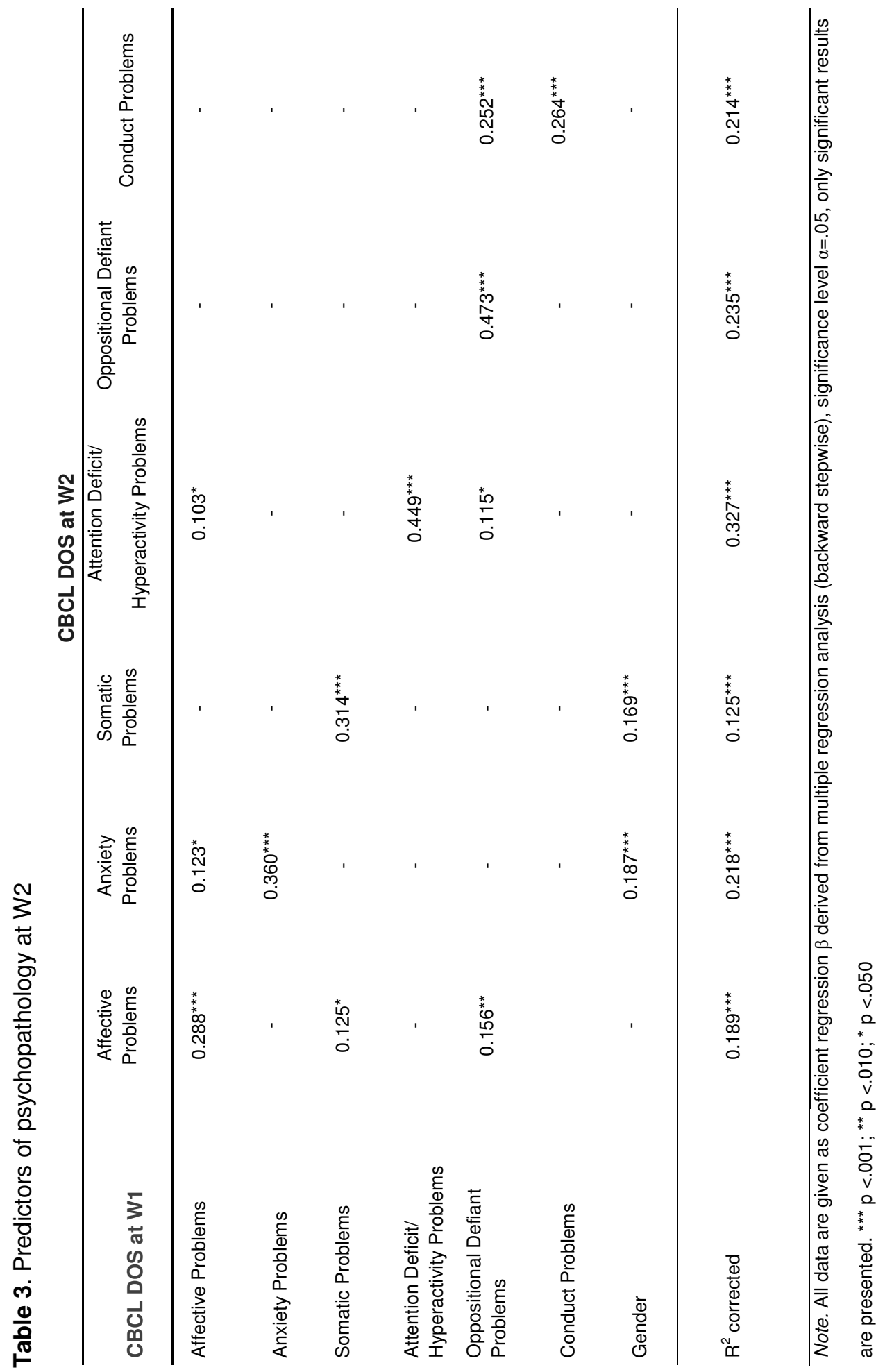


Fig. 1 Mediational Analysis. Step (a) represents the direct effect of CBCL DOS z scores at W1 on CBCL DOS z scores at W2; step (b) represents the direct effect of CBCL DOS scores at W1 on number of recent SLEs; step (c) represents the association of SLEs with DOS at W2. Step (d) and $\beta^{\prime}$ represents the effect of CBCL DOS scores at W1 after recent SLEs were added to the model. All steps were conducted controlling for other psychopathologies at $\mathrm{W} 1$ and gender. For all regression analysis $\beta$ values and significance level $\left({ }^{*} p<0.05 ;{ }^{* *} p<0.01 ;{ }^{* *} p<0.001\right)$ are reported.

Fig. 1a

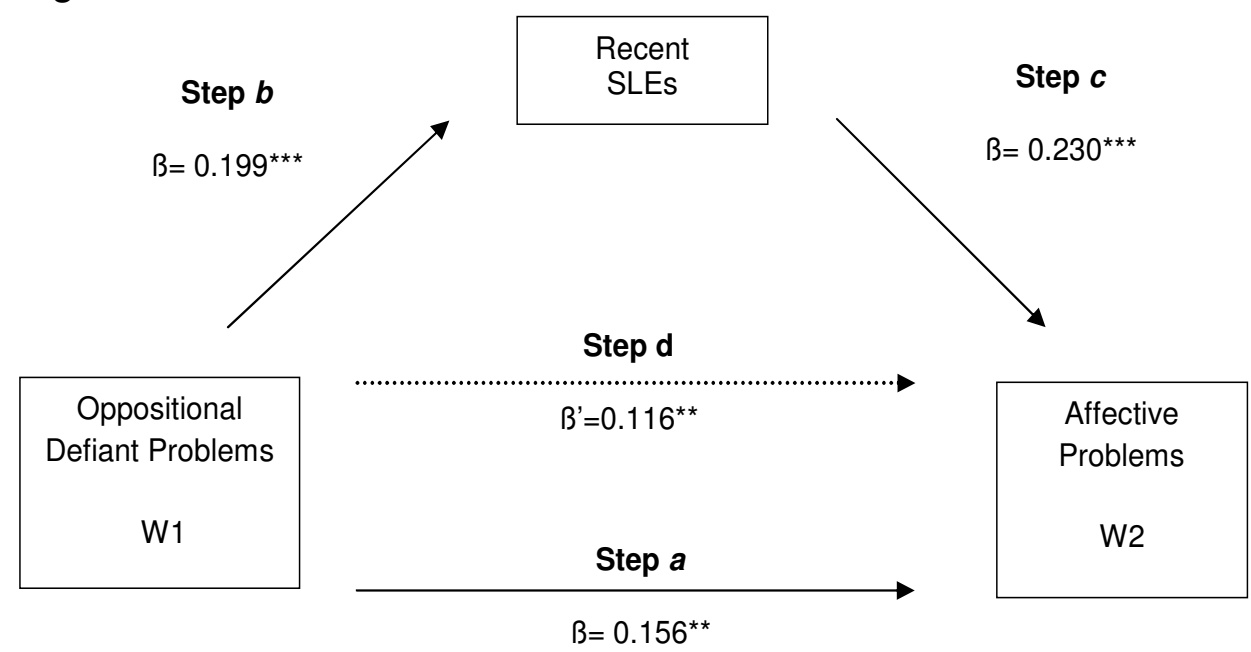

Fig. 1b

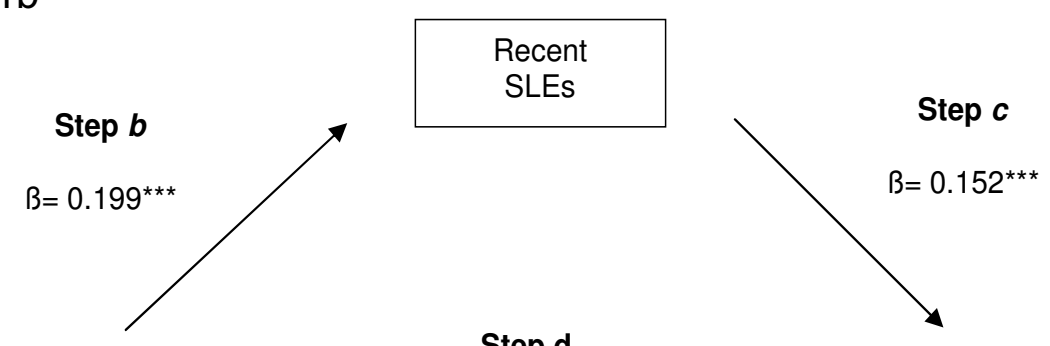

Oppositional

Defiant Problems

W1
Step d

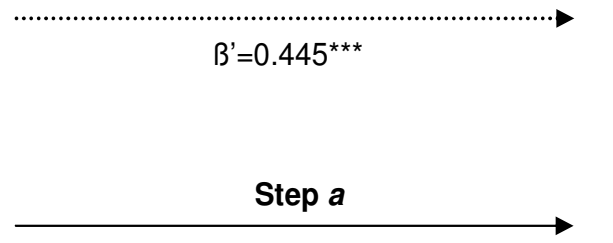

$B=0.473^{\star \star \star}$
Oppositional Defiant Problems

W2 


\section{REFERENCES}

Achenbach TM, Rescorla LA (2001). Manual for ASEBA School-Age Forms \& Profiles. University of Vermont, Research Center for Children, Youth, \& Families, Burlington, VT

Achenbach TM, Howell CT, McConaughy SH, Stanger C (1995). Six-year predictors of problems in a national sample of children and youth: I.Crossinformant syndromes. Journal of the American Academy of Child and Adolescent Psychiatry 34,336-347

Amone-P'Olak K, Ormel J, Huisman M, Verhulst FC, Oldehinkel AJ, Burger $H$ (2009). Life stressors as mediators of the relation between socioeconomic position and mental health problems in early adolescence: the TRAILS study. Journal of the American Academy of Child and Adolescent Psychiatry 48, 1031-1038

Angold A, Costello EJ, Erkanli A (1999). Comorbidity. Journal of child psychology and psychiatry, and allied disciplines 40, 57-87

Baron RM, Kenny DA (1986). The moderator-mediator variable distinction in social psychological research: conceptual, strategic, and statistical considerations. Journal of personality and social psychology 51, 1173-1182

Bot M, de Leeuw den Bouter BJE, Adriaanse MC (2011) Prevalence of psychosocial problems in Dutch children aged 8-12 years and its association with risk factors and quality of life. Epidemiology and Psychiatric Sciences 20, 357-365

Boylan K, Georgiades K, Szatmari P (2010). The longitudinal association between oppositional and depressive symptoms across childhood. Journal of the American Academy of Child and Adolescent Psychiatry 49, 152-161

Brown GW, Bifulco A, Harris TO (1987). Life events, vulnerability and onset of depression: some refinements. The British journal of psychiatry : the journal of mental science 150, 30-42

Caspi A, Moffitt TE, Newman DL, Silva PA (1996). Behavioral observations at age 3 years predict adult psychiatric disorders. Longitudinal evidence from a birth cohort. Archives of General Psychiatry 53, 1033-1039

Cicchetti D (1990). A historical perspective on the discipline of developmental psychopathology. In: Rolf JE, Masten AS, Cicchetti D, Nuechterlein $\mathrm{KH}$, Weintraub $S$ Risk and protective factors in the development of psychopathology. Cambridge University Press, New York, 2-28 
Cohen J (1988). Set correlation and contingency tables. Applied Psychological Measurement 12, 425-434

Copeland WE, Shanahan L, Costello EJ, Angold A (2009a). Childhood and adolescent psychiatric disorders as predictors of young adult disorders. Archives of General Psychiatry 66, 764-772

Copeland WE, Shanahan L, Costello EJ, Angold A (2009b) Configurations of common childhood psychosocial risk factors. Journal of Child Psychology and Psychiatry 50: 451-459

Costello EJ, Angold A, Burns BJ, Stangl DK, Tweed DL, Erkanli A, Worthman CM (1996). The Great Smoky Mountains Study of Youth. Goals, design, methods, and the prevalence of DSM-III-R disorders. Archives of General Psychiatry 53, 1129-1136

de Girolamo G, Dagani J, Purcell R, Cocchi A, McGorry PD (2012). Age of onset of mental disorders and use of mental health services: needs, opportunities and obstacles. Epidemiology and Psychiatric Science 21: 47-57

Essex MJ, Kraemer HC, Armstrong JM, Boyce WT, Goldsmith HH, Klein $\mathrm{MH}$, Woodward H, Kupfer DJ (2006). Exploring risk factors for the emergence of children's mental health problems. Archives of General Psychiatry 63, 1246-1256

Ferdinand RF (2008). Validity of the CBCL/YSR DSM-IV scales Anxiety Problems and Affective Problems. Journal of anxiety disorders 22, 126134

Ford T, Goodman R, Meltzer H (2003). The British Child and Adolescent Mental Health Survey 1999: the prevalence of DSM-IV disorders. Journal of the American Academy of Child and Adolescent Psychiatry 42, 12031211

Frigerio A, Rucci P, Goodman R, Ammaniti M, Carlet O, Cavolina P, De Girolamo G, Lenti C, Lucarelli L, Mani E, Martinuzzi A, Micali N, Milone A, Morosini P, Muratori F, Nardocci F, Pastore V, Polidori G, Tullini A, Vanzin L, Villa L, Walder M, Zuddas A, Molteni M (2009). Prevalence and correlates of mental disorders among adolescents in Italy: the PrISMA study. European child \& adolescent psychiatry 18, 217-226

Frigerio A, Vanzin L, Pastore V, Nobile M, Giorda R, Marino C, Molteni M, Rucci P, Ammaniti M, Lucarelli L, Lenti C, Walder M, Martinuzzi A, Carlet O, Muratori F, Milone A, Zuddas A, Cavolina P, Nardocci F, Tullini A, 
Morosini P, Polidori G, De Girolamo G (2006). The Italian preadolescent mental health project (PrISMA): rationale and methods. International journal of methods in psychiatric research 15, 22-35

Grant KE, Compas BE, Thurm AE, McMahon SD, Gipson PY, Campbell AJ, Krochock K, Westerholm RI (2006). Stressors and child and adolescent psychopathology: evidence of moderating and mediating effects. Clinical psychology review 26, 257-283

Haggerty RL, Sherrod LR, Garmezy N, Rutter M (1994) Stress, risk and resilience in children and adolescents: Process, mechanisms and interventions. Cambridge University Press, London

Hammen C (2006). Stress generation in depression: reflections on origins, research, and future directions. Journal of clinical psychology 62, 10651082

Hatch SL, Harvey SB, Maughan B (2010). A developmental-contextual approach to understanding mental health and well-being in early adulthood. Social science \& medicine (1982) 70, 261-268

Hofstra MB, van der Ende J, Verhulst FC (2002). Child and adolescent problems predict DSM-IV disorders in adulthood: a 14-year follow-up of a Dutch epidemiological sample. Journal of the American Academy of Child and Adolescent Psychiatry 41, 182-189

Hofstra MB, Van der Ende J, Verhulst FC (2000). Continuity and change of psychopathology from childhood into adulthood: a 14-year follow-up study. Journal of the American Academy of Child and Adolescent Psychiatry 39, 850-858

Kraemer HC, Blasey CM (2004). Centring in regression analyses: a strategy to prevent errors in statistical inference. International journal of methods in psychiatric research 13, 141-151

Krol NP, De Bruyn EE, Coolen JC, van Aarle EJ (2006). From CBCL to DSM: a comparison of two methods to screen for DSM-IV diagnoses using CBCL data. Journal of clinical child and adolescent psychology : the official journal for the Society of Clinical Child and Adolescent Psychology, American Psychological Association, Division 53 35, 127-135

Lengua LJ, Sadowski CA, Friedrich WN, Fisher J (2001). Rationally and empirically derived dimensions of children's symptomatology: expert ratings and confirmatory factor analyses of the CBCL. Journal of consulting and clinical psychology 69, 683-698 
Mash EJ, Barkley RA (1996) Child psychopathology. Guilford Press, New York, NY, US

Meltzer H, Gatward R, Corbin T, Goodman R, Ford T (2003) Persistence, onset, risk factors and outcomes of childhood mental disorders. TSO, London

Nobile M, Giorda R, Marino C, Carlet O, Pastore V, Vanzin L, Bellina M, Molteni M, Battaglia M (2007). Socioeconomic status mediates the genetic contribution of the dopamine receptor D4 and serotonin transporter linked promoter region repeat polymorphisms to externalization in preadolescence. Development and psychopathology 19, 1147-1160

Nobile M, Rusconi M, Bellina M, Marino C, Giorda R, Carlet O, Vanzin L, Molteni M, Battaglia M (2010). COMT Val158Met polymorphism and socioeconomic status interact to predict attention deficit/hyperactivity problems in children aged 10-14. European child \& adolescent psychiatry $19,549-557$

Nobile M, Rusconi M, Bellina M, Marino C, Giorda R, Carlet O, Vanzin L, Molteni M, Battaglia M (2009). The influence of family structure, the TPH2 G-703T and the 5-HTTLPR serotonergic genes upon affective problems in children aged 10-14 years. Journal of child psychology and psychiatry, and allied disciplines 50, 317-325

Plomin R, DeFries JC, Loehlin JC (1977). Genotype-environment interaction and correlation in the analysis of human behavior. Psychological bulletin 84, 309-322

Preacher KJ, Hayes AF (2008). Asymptotic and resampling strategies for assessing and comparing indirect effects in multiple mediator models. Behavior research methods 40, 879-891

Rowe R, Maughan B, Eley TC (2006). Links between antisocial behavior and depressed mood: the role of life events and attributional style. Journal of abnormal child psychology 34, 293-302

Roza SJ, Hofstra MB, van der Ende J, Verhulst FC (2003). Stable prediction of mood and anxiety disorders based on behavioral and emotional problems in childhood: a 14-year follow-up during childhood, adolescence, and young adulthood. The American Journal of Psychiatry $160,2116-2121$

Rudolph KD, Flynn M, Abaied JL, Groot A, Thompson R (2009). Why is past depression the best predictor of future depression? Stress generation 
as a mechanism of depression continuity in girls. Journal of clinical child and adolescent psychology : the official journal for the Society of Clinical Child and Adolescent Psychology, American Psychological Association, Division 53 38, 473-485

Rutter M, Moffitt TE, Caspi A (2006). Gene-environment interplay and psychopathology: multiple varieties but real effects. Journal of child psychology and psychiatry, and allied disciplines 47, 226-261

Spatola CA, Fagnani C, Pesenti-Gritti P, Ogliari A, Stazi MA, Battaglia M (2007). A general population twin study of the CBCL/6-18 DSM-oriented scales. Journal of the American Academy of Child and Adolescent Psychiatry 46, 619-627

Spencer TJ, Biederman J, Mick E (2007). Attention-deficit/hyperactivity disorder: diagnosis, lifespan, comorbidities, and neurobiology. Journal of pediatric psychology 32, 631-642

Stanger C, McConaughy SH, Achenbach TM (1992). Three-year course of behavioral/emotional problems in a national sample of 4- to 16-yearolds: II. Predictors of syndromes. Journal of the American Academy of Child and Adolescent Psychiatry 31, 941-950

Verhulst FC, Van der Ende J (1992). Six-year stability of parent-reported problem behavior in an epidemiological sample. Journal of Abnormal Child Psychology 20, 695-610.

Verhulst FC, Van der Ende J (1995). The eight-year stability of problem behavior in an epidemiologic sample. Pediatric research 38, 612-617 


\section{CHAPTER 3}

\section{Effects of Serotonin Transporter Promoter Genotype on Platelet Serotonin Transporter Functionality in Depressed Children and adolescents}

Maria Nobile, Barbara Begni, Roberto Giorda, Alessandra Frigerio, Cecilia Marino, Massimo Molteni, Carlo Ferrarese and Marco Battaglia

Journal of American Academy of Child and Adolescent Psychiatry. 1999 Nov; 38(11): 1396-402. 


\section{ABSTRACT}

Objective: To investigate possible associations between serotonin transporter (5-HTT) promoter genotypic variants $(I / I, I / s$, and $s / s)$ and differential regulation of platelet serotonin transporter functionality parameters in a group of drug-naive depressed children and adolescents and healthy controls.

Methods: Children and adolescents with major depression $(n=18)$ defined by DSM-III-R criteria and normal controls $(n=21)$ were assessed both for platelet serotonin functionality and for genotypic variants on 5-HTT promoter region.

Four parameters were considered: serotonin 1)uptake rate (Vmax), and 2)dissociation constant $(K m)$; Paroxetine: 3 )binding and density of site (Bmax), and 4)dissociation constant (Kd).

Results: Depressed children had lower Vmax and $\mathrm{Km}$. Control subjects with $I / I$ genotype had significantly higher $V \max$ than control subject with $I / s$ and $s / s$ genotype. Control subjects with $I / I$ genotype had also significantly higher Vmax than their depressed homologues. In contrast, $V \max$ was not significantly different between depressed and normal subjects who carried the other two genotypes. The 5-HTT promoter genotype, diagnoses or their interaction had no effect on the other serotonin parameters.

Conclusions: While showing a significant decrease of Vmax and $\mathrm{Km}$ in a group of drug-naive depressed children and adolescents, these data suggest that I/I genotype has a substantial effect on the decrease of Vmax during a depressive episode. 


\section{INTRODUCTION}

A sizable amount of evidence from studies of adult depressed patients supports abnormalities in Serotonin (5-HT) system functioning (Owens and Nemeroff, 1994). These include: (1) low concentration of the 5-HT metabolite 5-hydroxyindoleacetic acid (5-HIAA) in the liquor; (2) low density of platelet and brain 5-HT transporter (5-HTT) binding sites (determined with $\left[{ }^{3} \mathrm{H}\right]$-Imipramine or $\left[{ }^{3} \mathrm{H}\right]$-Paroxetine) and low platelet serotonin uptake in suicide victims and depressed patients; (3) a high density of platelet and brain 5HT2 binding sites; (4) sensitivity to dietary tryptophan depletion; (5) positive response to Serotonin Selective Reuptake Inhibitor (SSRI) treatment.

The platelet serotonin transporter (5-HTT) system is in turn now accepted as a less invasive model of the 5-HT nerve terminal since it shares embryological ancestry, biochemistry, transport protein gene sequences and functionality (Owens and Nemeroff, 1994). As consequence, considerable data on platelet serotonin transporter functionality is being collected in healthy controls and psychiatric patients. Decreased rate of serotonin uptake ( $V \max$ ) (and/or dissociation constant $\mathrm{Km}$ ) in platelets of adult subjects with major depression has been repeatedly reported (Arora et al., 1984; Coppen et al., 1978; Meltzer et al., 1981; Scott et al., 1979; Stahl et al., 1983), and this abnormality has been proposed as both a state (Rausch et al., 1988) and a trait marker (Coppen et al., 1978). Decreased $5 \mathrm{HTT}$ binding sites in either platelets or brains of adults with major depressive disorder (MDD) have been demonstrated in many, but not in all, studies using [ $\left.{ }^{3} \mathrm{H}\right]$-Imipramine binding (Owens and Nemeroff, 1994; Perry et al., 1983; Stanley et al., 1982) or more selective ligands, such as [3H]-Paroxetine (Lawrence et al., 1993; Nemeroff et al., 1991; Nemeroff et al.,1994; D'Hondt et al., 1994; Iny et al., 1994; Nelson et al., 1995).

Recently, 5HTT gene transcription has been found to be regulated by a deletion/insertion polymorphism in the promoter region (Heils et al., 1996). The long $(I)$ and short $(s)$ variants of this polymorphic region have different transcriptional efficiencies in transfection assays and lymphoblastoid cell lines (Heils et al., 1996; Lesch et al., 1996). The $s$ variant reduces 5-HTtransporter gene transcription, resulting in reduced transporter levels and $5-\mathrm{HT}$ uptake, thus acting as a dominant allele. Consistent with prior in vitro studies, studies of healthy subjects found the I variant to be associated with more rapid initial platelet $5-\mathrm{HT}$ uptake (Vmax), while the 5-HT transporter genotype was found to have no effect on platelet $\left[{ }^{3} \mathrm{H}\right]$ Paroxetine binding $(B m a x)$, affinity for $\left[{ }^{3} \mathrm{H}\right] 5-\mathrm{HT}(1 / \mathrm{Km})$ or $\left[{ }^{3} \mathrm{H}\right]$ Paroxetine(1/Kd), or 5-HT content (Greenberg et al., 1999). 
The study of the effect of this polymorphism on platelet 5-HTT functionality in depressed children seemed to be particularly interesting for two main reasons. First, platelet studies of both healthy controls and psychiatric patients are not currently available. Second, patients with childhood-onset affective disorders (Todd et al., 1993) are ideal for selecting a group with greater genetic specificity. This study looks at possible associations between 5-HTT promoter variants and differential regulation of platelet $5 \mathrm{HTT}$ functionality parameters and at their possible interactions with the psychiatric diagnoses.

\section{METHODS}

\section{Subjects}

Subjects in the study were children and adolescent outpatients with major depression according to DSM III-R consecutively seen at a depression treatment facility for the young, and normal subjects of similar age from the same geographical area, as controls. For patients to be included in the study, previous clinical diagnoses of depression had to be independently confirmed by child psychiatrists by administration of the child version of the Diagnostic Interview for Children and Adolescents Revised (DICA-R, Reich et al., 1991), and their IQ had to be $>80$ at the Wechsler Intelligence Scale for Children-Revised (WISC-R, Kaufman, 1979).

A history of current or previous antidepressant treatment, as collected by interviews with parents and the referring pediatricians, was an exclusion criterion. Eighteen young depressed subjects were recruited in 11 months in order to study their indices of $5 \mathrm{HT}$ functionality and genotypes.

Since several parameters of $5 \mathrm{HT}$ function show circadian and seasonal variations (D'Hondt et al., 1994; D'Hondt et al., 1996; Halbreich et al., 1991; DeMet et al., 1991), the recruitment of depressed and normal subjects followed similar seasonal patterns by adopting the following procedures. At the beginning of the study, a pool of children and adolescents volunteering as possible control subjects - upon previous consent of both their parents -were identified from schools of the same geographic area. Then, every time a depressed subject was recruited for the study, a control subject (on three occasions, two control subjects) of similar age was randomly extracted from the pool, and his/her blood collected for analyses.

Healthy control children were interviewed with the same instruments: to be included in the study they had to have an $I Q>80$, no current or past history of major depression, no current history of any Axis I disorder. 
Blood samples were then collected from both patients and control subjects between 8.30 a.m and 9.30 a.m. of the same day. Eighteen depressed subjects and 21 normal subjects entered the study, with a homogeneous time spread of recruitment and blood analyses across the 11 months of the study.

All subjects also received a thorough medical and neurological examination. All cases and controls were unrelated and caucasian. Sample demographics, clinical characteristics and comorbid status are presented in Table1.

Both parents of all subjects participating in the study gave written informed consent.

\section{Biochemical and Molecular Genetic Methods}

$25 \mathrm{ml}$ of blood were drawn from controls and patients between 8.30 a.m. and 9.30 a.m. and collected into plastic tubes containing $3.8 \% \mathrm{Na}$ citrate as anticoagulant $(1 \mathrm{ml} / 9 \mathrm{ml}$ blood). $3 \mathrm{ml}$ of blood were used for genetic procedures. Platelet Rich Plasma (PRP) was obtained by centrifugation at $200 \times \mathrm{g}$ for $15 \mathrm{~min}$ at $15^{\circ} \mathrm{C}$. A part of PRP was immediately utilized for serotonin uptake studies while the remaining PRP was centrifuged at 3700 $\mathrm{x} \mathrm{g}$ for $20 \mathrm{~min}$ at $4^{\circ} \mathrm{C}$. The platelet pellet was frozen at $-80^{\circ} \mathrm{C}$ and kept for Paroxetine binding study.

\section{Determination of 5-HT Uptake}

Serotonin uptake was determined as described by Arora and Meltzer (1981). PRP $100 \mathrm{ml}$ was preincubated for $2 \mathrm{~min}$ at $37^{\circ} \mathrm{C}$ after addition of saline $(10 \mathrm{ml})$ or fluoxetine $(10 \mathrm{ml}, 1.2 \mathrm{mM})$. Then $10 \mathrm{ml}$ of $\left[{ }^{3} \mathrm{H}\right]$-serotonin (5-hydroxytryptamine-creatinine sulfate, specific activity $21 \mathrm{Ci} / \mathrm{mmole}$ from Amersham, UK) at five different concentrations $(0.5-9 \mathrm{mM}$ in assay volume) was added and uptake was performed for $2 \mathrm{~min}$. Serotonin uptake was stopped by addition of ice-cold EDTA $0.4 \%$ in saline $(500 \mathrm{ml})$. The platelet pellet, obtained by centrifuging at $3700 \mathrm{~g}$ for $20 \mathrm{~min}$, was rinsed with $250 \mathrm{ml}$ of the same solution and was then processed for $24 \mathrm{~h}$ with $85 \%$ formic acid. Active uptake was determined by subtracting the disintegrations per minute $(\mathrm{dpm})$ of the tubes that had been preincubated with fluoxetine from the dpm of the tubes preincubated with saline. Values for $V \max$ and $\mathrm{Km}$ were calculated using the Ligand programs (Munson and Rodbar, 1980). Serotonin uptake and $K m$ values were expressed as picomol/107 $\mathrm{plt} / \mathrm{min}$ and as micromol respectively.

Determination of $\left[{ }^{3} \mathrm{H}\right]$-Paroxetine Binding (Bmax)

The method of Mellerup et al., (1983) was used to determine $\left[{ }^{3} \mathrm{H}\right]-$ 
paroxetine binding. Platelet pellets were washed twice $(10000 \mathrm{~g}$ for $10 \mathrm{~min}$ at $4^{\circ} \mathrm{C}$ ) in $5 \mathrm{ml}$ of buffer ( $50 \mathrm{mM}$ Tris, $150 \mathrm{mM} \mathrm{NaCl}, 20 \mathrm{mM}$ EDTA, pH 7.5). Pellets were suspended in $5 \mathrm{ml}$ of buffer ( $5 \mathrm{mM}$ Tris, $5 \mathrm{mM}$ EDTA, pH 7.5) and centrifuged at $20000 \mathrm{~g}$ for $10 \mathrm{~min}$ at $4^{\circ} \mathrm{C}$ ). The membrane pellets thus obtained were washed $\left(20000 \mathrm{~g}\right.$ for $10 \mathrm{~min}$ at $\left.4^{\circ} \mathrm{C}\right)$ in $5 \mathrm{ml}$ of buffer $(70$ $\mathrm{mM}$ Tris, $\mathrm{pH}$ 7.5). Membrane pellets $(0.1-0.2 \mathrm{mg}$ protein $/ \mathrm{ml})$ were suspended in assay buffer ( $50 \mathrm{mM}$ Tris, $120 \mathrm{mM} \mathrm{NaCl}, 5 \mathrm{mM} \mathrm{KCl}, \mathrm{pH}$ 7.5). $\left[{ }^{3} \mathrm{H}\right]$-paroxetine (specific activity $17.1 \mathrm{Ci} / \mathrm{mmole}$ from NEN-Dupont) at 5 different concentrations (0.1-2 $\mathrm{nM}$ in assay volume) and $30 \mathrm{ml}$ of assay buffer or fluoxetine $300 \mathrm{mM}$ were added to $250 \mathrm{ml}$ of membrane suspension and binding was performed for 90 minutes at $25^{\circ} \mathrm{C}$. Samples were then run through Whatman GF/C filters and washed three times with $3 \mathrm{ml}$ of ice-cold assay buffer. Specific paroxetine binding was determined by subtracting the disintegrations per minute (dpm) of the tubes incubated with fluoxetine from the dpm of the tubes incubated with saline. Values for $B$ max and $K d$ were calculated using the Ligand programs (Munson and Rodbar, 1980). Paroxetine binding and $K d$ values were expressed as $\mathrm{fmol} /$ microgr proteins and as micromol, respectively.

\section{Genetic procedures}

Genomic DNA was extracted with a standard SDS/ Proteinase K method (Current Protocols in Human Genetics, Unit 9.7) from $3 \mathrm{ml}$ of blood. The polymorphism in the transcriptional control region upstream of the 5-HTT coding sequence (5-HTTLPR) was analyzed by polymerase chain reaction (PCR) according to the method reported by Lesch et al.,. (1996). Two fragments were generated: a short variant (s) of 484-bp, and a long variant (I) of 528-bp. All amplification reactions were performed on a Gene Amp PCR System 2400 Thermocycler (Perkin-Elmer). The amplified products were analyzed on 4\% (3:1 NuSieve GTG: Standard) agarose gels.

\section{Data Analyses}

Preliminary analyses by chi-square tests applied to the contingency tables showed that genotype distribution, sex, and seasonality of blood sampling were evenly distributed across depressed and normal subjects, and seasonality of blood sampling was evenly distributed across the three differents genotypes, independently of the grouping criterion (depressed/normal). Age distribution was also unrelated to any of the variables mentioned above.

Four separate two-way analyses of covariance (ANCOVA) were performed, with 'age' as covariate, owing to its apparent influence on platelet serotonin parameters (Owens and Nemeroff, 1994), and 
'diagnosis' (depressed/nondepressed) and '5HTT promoter genotype' as independent variables. The four binding parameters were taken as dependent variables: serotonin 1) uptake rate ( $V \max )$, and 2) dissociation constant $(\mathrm{Km})$; Paroxetine: 3 ) binding, and density of site (Bmax), and 4) dissociation constant $(K d)$. Post-hoc comparisons were performed with Newman-Keuls test. All probability values reported are two-tailed, with significance as $p £ 0.05$. Statistical analyses were made with SPSS version 6.1 for Windows (SPSS Inc., Chicago).

\section{RESULTS}

In addition to not having ever taken antidepressants, all patients in the study turned out to be drug-naive, except for one girl who had taken benzodiazepine for about 6 months prior to inclusion in the study.

$5 \mathrm{HTT}$ promoter genotype and alleles were equally distributed between the two groups and the distribution in the whole sample was consistent with Hardy-Weinberg equilibrium (Table 2).

Table 3 shows the main effects results of ANCOVAs.

Serotonin uptake parameters: Vmax

'Diagnosis' had a significant effect on the $V \max (F=6.08$, d.f. $=1.29$, $\mathrm{p}=0.02$ ), while the ' 5 -HTT promoter genotype' did not reach a statistically significant effect $(F=3.10$, d.f. $=2.29 ; p=0.06)$. However, the interaction between 'diagnosis' and the '5-HTT promoter genotype' was significant $(F=6.07 ;$ d.f. $=2.29 ; p=0.006)$.

Post-hoc comparisons showed that control subjects with $/ / /$ genotype had significantly higher Vmax than control subjects with $I / s(p=0.005)$ and $s / s$ $(p=0.005)$ genotype. More importantly, control subjects with $1 / /$ genotype had significantly higher Vmax than their depressed homologues $(p=0.001)$. In contrast, there was no significant difference between Vmax in depressed vs. normal subjects who carried the other two genotypes. Figure 1 shows these results.

There was no significant correlation between Vmax and Bmax (Pearson's $r=0.1855 p=0.293)$.

Serotonin uptake parameters: $\mathrm{Km}$

Only 'diagnosis' had a statistical significant effect on the $K m \quad(F=7.79$, d.f. $=1.29, p=0.009$ ).

As for the covariate 'age', the test of the hypothesis of non null slope did not attain significance for either $V \max$ or $\mathrm{Km}$. Km significantly correlated 
with $V \max ($ Pearson's $r=0.438, p=0.008)$.

Paroxetine binding parameters: Bmax and $K d$.

No significant effect of 'diagnosis', of 5-HTT promoter genotype, or of their interaction was found for the Bmax or the $K d$. Bmax significantly correlated with $K d$ (Pearson's $r=0.5 ; p=0.003$ ).

A moderate, positive correlation was found between age and Bmax in the whole sample (Pearson's $r=0.514, F=7.47$, d.f. $=1.30, p=0.01$ ), but not between age and $K d$.

\section{DISCUSSION}

While showing a significant decrease of maximum serotonin uptake (Vmax) in a study group of drug-naive depressed children and adolescents for the first time, these data suggest that this finding can be at least partially explained on the basis of variations connected with a specific genotypic set, namely the $I / /$ genotypic variant of the 5 -HTT promoter gene in the course of a depressive episode. To our knowledge this is also the first report investigating possible relationship between 5-HTT promoter polymorphism and in vivo platelet Serotonin uptake and Paroxetine binding in healthy controls and drug-naive depressed patients.

Among normal controls, subjects who were homozygous for the / form of the 5-HTT promoter gene had an uptake 1.4 to 1.9 times higher than that of subjects carrying one or two copies of the $s$ variant, and subjects with the $I / s$ and $s / s$ genotypes were not significantly different from each other. These figures are consistent with the association observed between long allele and increased 5-HT uptake in lymphoblast cell lines (Lesch et al., 1996), and in platelets of healthy controls (Greenberg et al., 1999), suggesting a dominant- rather than codominant- effect for the $s$ allele.

A comparison between diagnostic groups showed that the I/I genotype determined a substantial difference in serotonin uptake, while the short variants $(I / s$ or $s / s)$ brought about minimal differences in platelet serotonin uptake. These data altogether suggest that during a depressive episode subjects carrying both I alleles may be exposed to epistatic/epigenetic effects specifically affecting serotonin uptake.

Some evidence is indeed in favor of a differential serotonin modulation system in subjects carrying an I/I genotype in physiological conditions, and, in a more indirect way, when they are psychiatrically ill. Subjects from OCD families (both healthy and affected) carrying the $I / I$ genotype had higher $5 \mathrm{HT}$ blood levels and more marked seasonal variations than subjects with 
the short allelic variant ( $/ / s$ or $s / s$ ), who had intermediate/low blood $5 \mathrm{HT}$ levels, and minimal seasonal fluctuations (Hanna et al., 1998). Depressed I/I homozygote patients were found to have a significantly better response to fluvoxamine (an SSRI potentiating 5HT neurotransmission) than homozygotes with the short variant, while heterozygotes had an intermediate pattern of response (Smeraldi et al., 1998).

None of the other platelets serotonin parameters are influenced by the 5HTT genotype, thus confirming prior findings of platelet studies in human subjects (Greenberg et al., 1999)

The lack of genotypic effect on the $\left[{ }^{3} \mathrm{H}\right]$-serotonin and $\left[{ }^{3} \mathrm{H}\right]$-Paroxetine dissociation constants ( $K d$ and $K m$ ) could be expected, since the influence of 5 HTT promoter variants is believed to be due to different transcriptional efficiences among the different alleles, which would result in the production of different amounts of transporter molecules that are otherwise identical (Greenberg et al., 1999).

Our finding on the lack of genetic control on Paroxetine binding values is in contrast with the data obtained from lymphoblast when using [ $\left.{ }^{123} \mid\right]-R T I 55$ ([ $\left.{ }^{123} \mathrm{I}\right]-\mathrm{b}$ carbomethoxy-3b-(4-iodophenyl)tropane also known as [123I]-CIT) (Lesch et al., 1996). It could be explained by the use of different ligands and the consequent identification of differently modulated molecular sites. Recent work (Malison et al., 1998) quantifying brainstem [ ${ }^{123}$ I]-CIT by Single Photon Emission Computed Tomography (SPECT), and platelet $\left[{ }^{3} \mathrm{H}\right]$-Paroxetine binding, failed to show a correlation between the two parameters, thus indirectly supporting our results.

The lack of a significant reduction in $\left[{ }^{3} \mathrm{H}\right]$-Paroxetine binding in depressed patients compared to normal controls is consistent with many, but not all, previous controlled studies measuring $\left[{ }^{3} \mathrm{H}\right]$-Paroxetine binding in depression (Malison et al., 1998; Nelson et al., 1995; D'Hondt et al., 1994; Iny et al., 1994) and, at the same time, is at variance with most studies employing Imipramine as 5-HTT ligand (Suranyi-Cadotte et al., 1989; D'Haenen et al., 1988). The observation (Iny et al., 1994) that the sites labeled by $\left[{ }^{3} \mathrm{H}\right]$-Imipramine and $\left[{ }^{3} \mathrm{H}\right]$-Paroxetine are probably not identical - as no correlation was observed between Bmax and $K d$ values for these ligands in controls and in psychiatric patients with various diagnosis should be considered when addressing this inconsistency. In the same way, our finding of a lack of correlation between Paroxetine binding and $5 \mathrm{HT}$ uptake is basically in accordance with some studies of simultaneous measurement of 5-HT uptake and Paroxetine (or Imipramine) binding (Wirz-Justice, 1988; Halbreich et al., 1991).

In a more general perspective, when considering the independence of $B$ max from both the Vmax and the group variables (diagnosis and 
genotypes) in this study, other important factors need be borne in mind. First, 5HT uptake site is assayed in intact platelets, while Paroxetine binding is measured in membrane fractions. Second, it is known (Blakely et al., 1998) that both the 5HT uptake process, and the processes of 5HTT gene translation and transcription involve several different steps, all potentially prone to different regulation and/or alteration in disease status.

\section{Limitations}

There are several specific issues, in addition to more general caveats, that need careful consideration when looking at these results. Potential sources of confounding at this level may include differential sensitivity in the $5 \mathrm{HT}$ uptake assay, random variation inherent to the small group size, and the interaction of Bmax with other factors, including age. The latter point may deserve further evaluation: while we found a positive, significant correlation between Bmax and age, data from both depressed and normal adults (Owens and Nemeroff,1994) provided evidence for negative correlation, while the only two studies available on young subjects gave unclear results. One investigation using $\left[{ }^{3} \mathrm{H}\right]$-Paroxetine as ligand reported no association between Bmax and age (Sallee et al., 1998), and the other, using Imipramine as ligand, revealed lower values of Bmax in newborn babies vs. healthy adults (Marazziti et al., 1987).

Data on 5-HTT binding in depressed children and adolescents compared normal controls are controversial, and this makes the case for prudence. Using the nonselective index ligand Imipramine, Rehavi et al. (1984) found no difference in Bmax in medication-free depressed children and adolescents vs. normal subjects, while Carsten et al. (1988) found an elevate Bmax value. Ambrosini et al. (1992), on the contrary, demonstrated a decreased Bmax value in acutely depressed young patients. Recently Sallee et al. (1998), using the more selective ligand Paroxetine, showed a reduced binding capacity in medication-free MDD subjects. To further complicate the issue, $\left[{ }^{3} \mathrm{H}\right]$-Paroxetine binding is defined here by the competing cold ligand Fluoxetine, and several data on both children (Salle et al., 1998) and adults (Malison et al., 1998, D'Hondt et al., 1994, Iny et al., 1994) were obtained by employing molecules (Clomipramine, Imipramine, Citalopram) other than Fluoxetine as the cold ligand, making comparisons across platelet binding studies even more problematic.

In light of the caveats outlined above, of the small sample size and of the unprecedented nature of this report, these data need prudent consideration, and must be considered preliminary. In addition, the clinical and biochemical follow-up of these children is of crucial importance. Reassessments of the indices of $5 \mathrm{HT}$ functions will help clarify the very nature 
of these findings. Seasonally-controlled blood collections in euthymia of these same patients have begun, and will help answer these questions, including the question of a state- versus trait alteration of Vmax in children with depression and the $1 / /$ genotype.

\section{Clinical Implications}

This study found that human platelet $5 \mathrm{HT}$ uptake, which takes place via a transporter molecule identical to that found in the human brain, is influenced differentially in normal and depressed children by a common genetic variant of the promoter region of the $5 \mathrm{HT}$ transporter. Depressed children as a group had a decreased transporter activity (Vmax), but this difference was almost entirely sustained by children who carried a specific genotype, i.e., the I/I variant for the 5HTT promoter region. The main site of pharmacological action of SSRIs is neuronal $5 \mathrm{HTT}$, and any abnormality at this site may have implications for etiopathogenesis and treatment responsivity.

The potentially different biochemical profile of serotonin function for subjects with the $I / /$ genotype compared to subjects with the $I / s$ and $s / s$ genotype during depression may thus predict different levels of serotonergic dysfunction, and perhaps different pharmacological response. Potential advantages of this approach include the identification of a tentative, genetically-based criterion for defining subgroups of depressed children and adolescents, a contribution toward a better understanding of the mechanisms underlying the response to SSRIs, and a criterion to guide the choice of an antidepressant therapy.

\section{Acknowledgments}

This research was supported by Italian Health Department-Current Research Grant- R.C.97 
Table 1. Demographic and clinical characteristics of the study group

Findings

\begin{tabular}{lcc}
\multicolumn{1}{c}{ Characteristic } & Normal Controls $(n=21)$ & MDD $(n=18)$ \\
\hline Current age, mean (+/- SD) & $16.4(4.4)$ & \\
Sex, $\mathrm{n}(\%)$ & $7(33.3)$ & $7(38.9)$ \\
Female & $14(66.7)$ & $11(61.1)$ \\
Male & - & $11.7(3.2)$ \\
Age at onset (+/-SD) & - & 2 \\
Other diagnoses, current & - & 2 \\
Social phobia & - & 1 \\
Anxiety Disorder & & \\
Oppositional Defiant Disorder & & \\
\hline MDD: Major Depressive Disorder & & \\
\hline
\end{tabular}

MDD: Major Depressive Disorder 
Table 2. Genotype distribution and allele frequencies for the 5-HTT promoter polymorphism..

\begin{tabular}{llllllll}
\hline & \multicolumn{3}{l}{ Genotype distribution (\%) } & \multicolumn{4}{l}{ Allele frequencies (\%) } \\
\cline { 2 - 8 } & $\mathrm{n}$ & $1 / l$ & $1 / s$ & $\mathrm{~s} / \mathrm{s}$ & $\mathrm{n}$ & $I$ & $\mathrm{~s}$ \\
\hline controls & 21 & $6(28.6)$ & $12(57.1)$ & $3(14.3)$ & 42 & $24(57.1)$ & $18(42.9)$ \\
depressed & 18 & $5(27.8)$ & $9(50.0)$ & $4(22.2)$ & 36 & $19(52.8)$ & $17(47.2)$ \\
total & 39 & $11(28.2)$ & $21(53.8)$ & $7(18.0)$ & 78 & $43(55.1)$ & $35(44.9)$ \\
\hline
\end{tabular}


Table 3. Serotonin Uptake and Paroxetine Binding values according to 5-HTT promoter genotype (5-HTTLPR) distribution and psychiatric diagnoses.

\begin{tabular}{|c|c|c|c|c|c|c|c|c|c|}
\hline \multirow[t]{2}{*}{ 5-HTTLPR GENOTYPE } & \multicolumn{2}{|c|}{$I / I(n=7)$} & \multicolumn{2}{|c|}{$1 / s(n=21)$} & \multicolumn{2}{|c|}{$s / s(\mathrm{n}=7)$} & \multicolumn{3}{|c|}{ ANCOVA (main effects) } \\
\hline & mean & SD & mean & SD & mean & SD & $\mathrm{F}$ & d.f. & $p$ \\
\hline Vmax (pmol/10 $\mathrm{plts} / \mathrm{min})$ & & & & & & & 3.98 & 3.29 & 0.017 \\
\hline control subjects & 27.7 & 3.5 & 19.4 & 3.2 & 14.4 & 5.6 & & & \\
\hline depressed & 13.9 & 4.6 & 18.6 & 7.4 & 13.7 & 0.6 & & & \\
\hline $\mathrm{Km}(\mu \mathrm{M})$ & & & & & & & 2.82 & 3.29 & 0.057 \\
\hline control subjects & 4.6 & 1.8 & 3.8 & 1.8 & 3.6 & 2.0 & & & \\
\hline depressed & 2.4 & 1.1 & 2.9 & 1.4 & 2.4 & 0.4 & & & \\
\hline Bmax (fmol/ug protein) & & & & & & & 0.26 & 3.30 & 0.85 \\
\hline control subjects & 1.3 & 0.38 & 1.4 & 0.4 & 1.0 & 0.18 & & & \\
\hline depressed & 1.4 & 0.26 & 1.0 & 0.38 & 1.4 & 0.5 & & & \\
\hline $\operatorname{Kd}(\mu \mathrm{M})$ & & & & & & & 2.35 & 3.27 & 0.09 \\
\hline control subjects & 0.10 & 0.019 & 0.19 & 0.063 & 0.17 & 0.056 & & & \\
\hline depressed & 0.21 & 0.089 & 0.16 & 0.075 & 0.23 & 0.054 & & & \\
\hline
\end{tabular}


Figure 1

Platelet Serotonin Uptake in Healthy Controls and Depressed Patients

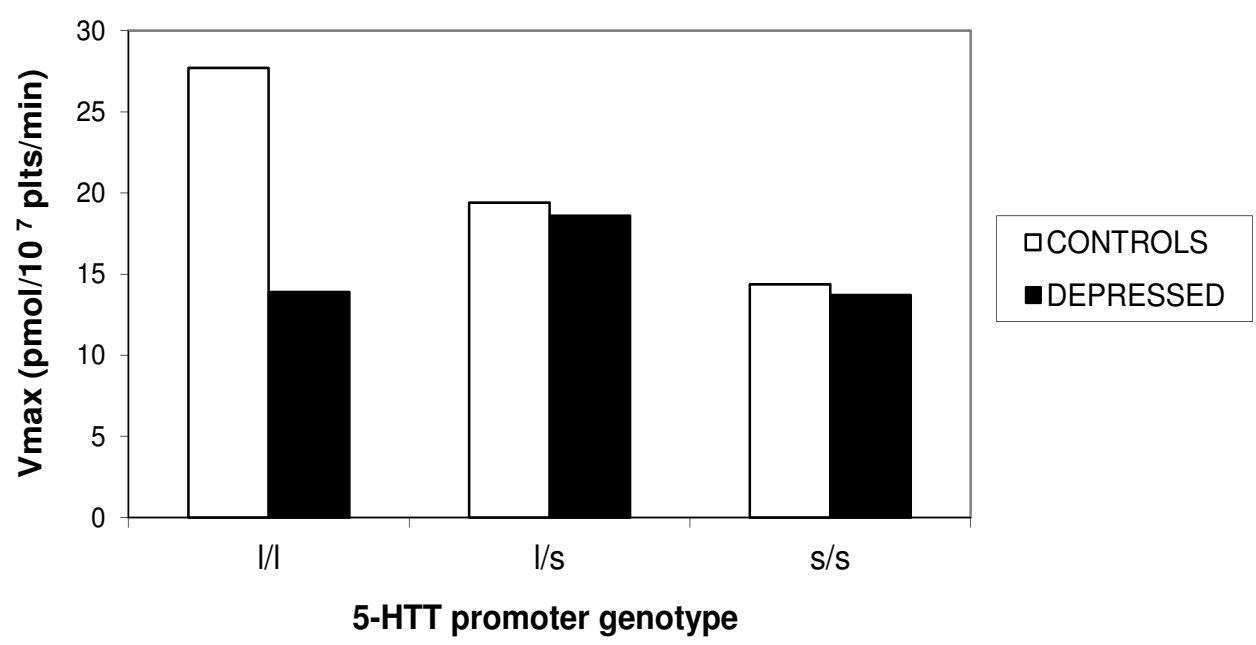




\section{REFERENCES}

Ambrosini PJ, Metz C, Arora RC, Lee JC, Kregel L, Meltzer HY (1992), Platelet imipramine binding in depressed children and adolescents. J Am Acad Child Adolesc Psychiatry 31:298-305

Arora RC, Meltzer HY (1981), A modified assay method for determining serotonin uptake in human platelets. Clinica Chimica Acta 112:225-233

Arora RC, Kregel L, Meltzer HY (1984), Seasonal variation of serotonin uptake in normal controls and depressed patients. Biol Psychiatry 19(6):795-804

Blakely RD, Ramamoorthy S, Schroeter S, Qian Y, Apparsundaram S, Galli A, DeFelice LJ (1998), Regulated phosphorylation and trafficking of antidepressant-sensitive serotonin transporter proteins. Biol Psychiatry 44:169-178

Carstens ME, Engelbrecht AH, Russell VA, van Zyl AM, Taljaard JJF (1988), Biological markers in juvenile depression. Psychiatry Res 23:7788

Coppen A, Swade C, Wood K (1978), Platelet 5-HT accumulation in depressive illness. Clin Chim Acta 87:165-168.

Current Protocols in Human Genetics, Unit 9.7, John Wiley \& Sons, Inc., 1995.

DeMet E, Reist C, Bell KM, Gerner RH, Chicz-DeMet A, Warren S, Wu J (1991), Decreased seasonal mesor of platelet ${ }^{3} \mathrm{H}$-Imipramine binding in depression. Biol Psychiatry 29:427-440

D'Haenen H, De Waele M, Leysen J (1988), Platelet ${ }^{3} \mathrm{H}$-paroxetine binding in depressed patients. Psychiatry Res 26:11-17

D'Hondt P, Maes M, Leysen J, Gommeren W, Scharpè S, Cosyns P (1994), Binding of ${ }^{3} \mathrm{H}$-Paroxetine to platelets of depressed patients: seasonal difference and effect of diagnostic classification. J Affective Dis $32: 27-35$

D'Hondt P, Maes M, Leysen J, Gommeren W, Heylen L, DeMeyer F, Scharpe S, Peeters D, Desnyder R (1996), Seasonal variation in 
platelet ${ }^{3} \mathrm{H}$-Paroxetine binding in healthy volunteers. Relation to climatic variables. Neuropsychopharmacology 15:187-198

Greenberg BD, Tolliver TJ, Huang S, Li Q, Bengel D, Murphy DL (1999), Genetic variation in the serotonin transporter promoter region affects serotonin uptake in human blood platelets. Am $J$ Med Genet (Neuropsychiatric Genet) 88:83-87

Halbreich U, Rojansky N, Zander KJ, Barkai A (1991), Influence of age, sex and diurnal variability on imipramine receptor binding and serotonin uptake in platelets of normal subjects. J Psychiat Res 25: 7-18

Hanna GL, Himle J, Curtis GC, Koram DQ, Weele JVV, Leventhal BL, Cook EH (1998), Serotonin transporter and seasonal variation in blood serotonin in families with Obsessive-Compulsive Disorder. Neuropsychipharmacology 18:102-111

Heils A, Teufel A, Petri S, Stoeber G, Riederer P, Bengel D, Lesch KP (1996), Allelic variation of human serotonin transporter gene expression. J Neurochemistry 66:2621-2624

Iny LJ, Pecknold J, Suranyi-Cadotte BE, Bernier B, Luthe L, Nair NPV, Meaney MJ (1994), Studies of a neurochemical link between depression, anxiety and stress from ${ }^{3} \mathrm{H}$-Paroxetine and ${ }^{3} \mathrm{H}$-Imipramine binding on human platelet. Biol Psychiatry 36:281-291

Kaufman AS (1979) Intelligence testing with the WISC-R. New York. John Wiley \& Sons.

Lawrence KM, Falkowsky J, Jacobson RR, Horton RW (1993), Platelet 5HT uptake sites in depression: three concurrent measures using $\left[{ }^{3} \mathrm{H}\right] \mathrm{imipramine}$ and $\left[{ }^{3} \mathrm{H}\right]$ paroxetine. Psychopharmacology 110:235-9

Lesch KP, Bengel D, Heils A, Sabol SZ, Greenberg BD, Petri S, Benjamin J, Muller CR, Hamer DH, Murphy DL (1996), Association of anxiety related traits with a polymorphism in the serotonin transporter gene regulatory region. Science 274:1527-1531

Malison RT, Price LH, Berman R, van Dyck CH, Pelton GH, Carpenter L, Sanacora G, Owens MJ, Nemeroff CB, Rajeevan N, Baldwin RM, Seibyl JP, Innis RB, Charney DS (1998), Reduced brain serotonin transporter availability in Major Depression as measured by [ $\left.{ }^{1231}\right]-2 b$-carbomethoxy- 
3b-(4iodophenyl)tropane and Single Photon Emission Computed Tomography. Biol Psychiatry 44:1090-1098

Marazziti D, Giusti P, Rotondo A, Placidi GF, Pacifici GM (1987), Imipramine receptors in human platelets: effect of age. Int $J$ Clin Pharmacol Res 7(2):145-8

Mellerup ET, Plenge P, Engelstoft M (1983), High affinity binding of ${ }^{3} \mathrm{H}-$ Paroxetine and ${ }^{3} \mathrm{H}$-Imipramine to human platelet membranes. Eur $\mathrm{J}$ Pharmacol 96:303-309

Meltzer H, Arora R, Baber R, Tricou B (1981), Serotonin uptake in blood platelets of psychiatric patients. Arch Gen Psychiatry 38:1322-1329

Munson PJ, Rodbar D (1980), A versatile computerized approach for characterization of ligand-binding systems. Anal Biochem 107:220-239

Nelson E.C., Sheline YI, Bardgett ME, Jackson JL, Csernansky JG (1995), Platelet Paroxetine binding in major depressive disorder with and without comorbid obsessive-compulsive disorder. Psychiatry Res 58:117-125

Nemeroff CB, Knight DL, Franks J, Craighed WE, Krishnan KRK (1994), Further studies on platelet serotonin transporter binding in depression. Am J Psychiatry 151:1623-1625

Nemeroff CB, Knight DL, Krishnan KRK (1991), Reduced platelet $\left[{ }^{3} \mathrm{H}\right]$ paroxetine and $\left[{ }^{3} \mathrm{H}\right]$ imipramine binding in major depression [abstract]. Soc Neurosci Abstr 17:586.4

Owens MJ, Nemeroff CB (1994), Role of serotonin in the pathophysiology of depression: focus on the serotonin transporter. Clin Chem 40(2):288295

Perry EK, Marshall EF, Blessed G, Tomlinson BE, Perry RH (1983), Decreased imipramine binding in the brains of patients with depressive illness. Br J Psychiatry 142:188-192

Rausch JL, Rich CL, Risc SC (1988), Platelet serotonin transport after a single ECT. Psychopharmacology 95:139-141

Rehavi M, Weizman R, Carel C, Apter A, Tyano S (1984), High affinity ${ }^{3} \mathrm{H}-$ 
imipramine binding in platelets of children and adolescents with major affective disorders. Psychiatry Res 13:31-39

Reich W, Shayka T, Taibleson C (1991), The Diagnostic Interview for Children and Adolescents-Revised (DICA-R). Washington University; St Louis MO.

Sallee FR, Hilal R, Dougherty D, Beach K, Nesbitt L (1998), Platelet serotonin transporter in depressed children and adolescents: ${ }^{3} \mathrm{H}-$ Paroxetine platelet binding before and after sertraline. J Am Acad Child Adolesc Psychiatry 37(7):777-784

Scott M, Reading H, Loudon J (1979), Studies on human blood platelets in affective disorders. Psychopharmacology 60:131-137

Stahl S, Woo D, Mefford I, Berger P, Ciaranello R (1983): Hyperserotoninemia and platelet serotonin uptake in schizophrenia and affective disorders. Am J Psychiatry 140:26-31

Stanley M, Virgilio J, Gershon S (1982), Tritiated $\left[{ }^{3} \mathrm{H}\right]$ imipramine binding sites are decreased in the frontal cortex of suicides. Science 216:13371339

Smeraldi E, Zanardi R, Benedetti F, Di Bella D, Perez J, Catalano M (1998), Polymorphism within the promoter of the serotonin transporter gene and antidepressant efficay of fluvoxamine. Mol Psychiatry 3(6):508511

Suranyi-Cadotte B, Quirion R, Nair N, Lafaille F, Schwartz G (1985) Imipramine treatment differentially affected platelet $\mathrm{H} 3$-imipramine binding and serotonin uptake in depressed patients. Life Sci 36:795-799

Todd RD, Neuman R, Geller B, Fox LW, Kickok J (1993), Genetic studies of affective disorders: should we be starting with childhood onset probands? J Am Acad Child Adolesc Psychiatry 32:1164-1171

Wirz-Justice A (1988), Platelets research in psychiatry. Experientia 44:145152 


\section{CHAPTER 4}

\section{A case-control and family-based association study of the 5-HTTLPR in pediatric-onset depressive disorder}

Maria Nobile, Maria Giulia Cataldo, Roberto Giorda, Marco Battaglia, Cinzia Baschirotto, Monica Bellina, Cecilia Marino and Massimo Molteni

Biological Psychiatry. 2004 Aug 15; 56(4): 292-5. 


\section{ABSTRACT}

Background: Pediatric depression can be particularly informative for clarification of the causes of mood disorders. The aim of this work was to explore the possible association between childhood- and early-adolescentonset DSM-IV depressive disorders (DD; including major depression and dysthymia) and the serotonin transporter-linked promoter polymorphism (5-HTTLPR) locus.

Methods: The case- control sample consisted of 68 unrelated patients with DD, and 68 unrelated age- and gender-matched healthy control subjects. The same patients were included in the family-based study, which consisted of 41 triads and 11 dyads. Results: An excess of the SS-genotype $(p=.025)$ and of the S-allele $(p=.021)$ was found among DD children (odds ratio $=1.81 ; 95 \%$ confidence interval $=1.12-2.94$ ). The family-based results suggested that the S-allele was preferentially transmitted to depressed children (haplotype-based haplotype relative risk: $\mathrm{X}^{2}=7.231, \mathrm{df}=1, \mathrm{p}=.007$; transmission disequilibrium test: $\mathrm{X}^{2}=5.233$, $d f=1, p=.022)$.

Conclusions: A role for the 5-HTTLPR locus that needs replication in larger samples is suggested in childhood DD. 


\section{INTRODUCTION}

Family and epidemiologic studies show that child- and adolescent-onset depressive disorders may be particularly informative for clarification of the causes of mood disorders (Todd et al 1993, 2002). Earlier onset of more severe illness with greater familial loading has been shown for prepubertal onset compared with adult-onset probands with major depressive disorder (Neuman et al 1997). A higher risk for mood disorders has been reported in the offspring of early-onset (age < 30 ) major depressive disorder cases compared with the offspring of later-onset cases (Weissman et al 1988; Wickramaratne et al 1998). Heritability estimates of children's depressive symptoms vary widely $(.30-.46$, Eley and Stevenson 1999; .28- .71, Happonen et al 2002) with some studies reporting heritability as high as $.60-.80$ (Eaves et al 1997; McGuffin and Katz 1989; Thapar and McGuffin 1994). They provide some indication, however, that the amount of variance explained by genetic factors is higher than for estimates (typically .4-.5) based on adult samples (Bierut et al 1999; Kendler et al 1992, 1999). Moreover, a sizeable amount of evidence suggests that the serotonin system is involved in the pathophysiology of affective disorders (Duman 1999). The serotonin transporter has received particular attention because it is involved in the re-uptake of serotonin at brain synapses and is the target of selective serotonin reuptake inhibitors. The promoter activity of the 5 -HTT gene is regulated by a deletion-insertion polymorphism in the proximal $5=$ promoter region, designated the $5 \mathrm{HTT}$ gene-linked polymorphic region (5-HTTLPR). The short (s) allele in the 5-HTTLPR is associated with lower transcriptional efficiency of the promoter compared with the long (L) allele (Lesch et al 1996). Regardless of age (adult, child, and adolescent), unaffected individuals with the $L-L$ genotype were found to have significantly higher maximal uptake of serotonin in platelets compared with those having L/s or s/s genotypes (Greenberg et al 1999; Nobile et al 1999). The 5HTTLPR has been investigated in a number of studies looking at emotionality and proneness to anxiety and depression. According to recent meta-analyses (Munafo et al 2003), the 5HTTLPR is probably associated with negative emotionality related to interpersonal hostility and depression in adults (Lesch 2003); however, meta-analyses of case-control association studies applied to adult populations of patients with affective disorders fail to provide support for a role for 5 HTTLPR (Anguelova et al 2003). There are fewer studies of the 5-HTTLPR in children. In early childhood, the short allele (by an interaction with the DRD4 repeat variant) was found to enhance avoidant-like behaviour (Auerbach et al 1999, 2001; Ebstein et al 1998; Lakatos et al 2003). In 
contrast, L/L genotype was found to be associated with higher anxiety in nonclinical children (Arbelle et al 2003; Jorm et al 2002). Only one familial association study of the 5HTTLPR and affective disorders proper has been published. It shows a negative association with manic symptoms (Geller and Cook 1999).

The aim of this work was to explore the possible association between childand early-adolescent-onset major depression and dysthymia and the 5HTTLPR locus using both the case- control and family-based approaches.

\section{METHODS AND MATERIALS}

This case- control sample consisted of 68 unrelated patients with childonset $\mathrm{DD}$, including major depression and dysthymia, and 68 unrelated age- and gender-matched healthy control subjects. All probands met DSMIV criteria for child- and earlyadolescent- onset DD and were recruited from the Child Psychiatry Unit of the Eugenio Medea Scientific Institute over 48 months. Major depression and dysthymia were pooled together in this study in a common DD group under the hypothesis that they share, at least in part, a common underlying genetic liability (Klein et al 1995).

Patients were included in the study if 1 ) clinical diagnosis of major depression or dysthymia at intake was confirmed independently by direct interviews using the Italian version of the Diagnostic Interview for Children and Adolescents-Revised (DICA-R; Battaglia et al 1997; Reich et al 1991) adapted to generate DSM-IV diagnoses and 2) the IQ total score was $>80$ on the Wechsler Intelligence Scale for Children-Revised (WISC-R; Kaufman 1979).

Interviews were administered separately to parents and children by trained psychologists (with the diagnosis confirmed by either the child or the parent interview).

Depressed children were also evaluated by the Italian version of the Children's Depression Inventory (CDI; Frigerio et al 2001; Kovacs 1992) and the 17-item Hamilton Depression Rating Scale (Hamilton 1967), which were completed by children and clinicians, respectively. Eighteen children belonged to the sample of a previous study (Nobile et al 1999). All patients were drug-naïve at the time of referral.

Children in the control group were recruited by advertisement from relatives of workers at the $\mathrm{E}$. Medea Scientific Institute and were interviewed using the DICA and WISC-R. They also completed the CDI questionnaire. To be included in the study, control children had to have an IQ greater than 80 and no current or past history of depressive disorders. 
Patient and control children also received a thorough medical and neurologic examination to rule out the presence of medical illnesses. The demographic and clinical characteristics of the sample are presented in Table 1.

Both parents of all children signed a written informed consent form for participation in the study, as approved by our ethics committee. To perform family-based association analyses, available parents of depressed probands were also recruited. Both parents were available for 41 families (triads); one parent was available for 11 families (dyads). All subjects in the study were Caucasian and of Italian ancestry.

Genomic DNA was extracted with a standard SDS/Proteinase $\mathrm{K}$ method (Current Protocols in Human Genetics, Unit 9.7; Dracopoli et al 1995) from a $3 \mathrm{~mL}$ venous blood sample. The polymorphism in the transcriptional control region upstream of the 5-HTT coding sequence (5-HTTLPR) was analyzed by polymerase chain reaction as reported by Lesch et al (1996). Two fragments were generated: a short variant (s) of 484-bp and a long variant ("L") of 528-bp.

The association of 5-HTTLPR with child- and adolescent-onset depression was tested by case-control association analysis and family-based association analysis (Qian et al 2003). Allele and genotype frequencies were compared in patient and control groups using the chi-square test. For the family-based analysis, we used the transmission disequilibrium test (TDT/S-TDT 1.1 program; Ewens 1996; Spielman et al 1993; Spielman and Ewens 1998) and the haplotype-based haplotype relative risk method (HHRR; Falk and Rubinstein, 1987) to avoid potential population stratification. Power calculations were carried out using the Genetic Power Calculator (Purcell et al 2003). All significance levels are two-tailed.

\section{RESULTS}

In the three groups (i.e., cases, parents, and control subjects) genotype distributions were in the Hardy-Weinberg equilibrium. Genotype and allele frequencies of the 5-HTTLPR polymorphism are shown in Table 2. The HHRR and TDT results are shown in Table 3 . Odds ratios, power calculations, and estimated sample size for case-control and family-based studies, are shown in Tables 2 and 3, respectively. 


\section{DISCUSSION}

The results of the case-control analyses support an association between 5-HTTLPR locus and DD with a small but significant effect of the S-allele and a moderately higher risk for DD, as indicated by the odds ratio. The family-based association analyses, which are more persuasive because they are not prone to stratification bias, reveal that the S-allele was preferentially transmitted to DD children.

These results are consistent with studies suggesting a role of the 5HTTLPR locus in adult and child negative emotionality as a general construct of liability to anxiety and depression (Ebstein and Auerbach 2002; Lesch 2003). They are also consistent with some (Collier et al 1996; Gutierrez et al 1998), but not all (Bellivier et al 1998; Frisch et al 1999; Hoehe et al 1998; Ohara et al 1998), studies of adults with affective disorders and with the finding of a positive association between the 5HTTLPR polymorphism and DD in presence of early life adversities in young adults (Caspi et al 2003). Through gene-environment interactions, adversity may thus reveal genetic associations, perhaps even in relatively small groups of subjects, including our sample. The negative results of a recent meta-analysis of association studies of affective disorders in adults (Anguelova et al 2003) should, on the other hand, be borne in mind when considering these findings. The odds ratios, 95\% confidence intervals, and power calculations of the case-control and family-based studies show moderate power, which should be taken into account when one compares these data with the only other similar published study, which focused on childhood-onset bipolar disorder (Geller and Cook 1999).

At least four main limitations to our study need consideration. First, although the sample size is in line with the figures usually found in child mood disorders, this is a small sample and needs confirmation in larger independent samples. Second, childhood major depression and dysthymia are pooled together within the DD group based on the hypothesis that they share an underlying liability (Klein et al 1995), but this remains to be proven. Third, with regard to our control sample, it has been shown that people who volunteer (or volunteer their children) for biological studies may differ from unselected community subjects on several variables (Kruesi et al 1990). Fourth, although our results are internally consistent, caution is necessary in view of the relatively small magnitude of the association

\section{Acknowledgements}

This study was supported by the Italian Health Department, Current Research Grant No. R.C.2000-2002. We thank Dr. Barbara Alberti for her assistance. 


\begin{tabular}{|c|c|c|c|c|}
\hline & $\begin{array}{l}\text { CONTROLS } \\
\qquad(\mathrm{n}=68)\end{array}$ & $\begin{array}{c}\text { DEPRESSIVE } \\
\text { DISORDER } \\
(\mathrm{n}=68)\end{array}$ & $\begin{array}{c}\text { MAJOR } \\
\text { DEPRESSION } \\
(\mathrm{N}=34)\end{array}$ & $\begin{array}{l}\text { DYSTHYMIA } \\
\qquad(\mathrm{N}=34)\end{array}$ \\
\hline \multicolumn{5}{|l|}{ Sex, N (\%) } \\
\hline Boys & $42(62 \%)$ & $42(62 \%)$ & $18(53 \%)$ & $24(70 \%)$ \\
\hline Girls & $26(38 \%)$ & $26(38 \%)$ & $16(47 \%)$ & $10(30 \%)$ \\
\hline Age $( \pm s d)$ & $12.14(2.32)$ & $12.14(2.32)$ & $12.41(2.66)$ & $12.06(1.95)$ \\
\hline IQ total $( \pm \mathrm{sd})$ & $102.78(11.58)$ & $94.14(12.97)$ & $93.13(14.97)$ & $95.10(11.01)$ \\
\hline Age at onset $( \pm s d)$ & - & $11.47(2.65)$ & $12.11(2.61)$ & $10.36(2.15)$ \\
\hline C.D.I. $( \pm s d)$ & $7.00 \pm 2.86$ & $17.49 \pm 7.57$ & $19.09(8.06)$ & $15.56(6.89)$ \\
\hline HAM-D & - & $16.37 \pm 5.57$ & $18.0(6.01)$ & $14.03(4.44)$ \\
\hline \multicolumn{5}{|c|}{ Other diagnoses, current $\mathrm{N},(\%)$} \\
\hline S.A.D. & - & $4(5.88 \%)$ & $3(8.82 \%)$ & $1(2.94 \%)$ \\
\hline Social Phobia & - & $4(5.88 \%)$ & - & $4(11.76 \%)$ \\
\hline Panic Disorder & - & $1(1.47 \%)$ & - & $1(2.94 \%)$ \\
\hline G.A.D. & $2(5.88 \%)$ & $8(11.76 \%)$ & $5(14.71 \%)$ & $3(8.82 \%)$ \\
\hline A.D.H.D. & $2(5.88 \%)$ & $10(14.71 \%)$ & $5(14.71 \%)$ & $5(14.71 \%)$ \\
\hline O.D.D. & - & $5(7.35 \%)$ & $3(8.82 \%)$ & $2(5.88 \%)$ \\
\hline
\end{tabular}

Table I. Demographic and Clinical Characteristics of the study group.

(C.D.I.: Children Depression Inventory; HAM-D: 17- Hamilton Depression Rating Scale; S.A.D.:

Separation Anxiety Disorder; G.A.D.: Generalized Anxiety Disorder; A.D.H.D.: Attention Deficit and Hyperactivity Disorder; O.D.D.: Oppositional Defiant Disorder.) 


\begin{tabular}{lccccc}
\hline & \multicolumn{2}{c}{ Genotype Distribution (\%) } & \multicolumn{3}{c}{ Allele Frequencies (\%)^ } \\
\cline { 2 - 5 } & $L / L$ & $L / s$ & $s / s$ & $L$ & $s$ \\
\hline Depressed n=68 & $17(25 \%)$ & $29(42.6 \%)$ & $22(32.4 \%)$ & $63(46.3 \%)$ & $73(53,7 \%)$ \\
Controls n=68 & $25(36.8 \%)$ & $34(50 \%)$ & $9(13.2 \%)$ & $83(61 \%)$ & $53(39 \%)$ \\
\hline
\end{tabular}

Table II. 5-HTTLPR allele and genotype frequencies in DD subjects and Controls

$\chi^{2}=7.372, d f=2, p=0.025$

${ }^{\wedge} \chi^{2}=5.914, d f=1, p=0.021 ; O R=1.81,95 \%$ C.I. $=1.12-2.94$

Power calculation for case-control study: 0.83 ; Estimated sample size $(\alpha=0.05, \beta=0.80)$ : $\mathrm{N}$ of cases $=63$ 


\begin{tabular}{|c|c|c|c|c|}
\hline \multirow[t]{2}{*}{ 5-HTTLPR } & \multicolumn{2}{|c|}{$\begin{array}{l}\text { HHRR }^{\circ} \\
\text { (41 trios) }\end{array}$} & \multicolumn{2}{|c|}{$\begin{array}{c}\text { TDT^ }^{\wedge} \\
(41 \text { trios }+11 \text { dyads })\end{array}$} \\
\hline & Transmitted & Non-Transmitted & Transmitted & Non-Transmitted \\
\hline Allele L & $39(41.1 \%)$ & 56 (58.9\%) & 14 & 29 \\
\hline Allele S & $43(62.3 \%)$ & 26 (37.7\%) & 29 & 14 \\
\hline
\end{tabular}

Table III. HHRR and TDT analyses of 5-HTTLPR in depressed children.

${ }^{\circ} \chi^{2}=7.231 \mathrm{df}=1, p=0.007 ;$ OR: $2.37,95 \%$ C.I.: $1.25-4.48$

${ }^{\wedge} \chi^{2}=5.233, \mathrm{df}=1, p=0.022$

Power calculation for TDT-study: 0.61 ; Estimated sample size $(\alpha=0.05, \beta=0.80)$ : $\mathrm{N}$ of trios $=72$ 


\section{REFERENCES}

Anguelova M, Benkelfat C, Turecki G (2003): A systematic review of association studies investigating genes coding for serotonin receptors and the serotonin transporter: I. Affective disorders. Mol Psychiatry 8: 574591.

Arbelle S, Benjamin J, Golin M, Kremer I, Belmaker RH, Ebstein RP (2003): Relation of shyness in grade school children to the genotype for the long form of the serotonin transporter promoter region polymorphism. Am J Psychiatry 160: 671-676.

Auerbach JG, Faroy M, Ebstein R, Kahana M, Levine J (2001): The association of the dopamine D4 receptor gene (DRD4) and the serotonin transporter promoter gene (5-HTTLPR) with temperament in 12-monthold infants. J Child Psychol Psychiatry 42: 777-83.

Auerbach JG, Geller V, Lezer S, Shinwell E, Belmaker RH, Levine J, Ebstein R (1999): Dopamine D4 receptor (DRD4) and serotonin transporter promoter (5-HTTLPR) polymorphisms in the determination of temperament in 2-month-old infants. Mol Psychiatry 4: 369-373.

Battaglia M, Bajo S, Ferini Strambi L, Brambilla F, Castronovo C, Vanni G, Bellodi L (1997): Physiological and behavioral responses to minor stressors in offspring of patients with panic disorder. J Psychiatr Res 31: 365-376.

Bellivier F, Henry C, Szoke A, Schurhoff F, Nosten-Bertrand M, Feingold J et al (1998): Serotonin transporter gene polymorphisms in patients with unipolar and bipolar depression. Neurosci Lett 255: 143-146.

Bierut LJ, Heath AC, Bucholz KK, Dinwiddie SH, Madden PA, Statham DJ et al (1999): Major depressive disorder in a community-based twin sample: are there different genetic and environmental contributions for men and women? Arch Gen Psychiatry 56:557-63

Caspi A, Sugden K, Moffitt TE, Taylor A, Craig IW, Harrington $\mathrm{H}$ et al (2003): Influence of life stress on depression: moderation by a polymorphism in the 5-HTT gene. Science 301: 386-9

Collier DA, Strober G, Li T, Heils A, Catalano M, DiBella D, Arranz MJ, Murray RM, Vallada HP, Bengel D, Muller CR, Roberts GW, Smeraldi E, Kirov G, Sham P, Lesch KP (1996): A novel functional polymorphism within the promoter of the serotonin transporter gene: possible role in the susceptibility to affective disorders. Mol Psychiatry 1, 453-460. 
Current Protocols in Human Genetics (1995), Unit 9.7, New York: Wiley.

Duman RS (1999): The neurochemistry of mood disorders: preclinical studies. In: Charney DS, Nestler EJ, Bunney BS, editors. Neurobiology of Mental IIIness. New York: Oxford University Press, pp 333-347.

Eaves LJ, Silberg JL, Meyer JM, Maes HH, Simonoff E, Pickles A, Rutter M, Neale M, Reynolds CA, Erikson MT, Heath AC, Loeber R, Truett KR, Hewitt JK (1997): Genetics and developmental psychopathology:2. The main effects of genes and environment on behavioral problems in the Virginia Twin Study of Adolescent Behavioral Development. J Child Psychol Psychiatry 38: 965-980.

Ebstein RP, Levine J, Geller V, Auerbach J, Gritsenko I, Belmaker RH (1998): Dopamine D4 receptor and serotonin transporter promoter in the determination of neonatal temperament. Mol Psychiatry 3: 328-46.

Ebstein RP, Auerbach JG (2002): Dopamine D4 receptor and serotonin promoter polymorphisms and temperament in early childhood. In Benjamin $\mathrm{J}$, Ebstein RP, Belmaker RH, editors. Molecular Genetics and the Human Personality. Washington DC: American Psychiatric Publishing, pp 137-149.

Eley TC, Stevenson J (1999): Exploring the covariation between anxiety and depression symptoms: A genetic analysis of the effects of age and sex. J Child Psychol Psychiatry 40:1273-1282.

Ewens WJ (1996): The TDT and other family-based tests for linkage disequilibrium and association. Am J Hum Genet 59: 983-989.

Falk CT, Rubinstein P (1987): Haplotype relative risks: an easy reliable way to construct a proper control sample for risk calculations. Ann Hum Genet 51: 277-33.

Frigerio A, Pesenti S, Molteni M, Snider J, Battaglia M (2001): Depressive symptoms as measured by the CDI in a population of northern Italian children. Eur Psychiatry, 16: 33-7.

Frisch A, Postilnick D, Rockah R, Michaelowsky E, Postilnick S, Birman E et al (1999): Association of unipolar major depressive disorder with genes of the serotonergic and dopaminergic pathways. Mol Psychiatry 4:389-92.

Geller B, Cook EH (1999): Serotonin transporter gene (5-HTTLPR) is not in linkage disequilibrium with prepubertal and early adolescent bipolarity. Biol Psychiatry 45:1230-1233.

Greenberg BD, Tolliver TJ, Huang SJ, Li Q, Bengel D, Murphy DL (1999): 
Genetic variation in the serotonin transporter promoter region affects serotonin uptake in human blood platelets. Am J Med Genet 88:83-87.

Gutierrez B, Pintor L, Gasto C, Rosa A, Bertranpetit J, Vieta E, Fananas L (1998): Variability in the serotonin transporter gene and increased risk for major depression with melancholia. Human Genetics 103: 319-322.

Hamilton M (1967) : Development of a rating scale for primary depressive illness. Br J Soc Clin Psychol 6: 278-296.

Happonen M, Pulkkinen L, Kaprio J, Van der Meere J, Viken RJ, Rose RJ (2002): The heritability of depressive symptoms: multiple informants and multiple measures. J Child Psychol Psychiatry 43:471-479.

Hohe MR, Wendel B, Grunewald I, Chiaroni P, Levy N, Morris-Rosendahl $D$ et al (1998): Serotonin transporter (5-HTT) gene polymorphisms are not associated with susceptibility to mood disorders. Am J Med Genet 81:1-3.

Jorm AF, Prior M, Sanson A, Smart D, Zhang Y, Easteal S (2002): Association of a functional polymorphism of the serotonin transporter gene with anxiety-related temperament and behavior problems in children: a longitudinal study from infancy to the mid-teens. Mol Psychiatry 5: 542-7.

Kaufman AS (1979): Intelligence testing with the WISC-R. New York: John Wiley \& Sons

Kendler KS, Neale MC, Kessler RC, Heath AC, Eaves LJ (1992): A population-based twin study of major depression in women. The impact of varying definitions of illness. Arch Gen Psychiatry 49: 257-66.

Kendler KS, Prescott CA (1999): A population-based twin study of life-time major depression in men and women. Arch Gen Psychiatry 56:39-44.

Klein DN, Riso LP, Donaldson SK, Schwartz JE, Anderson RL, Ouimette PC et al (1995): Family study of early onset dysthymia: mood and personality disorders in relatives of outpatients with dysthymia and episodic major depression and normal controls. Arch Gen Psychiatry; 52: 487-96

Kovacs M (1992): Children's Depression Inventory. CDI. Manual. Toronto: Multi-Health System Inc.

Lakatos K, Nemoda Z, Birkas E, Ronai Z, Kovacs E, Ney K, Toth I, Sasvary-Szekely M, Gervai J (2003): Association of D4 dopamine receptor gene and serotonin transporter promoter polymorphisms with infants' response to novelty. Mol Psychiatry 8: 90-97. 
Lesch KP, Bengel D, Heils A, Sabol SZ, Greenberg BD, Petri S, Benjamin J, Muller CR, Hamer DH, Murphy DL (1996): Association of anxiety-related traits with a polymorphism in the serotonin transporter gene regulatory region. Science 274:1527-31.

Lesch KP (2003): Neuroticism and serotonin: a developmental genetic perspective. In: Plomin R, DeFries JC, Craig IW, McGuffin P, editors. Behavioral Genetics in the Postgenomic Era. Washington DC: APA, pp 389-424.

McGuffin P, Katz R (1989): The genetics of depression and manic depressive disorder. Br J Psychiatry 155:294-304.

Munafo MR, Clark TG, Moore LR, Payne E, Walton R, Flint J (2003): Genetic polymorphisms and personality in healthy adults: a systematic review and meta-analysis. Mol Psychiatry 8: 471-84

Neuman RJ, Geller B, Rice JP, Todd RD (1997): Increased prevalence and earlier onset of mood disorders among relatives of prepubertal versus adult probands. J Am Acad Child Adolesc Psychiatry 36:466-473.

Nobile M, Begni B, Giorda R, Frigerio A, Marino C, Molteni M et al (1999): Effects of serotonin transporter promoter genotype on platelet serotonin transporter functionality in depressed children and adolescents. J Am Acad Child Adolesc Psychiatry 38:1396-1402.

Ohara K, Nagai M, Tsukamoto T, Tani K, Suzuki Y (1998): Functional polymorphism in the serotonin transporter promoter at the SCL64A locus and mood disorders. Biol Psychiatry 44: 550-554.

Purcell S, Cherney SS, Sham PC (2003): Genetic Power Calculator: design of linkage and association genetic mapping studies of complex traits. Bioinformatics 19 (1): 149-150.

Qian Q, Wang Y, Zhou R, Li J, Wang B, Glatt S, Faraone SV (2003): Family-based and case-control association studies of Catechol-OMethyltransferase in Attention Deficit Hyperactivity Disorder suggest genetic sexual dimorphism. Am J Med Genet 118B: 103-9.

Reich W, Shayka T, Taibleson C (1991): The Diagnostic Interview for Children and Adolescents-Revised (DICA-R). St Louis MO: Washington University.

Spielman RS, McGinnis RE, Ewens WJ (1993): Transmission test for linkage disequilibrium: The insulin gene region and insulin-dependent diabetes mellitus (IDDM). Am J Hum Genet 52: 506-516. 
Spielman RS, Ewens WJ (1998): A sibship test for linkage in the presence of association: the sib transmission/disequilibrium test. Am J Hum Genet 62: 450-458.

Thapar A, McGuffin P (1994): A twin study of depressive symptoms in childhood. Br J Psychiatry 165: 259-265.

Todd RD, Neuman R, Geller B, Fox LW, Kickok J (1993): Genetic studies of affective disorders: should we be starting with childhood onset probands? J Am Acad Child Adolesc Psychiatry 32:1164-1171.

Todd RD, Botteron KN (2002): etiology and genetics of early-onset mood disorders. Child Adolesc Psychiatric Clin N Am 11:499-518.

Weissman MM, Warner V, Wickramaratne PJ, Prusoff BA (1988): Early onset major depression in parents and their children. J Affective Dis 15:269-277.

Wickramaratne PJ, Weissman MM (1998): Onset of psychopathology in offspring by developmental phase and parental depression. J Am Acad Child Adolesc Psychiatry 37: 933-942. 


\section{CHAPTER 5}

\section{The influence of family structure, and the TPH2 G-703T and 5-HTTLPR serotonergic genes upon affective problems in children aged $10-14$ years}

Maria Nobile, Marianna Rusconi, Monica Bellina, Cecilia Marino, Roberto Giorda, Ombretta Carlet, Laura Vanzin, Massimo Molteni and Marco Battaglia

Journal of Child Psychology and Psychiatry. 2009 Mar; 50(3): 317-25. 


\section{ABSTRACT}

Background: Both genetic and psychosocial risk factors influence the risk for depression in development. While the impacts of family structure and of serotonergic polymorphisms upon individual differences for affective problems have been investigated separately, they have never been considered together in a gene-environment interplay perspective.

Methods: We examined the effects of family structure and two serotonergic polymorphisms (the TPH2 G-703T and the 5-HTTLPR) upon depressive symptoms assessed by the new CBCL/6-18 DSM-oriented Affective Problems scale in a general population sample of 607 Italian children aged $10-14$ years.

Results: Belonging to 'one-parent' families, the TPH2 G-703T ' $G$ variant', and the 5-HTTLPR 'short' alleles were associated - both alone and in apparent gene-by-environment interaction - with higher Affective Problems scores. As predicted by quantitative genetics theory, both polymorphisms contributed with a small effect size, while 'family structure' had a moderate effect size.

Conclusions: A putative hazard factor impinging on individual risk at the family-wide level, namely family structure, appears to act interactively with two pivotal serotonergic genes in heightening risk for Affective Problems. Although it remains to be demonstrated that belonging to a one - rather than a two-parent family has true environmental causal effects on Affective Problems, these data may contribute to identify/prevent risk for depression in childhood. 


\section{INTRODUCTION}

It is now widely recognised that most - if not all - complex behavioural traits have a multi-factorial aetiology, and that both genes and the environment influence virtually all psychopathological traits. As for many other behavioural traits, there is good evidence of genetic influences for depressive symptoms in children and adolescents, where heritability estimates obtained by paper-and-pencil questionnaires typically vary from moderate (.30-.46) to substantial (.60-.80, e.g., Thapar \& McGuffin, 1994), and are often higher than those typically found in adult samples (Neuman, Geller, Rice, \& Todd, 1997). Also, environmental factors are known to influence depressive symptoms: several psychosocial risk factors impinge on the risk for depression, and even more heavily when they strike early in development, as suggested by longitudinal studies comparing 'preschool'/'juvenile onset' depression to adult onset depression (Jaffee et al., 2002; Luby, Belden, \& Spitznagel, 2006). General familial functioning (encompassing family-wide factors such as harmony, cohesion and the capacity to manage conflicting issues) can have a profound impact on offspring's experiences and life trajectories, and has been associated with emotional development in childhood (Cuffe, McKeown, Addy, \& Garrison, 2005; Hetherington, Bridges, \& Insabella, 1998). More specifically, the 'family structure' variable (Meltzer, Gatward, Corbin, Goodman, \& Ford, 2003) refers to the makeup of the family where a child lives; families in which both the biological mother and father live are the most frequent occurrence, and are usually associated with the lowest risk for offspring's dysfunction (Bramlett \& Blumberg, 2007). On the contrary, offspring living in one-parent households are more likely to show behavioural and emotional problems in childhood (O'Connor, Dunn, Jenkins, Pickering, \& Rasbash, 2001) and an excess of depressive symptoms in adolescence (Cuffe et al., 2005).

The associations between parental divorce/family disruption and offspring adjustment/mental health have often been studied by assuming a causal relationship within a stress-adjustment framework of reference (e.g., Hetherington et al., 1998), with factors such as parental conflict acting as mediators between negative familial atmosphere and children's behavioural problems. However, the rearing environment is partially influenced by heritable parental behavioural characteristics that may lead simultaneously to familial disruption and psychological difficulties in the offspring (Rutter, 2005). This points towards the general concept that part of the risk conveyed by adverse environments can be mediated genetically (Rutter, 2005) and implies the need for a correct understanding of risk 
processes, including the careful delineation and quantification of separate effects, such as gene-environment correlation (rGE) and geneenvironment interaction $(G \cdot E)$. While $r G E$ occurs when genetic factors influence the degree of exposure to some environmental risks, $G$ - E occurs when one variable's effects vary across levels of another (Lau \& Eley, 2008). Failure to distinguish both conceptually and statistically between these two mechanisms can bias the results and the interpretation of important research endeavours (Lau \& Eley, 2008), especially in childhood depression where both rGE and G - E appear to occur (Eaves, Silberg, \& Erkanli, 2003).

Adoption studies and children of twins (CoT) studies can help clarify these issues. A study (O'Connor, Caspi, DeFries, \& Plomin, 2000) of preadolescents in the Colorado Adoption Project found evidence of an environmentally-mediated association between parental divorce and children's psychopathology, and a further investigation (O'Connor et al., 2003) based on the CBCL found that without parental separation genetic risk resulted uncorrelated with the adoptees' adjustment. Therefore, psychosocial stressors - including familial disruption - seemed to accentuate genetic vulnerability to psychopathology. Two CoT of adults found that the higher risks for psychopathology - including internalising (D'Onofrio et al., 2005) and adjustment (D'Onofrio et al., 2006) problems - associated with parental divorce were consistent with a causal (i.e., nonselection factors) connection. A more recent study by the same group (D'Onofrio et al., 2007), however, concluded that the relationship between parental marital instability and offspring internalisation was entirely attributable to selection factors of genetic origin, implying that offspring of divorced parents with heightened liability to internalisation would have had increased depressive symptoms even in absence of parental divorce. Since environmental and genetic risk factors correlate within families, these CoT studies concur to show the complexity of the relationships between 'environmental' risk factors and child psychopathology. However, they were based on adults, and since the role of selection factors may depend on age at incidence, their conclusions may not be extendable to children.

While genetic biometrical model fitting studies of familial disruption and childhood psychopathology provide conflicting results, no study has so far addressed the role of identified genetic polymorphisms and the integrity vs. disruption of the nuclear family in influencing internalisation and depressive symptoms in the developmental years. When addressing this issue some polymorphisms appear to be candidates of particular interest. The serotoninergic system is a reasonable candidate for genetic studies 
of internalisation and depression given its involvement in the control of affects and emotion (Lesch, 2003). Several neurochemical steps affect serotonin $(5 \mathrm{HT})$ function and metabolism at different stages. The $5 \mathrm{HT}-$ transporter (5-HTT) plays an important role in the regulation of 5-HT re-uptake from the intrasynaptic cleft. The promoter activity of the 5-HTT gene is regulated by a deletion/insertion polymorphism in the proximal 5' promoter region, designated the 5HTT gene-linked polymorphic region (5HTTLPR). The short ('S') allele in the 5-HTTLPR is associated with lower transcriptional efficiency of the promoter compared with the long ('L') allele (Lesch et al., 1996). Unaffected adults, children and adolescents with the L-L genotype have been found to have significantly higher maximal uptake of serotonin in platelets compared to subjects with L-S or S-S genotypes (Nobile et al., 1999). The 5-HTTLPR has been investigated by a number of studies looking at emotionality and proneness to anxiety/depression, leading to both replication and non-replication (Munafo et al., 2003). Several studies addressed the possible interplay between the 5-HTTLPR and several environmental variables to influence internalisation across the life course (for a review see Zammit \& Owen, 2006). A potential causal role for early psychosocial risk factors and the 5-HTTLPR in depression was retrospectively demonstrated by Caspi et al. (2003), and similar, cross-sectional evidence has been reported for adolescent girls and maltreated children (Eley et al., 2004; Kaufman et al., 2004).

Tryptophan hydroxylase (TPH) is the rate-limiting enzyme in the 5-HT synthesis. Recent studies found a newly-identified second isoform of the tryptophan hydroxylase gene (TPH2) preferentially involved in 5-HT regulation in human CNS and several genetic variations in the human TPH2 gene have been found implicated in emotional disorders (for a review see Zhang, Beaulieu, Gainetdinov, \& Caron, 2006). A common single nucleotide polymorphism (SNP G-703T, rs 4570625) in the transcriptional control region of $\mathrm{TPH} 2$ has been reported to modulate amygdala responsiveness to affective stimuli (Brown et al., 2005), and has been found to be associated with emotional dysregulation (Gutknecht et al., 2007).

It is sometimes difficult to relate measures of depression derived from questionnaires with the constructs adopted by the DSM-IV or ICD-10. However, the Affective Problems scale - which belongs to the newlyestablished CBCL 6/18 DSM-Oriented Scales (DOS) system - appears to correspond well to the current DSM classification of depression (Ferdinand, 2008) - and to be substantially heritable (h2 = .63, 95\%C.I: .54-.71), according to a study of children of the general population-based Italian Twin Registry (Spatola et al., 2007). 
In the present study we examined the effects of two genetic polymorphisms within the serotonergic system (the TPH2 and 5-HTTLPR, which regulate two fundamental functions within the $5 \mathrm{HT}$ system, namely synthesis and re-uptake) and a family-wide environmental predictor (family structure) to predict the risk of CBCL-DOS Affective Problems in a general population sample of Italian children aged 10- 14 years.

\section{MATERIAL AND METHODS}

\section{Subjects}

Participants in this study were subjects involved in two epidemiological studies of mental health in youth. Subjects from sample $1(n=441)$ were recruited by our group as a collaborating centre of the Italian Project on Pre-adolescent Mental Health (the PrISMA project - Progetto Italiano Salute Mentale Adolescenti) (Frigerio et al., 2006). The PrISMA project was designed to estimate the prevalence of behavioural problems with the CBCL/ 6-18 (Achenbach \& Rescorla, 2001) scale in a national probability sample of children aged 10-14 years living and attending secondary schools in seven medium-to large Italian urban areas (Milan, Rimini, Lecco and Conegliano located in the north of Italy, Rome and Pisa in the centre - and Cagliari in the south of the country) and had an overall participation rate of $61 \%$ of the eligible subjects (Frigerio et al., 2006). The mean values of the CBCL/6-18 subscales of children assessed in the PrISMA project did not differ significantly across these seven different urban areas (data available from authors upon request) and were comparable to those obtained in previous epidemiological studies of the CBCL scale in Italy (Frigerio et al., 2004). Amongst the seven PrISMA participating units, two (one based in Bosisio Parini near Lecco, and the other in Conegliano) have interests in behavioural genetics and the technology for DNA collection and molecular genetic analyses. Therefore, for the PRiSMA children living in Lecco and Conegliano, we invited participants also to DNA collection, which were allowed by parental written informed consent for 441 of 1211 $(36 \%)$ eligible children, in addition to providing demographic and psychometric information.

Subjects from sample 2 belong to a relatively small suburban community (Ponte Lambro -PL, inhabitants 4065) currently involved in an ongoing longitudinal study of emotional and behavioural problems in childhood with the CBCL/6-18 (Achenbach \& Rescorla, 2001) and simultaneous DNA collection. The DNA of 166 of 317 (52\%) eligible children living in PL and aged 10-14 was made available after parental written informed consent. 
The PL and PrISMA samples have no overlapping subjects. Since the inclusion (age between 10 and 14 years, regular school attendance, parental written informed consent) and exclusion (certification of mental handicap, which was present in . $3 \%$ of eligible participants) criteria and the psychometric instrument (parental assessments of children behaviour through the CBCL/6-18) were the same for the PriSMA and the PL samples, after controlling for the homogeneity of demographic and behavioural variables, as in a previous study of externalising behaviour (Nobile et al., 2007), we pooled together subjects of both epidemiological samples for the present study to increase the statistical power.

\section{Procedures}

The study protocols were approved by the 'Eugenio Medea' Scientific Institute Ethical Committee. Parents' written informed consent was obtained for all participants.

\section{Behavioural assessment.}

The CBCL/6-18 (Achenbach \& Rescorla, 2001) is an empirically-based checklist of social competence and behavioural problems filled out by parents of children and adolescents aged 6-18 years. According to the Achenbach System of Empirically Based Assessment (ASEBA; Achenbach \& Rescorla, 2001), CBCL/6-18 items can be scored to obtain the following DSM-Oriented Scale (DOS): Affective Problems, Anxiety Problems, Somatic Problems, Attention Deficit/Hyperactivity Problems, Oppositional Defiant Problems and Conduct Problems. Although the DOS are ot directly equivalent to any clinical diagnosis, they predict DSM-IV diagnoses satisfactorily. Specifically, the Affective Problems DOS has been shown to correspond closely to DSM-IV Major Depressive Disorder and Dysthymia in referred children and adolescents (Ferdinand, 2008). Very recent genetic epidemiological data show that compared with the classic CBCL/6-18 empirical subscales, the DOS have higher heritability and simpler causal structure, in that the phenotypic variance is satisfactorily explained by additive genetic and unique environmental factors only (Spatola et al., 2007).

Socio-demographic form.

The individual and family characteristics of the sample were gathered by an 'ad hoc' form to be filled out by parents. The form encompassed questions on demographic data (child's gender and age, number of brothers/sisters, parents' marital status coded as: married, cohabiting, 
divorced, separated, widowed, single), socioeconomic status (SES based on parental employment according to the 1975 Hollingshead 9-point scale for parental occupation), mother's and father's educational level, child education (school attended, repeated year at school, presence of a remedial teacher) and contact with the health services such as recourse to mental health services.

\section{DNA collection and extraction.}

Genomic DNA was extracted from mouthwash samples collected in $4 \%$ sucrose using the DNAzol Genomic DNA Isolation reagent (Molecular Research Center, Cincinnati). The methods for determining 5-HTTLPR polymorphisms were the same as described by Lesch et al. (1996). All amplification reactions were performed on a Mastercycler thermocycler (Eppendorf). The amplified products were analysed on 2\% agarose gels. Rs4570625 genotypes were determined using a realtime detection system as previously described (Zhou et al., 2005). Briefly, PCR amplifications were performed in $15 \mathrm{ml}$ reactions containing $10 \mathrm{ng}$ of genomic DNA in 1X TaqMan Universal PCR Master Mix (Applied Biosystems), .9 mM of NTPH703 primers and $.2 \mathrm{mM}$ of NTPH-703 probes. The samples were amplified on an ABI PRISM 7900HT Sequence Detection System and the results were analysed with Sequence Detection System 2.2 software.

\section{Statistical analyses}

As adopted by major epidemiological surveys (Meltzer et al., 2003), the categories of parental marital status were recoded for analyses into two classes of family structure: 'two-parent' (encompassing: married - 89.4\%, and cohabiting parents $-1.4 \%$ of the combined sample) and 'one-parent' families (encompassing divorced $-2.3 \%$, separated $-5.3 \%$, widowed $1.2 \%$, and single parents $-.4 \%$ of the combined sample). The 5 -HTTLPR genotypes were divided into two groups: S-allele carriers (encompassing SS and LS subjects) and LL subjects. Based on previously reported functional evidence (Brown et al., 2005; Herrmann et al., 2007), we dichotomised the TPH2 genotypes by presence ( $G / T$ and $T / T)$ versus absence $(G / G)$ of the T allele.

Demographic and behavioural variables were submitted to preliminary analyse by ANOVA to check for some possible participation biases. Since in the PrISMA project parents were free to participate either in simple behavioural assessments or in behavioural assessment plus DNA collection, for sample 1 it was possible to check for participation biases. There were no significant differences owing to family structure $\left(\mathrm{X}^{2}=.162\right.$, 
d.f. $=1, p=.687)$, or age $(12.14 \pm .89$ vs. $12.05 \pm .95, t=-1.34, p=.18)$, between PrISMA children who belonged to families who agreed vs. those who belonged to families who did not agree to participate in the genetic study.

When we compared the 'Affective Problems' scores of PrISMA children who belonged to families who agreed vs. those who belonged to families who did not agree to participate in the genetic study, we found that the latter had significantly higher 'Affective Problems' scores $(1.79 \pm 1.9$ vs. $2.15 \pm 2.26, t=2.334, p=.02$ ). This slight difference was expected, since it is known that children and their families who agree to participate in behavioural genetic/biological psychiatry studies may to some extent deviate from the population's mean values of psychopathology/adaptation. Since it has recently been shown that some association between exposure to single parenthood in childhood and psychopathology and social adaptation may be explained by some social and contextual factors associated with exposure to single parenthood (Fergusson, Boden, \& Horwood, 2007), we preliminarily controlled the possible association of family structure with several socioeconomic measures available for sample 1 and sample 2. By multiple logistic regression analysis we found that class of family structure could not be predicted by parental SES, mother's education, or father's education (p-range: .34-.92) in either sample.

After controlling for independence of distribution of genotypes and class of family structure, the TPH2 genotype, the 5-HTTLPR genotype and family structure were entered simultaneously as independent variables in an ANCOVA of the 'Affective Problems' scores with gender and age as covariates. All analyses were performed using the Statsoft Statistica package (Version 6.0, 1997).

\section{RESULTS}

\section{Preliminary analyses}

Table 1 shows the demographic and behavioural variables in the two original epidemiological samples and in the combined sample. More than $95 \%$ of participating children were Caucasian and of Italian ancestry. Although all children were attending the same school grades, children in the PrISMA sample were slightly but significantly older than children in the $P L$ sample $(F=3.988$, d.f. $=1.603, p=.046)$ owing to a modest difference in the timing of recruitment of the two samples (winter-spring for the PrISMA sample and autumn for the PL sample).

Consistent with previous studies investigating internalisation and affective 
problems in children (Meltzer et al., 2003; Frigerio et al., 2004), the total score of Affective Problems was slightly, but nonsignificantly ( $F=3.607$, d.f. $=1,603, p=.058$ ), higher in boys than girls, again without significant differences between the PrISMA and the PL subsamples. Genotyping of 5-HTTLPR and of TPH2 was successful for 548 subjects with complete socio-demographic and behavioural data. Both polymorphisms were in Hardy-Weinberg equilibrium. The 5-HTTLPR genotype frequencies in the total sample were: L/L $33.0 \%$, L/S $49.1 \%$, S/S 17.9\%; and the allele frequencies were: $\mathrm{L} 57.5 \%$ and $\mathrm{S} 42.5 \%$. The TPH 2 genotype frequencies were: $\mathrm{G} / \mathrm{G} 60 \%, \mathrm{G} / \mathrm{T} 34.5 \%, \mathrm{~T} / \mathrm{T} 5.5 \%$; and the allele frequencies were: $\mathrm{G}$ $77.3 \%$ and $\mathrm{T} 22.7 \%$. Genotypes and allele frequencies were evenly distributed between the PrISMA and the PL sub-samples (genotype: 5HTTLPR: $X^{2}=.460$, d.f. $=2, p=.795 ; T P H 2: X^{2}=4.144$, d.f. $=2, p=.126$; alleles: HTTLPR $X^{2}=.325$, d.f. $=1, p=.569 ;$ TPH2 $X^{2}=1.552$, d.f. $=1, p$ $=.213$ ), and across genders (genotype: 5-HTTLPR: $X^{2}=.769$, d.f. $=2, p=$ .681; TPH2: $\mathrm{X}^{2}=1.399$, d.f. $=2, p=.497$; alleles: 5-HTTLPR $\mathrm{X}^{2}=.16$, d.f. $=1, p=.901 ;$ TPH2 $X^{2}=1.498$, d.f. $=1, p=.221$ ), and similar to those previously reported (Lesch et al., 1996; Gutknecht et al., 2007) for Caucasian populations. The frequencies of genotypes' distributions across the two family structure categories were even for the 5-HTTLPR defined as S-carriers vs. LL subjects $\left(X^{2}=1.36\right.$, d.f. $\left.=1, p=.243\right)$ while there was a slight, non-significant excess of SS children belonging to one-parent families $\left(X^{2}=5.614\right.$, d.f. $\left.=2, p=.064\right)$ when the 5 -HTLPR genotype was defined trichotomously. The frequencies of genotype distributions across the two family structure categories were even for the TPH2 both dichotomously $\left(\mathrm{X}^{2}=.032\right.$ d.f. $\left.=1, \mathrm{p}=.857\right)$ and trichotomously $\left(\mathrm{X}^{2}=3.795\right.$, d.f. $=2, p=.150)$ defined.

\section{Main analyses}

Table 2 shows the Affective Problems scores grouped by TPH2 and 5HTTLPR genotypes and family structure. The three-way ANCOVA - with gender and age as covariates - revealed significant univariate effects for the TPH2, 5-HTTLPR polymorphisms and family structure $(\mathrm{TPH} 2: \mathrm{F}=$ 4.867 , d.f. $=1,538, p<.028$, observed power $=.596$, partial $\eta^{2}=.009 ; 5$ HTTLPR: $F=4.513$, d.f. $=1,538, p<.034$, observed power $=.564$, partial $\eta^{2}=.008$; family structure: $F=11.725$, d.f. $=1,538, p<.001$, observed power $=.928$, partial $\eta^{2}=.021$ ). There were also a significant TPH2 $\cdot$ family structure interaction $(F=6.687$, d.f. $=1,538, p<.010$, observed power $=$ .733, partial $\eta^{2}=.012$ ) and a significant 5 -HTTLPR $\cdot$ family structure interaction $(F=4.162$, d.f. $=1,538, p<.042$, observed power $=.530$, partial 
$\left.\eta^{2}=.008\right)$. Neither the TPH2 $\cdot 5-$ HTTLPR - nor the TPH2 $\cdot 5-H T T L P R \cdot$ family structure interactions were significant.

Post-hoc analyses revealed significantly higher Affective Problems in children homozygous for the TPH2 'G-variant' living in 'one-parent' families than in children of all the other groups (significance range by Tukey HSD: $p=.02-.00001)$. Post-hoc analyses also showed more Affective Problems in 5-HTTLPR S-allele carriers living in 'one-parent' families than in children in all the other groups (Tukey HSD: $p=.00001$ ) except children homozygous for L-allele and living in 'one-parent' families $(p=.10)$ (Figure 1a, 1b).

\section{Control for specificity of effects}

In order to control for the specificity of the environmental risk factor, we repeated the three-way ANCOVA on Affective Problems with SES alternatively as covariate or factor - instead of 'family structure'. SES was split in two classes of risk, namely 'low' (SES 1-3) and 'medium-to-high' (SES 4-9), as previously done in a study of externalising behaviours in the same sample (Nobile et al., 2007). When SES was entered as covariate - along with gender and age - the ANCOVA showed a slight reduction of significance for the 'family structure', TPH2 and 5-HTTLPR main effects (respectively: $p=.001, p=.036, p=.053$ ) and for the TPH2 - family structure interaction $(p<.012)$ and 5 -HTTLPR $\cdot$ family structure interaction $(p<.062)$. When SES was entered as factor, the ANCOVA showed a significant effect of SES $(p=.03)$, but did not reveal any significant interaction with TPH2 or 5-HTTLPR.

We then tested the effects of the same factors (TPH2, 5-HTTLPR, family structure) and covariates on the broad-band 'Internalizing' CBCL/6-18 scale: the ANCOVA revealed significant univariate effects only for TPH2 and 'family structure' $(p=.022$ and $p=.001$, respectively). The only significant interaction $(p=.020)$ was between TPH2 and 'family structure'. Finally, we repeated our analyses after recoding children according to the novel functional variants identified in the 5-HTTLPR L-allele, LA and LG (Hu et al., 2006). Since the LG variant has a level of serotonin transporter expression comparable to the $S$ allele, and both have lower levels than LA, as $\mathrm{Hu}$ et al. (2006) we reclassified children dichotomously between LA homozygotes vs. rest of the sample, and re-ran the ANCOVA upon the Affective Problems scale: the univariate results for 5-HTTLPR were confirmed $(p=.049)$, and the 5-HTTLPR $\cdot$ family structure interaction provided a milder effect $(p=.071)$. 


\section{DISCUSSION}

In a relatively unselected general population sample of Northern Italian children we found evidence that belonging to a 'one-parent' family, and the TPH2 ' $G$ variant' and the 5-HTTLPR 'S' allele, are associated - both alone and in apparent gene-by-environment interaction - with higher scores at the CBCL/6-18 Affective Problems DSM-Oriented Scale. These results were confirmed as relatively specific after having taken into consideration other environmental variables (SES), a broader psychometric construct (Internalisation), and an alternative definition of the 5-HTTLPR (LA/LG). Our results appear consistent with a number of studies that found a role for the 5-HTTLPR locus in predicting adult and child negative emotionality as a general construct of liability to anxiety and depression (Lesch, 2003; Eley et al., 2004). Our finding of a significant interaction between 5HTTLPR genotype and a possible environmental risk factor is broadly consistent with several studies suggesting that the 5-HTTLPR short allele yields greater risk concomitantly with exposure to stressful events (Zammit \& Owen, 2006).

Our results are also consistent with the reported associations between the TPH2 locus and the increased risk for mood disorders/emotional dysregulation in adults, although the ' $T$ ' instead of the ' $G$ ' is usually reported as the risk allele (Zhang et al., 2006; Brown et al., 2005; Gutknecht et al., 2007). It could be the case that some other relevant variants in linkage disequilibrium with rs4570625 are the causative risk factor on mood disorder, and that inconsistent association findings are mainly due to stratification phenomena in different study populations. It is noteworthy that Scheuch et al. (2007) reported that rs11178997, an SNP within the TPH2 gene which is in strong linkage disequilibrium with rs4570625, lies in the core sequence of a transcription factor and reduces significantly the $\mathrm{TPH} 2$ transcriptional activity, suggesting this variant as a candidate risk factor for mood disorder for future association studies.

\section{Limitations}

Our results should be regarded with some limitations in mind. First, 'family structure' is a broad, distal, family-wide risk factor which is likely to encompass - as a probable end-point of many marital relationships gone awry - other several sub-factors including parental discord, or instability, which in turn can have exerted their effects for variable time frames across different families. Second, since family structure cannot be considered a simple 'environmental' risk factor, in that environmental and genetic risk factors correlate within families, the possibility remains that what we have interpreted as a gene-by-environment interaction is rather a gene by- gene 
interaction. Third, although the prevalence of one-parent families in our sample mirrors the average North-Eastern Italian general population prevalence (ISTAT, 2006), this remains a smaller figure than the average prevalence reported for other European or North-American cultures. Thus, in this specific culture separation/divorce may index only the most severely dysfunctional families, and the 'one-parent' variable may have acted as a particularly strong enhancer of risk for affective symptoms over genotypes. If this were the case, replication of the same design in other cultures with higher prevalence of one-parent families could fail. Fourth, we had a less than optimal participation rate. However, participation is within the average reported for population- based investigations of mental health in several European countries, including Norway (Battaglia, Pesenti-Gritti, Spatola, \& Ogliari, Tambs, 2007) and Italy (Spatola et al., 2007), and we found no evidence for selection owing to family structure, and only slight, positive selection effects for Affective Problems. Fifth, we did not conduct direct interviews of the children and based our analyses on single measures obtained by parents via a paper-and pencil questionnaire. Thus, the higher values of Affective Problems in children of one-parent families could reflect a bias of one-parent families' expectations that their children are more depressed as a consequence of familial disruption. Moreover, this indirect method of symptom collection prevents us from extending our considerations to clinical affective disorders proper. However, data on clinical populations show that the Affective Problems scale predicts depression in children quite well (Ferdinand, 2008). A further limitation connected to our use of only one measure to assess affective problems is the impossibility of performing sensitivity analysis, i.e., to see whether $G$. $E$ effects hold across different phenotypic measures that map the same diagnostic construct in the attempt to reveal spurious $G \cdot E$ due to scaling effects (Moffitt et al., 2006; Rutter et al., 2006).

There is currently a contrast between studies which suggest interactions of identified candidate genes and specific environmental factors, and the sobriety induced by simulated data analyses failing to find significant $G$. E interaction for liability to behavioural disorders (Eaves, 2006). Such divergence of results suggests prudence, since there might be risks of oversimplification, and inflation of significance in virtually any analysis of variance focused on a limited pool of polymorphisms and environmental risk factors for a single/few behavioural variable(s). 


\section{CONCLUSION}

As suggested by some advocates of deliberate $G \cdot E$ hypotheses' testing (Moffitt et al., 2006; Rutter et al., 2006), we based our investigation upon reasonable nomological network evidence that the environment moderates the behavioural effect of a biological system (serotonergic neurotransmission) involved in the disorder under study (affective symptoms), and that the candidate genes are associated with reactivity to environmental pathogens. We found that family structure - a hazard factor impinging on individual risk at the family-wide level - acts interactively with two pivotal serotonergic genes in heightening risk for affective symptoms. Although it remains to be demonstrated that belonging to a one-parent rather than a two-parent family has true environmental causal effects on affective symptoms, these data may contribute to identify/prevent risk for depression in childhood.

\section{Acknowledgements}

This study was supported by Grant R.F.2002- 2003 N.182 from the Italian Ministry of Health. 
FAMILY STRUCTURE AND SEROTONERGIC GENES IN AFFECTIVE SYMPTOMS

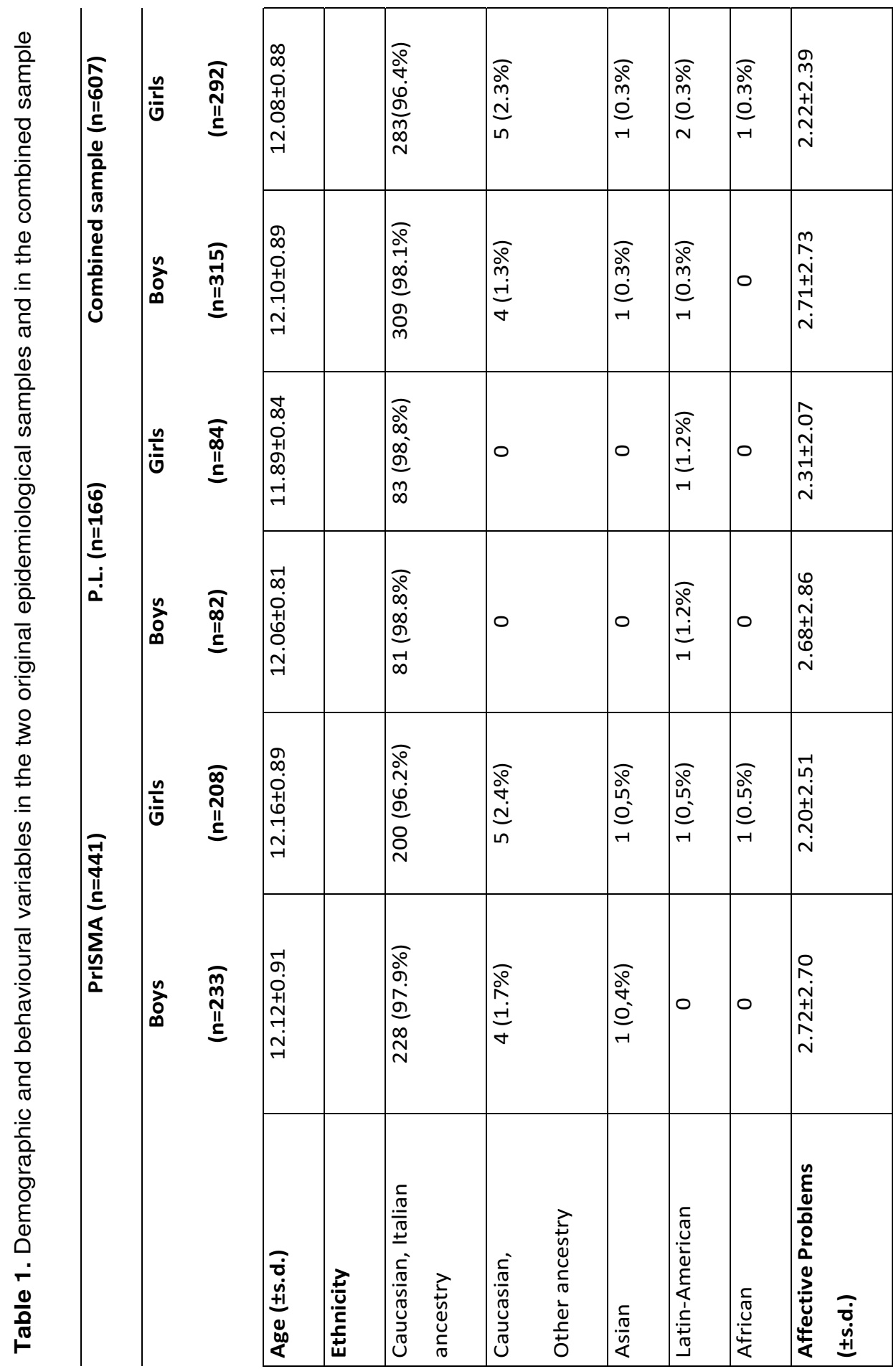


CHAPTER 5

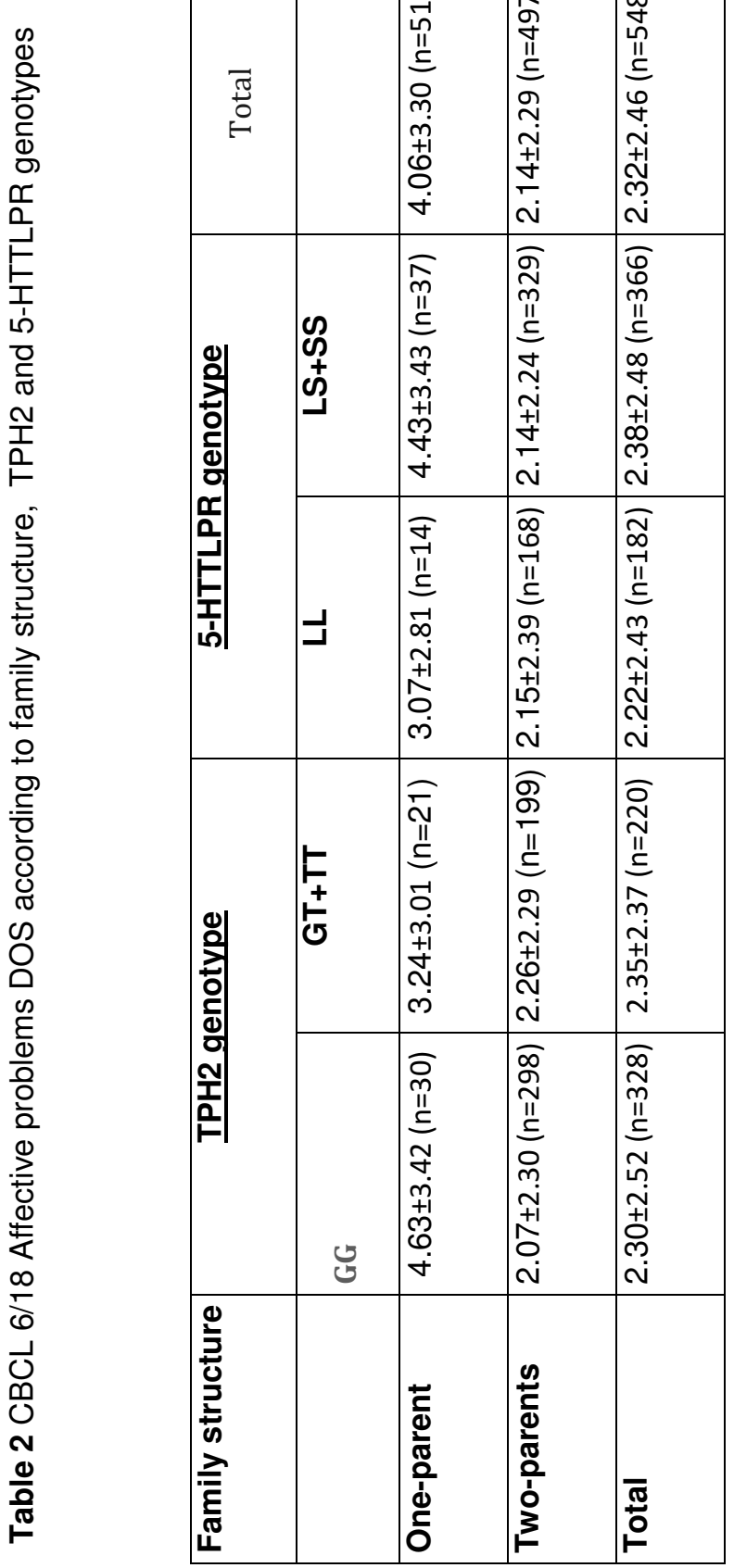


Figure 1a. CBCL 6/18 Affective Problems DOS according to family structure x TPH2 genotype $(p<0.010)$

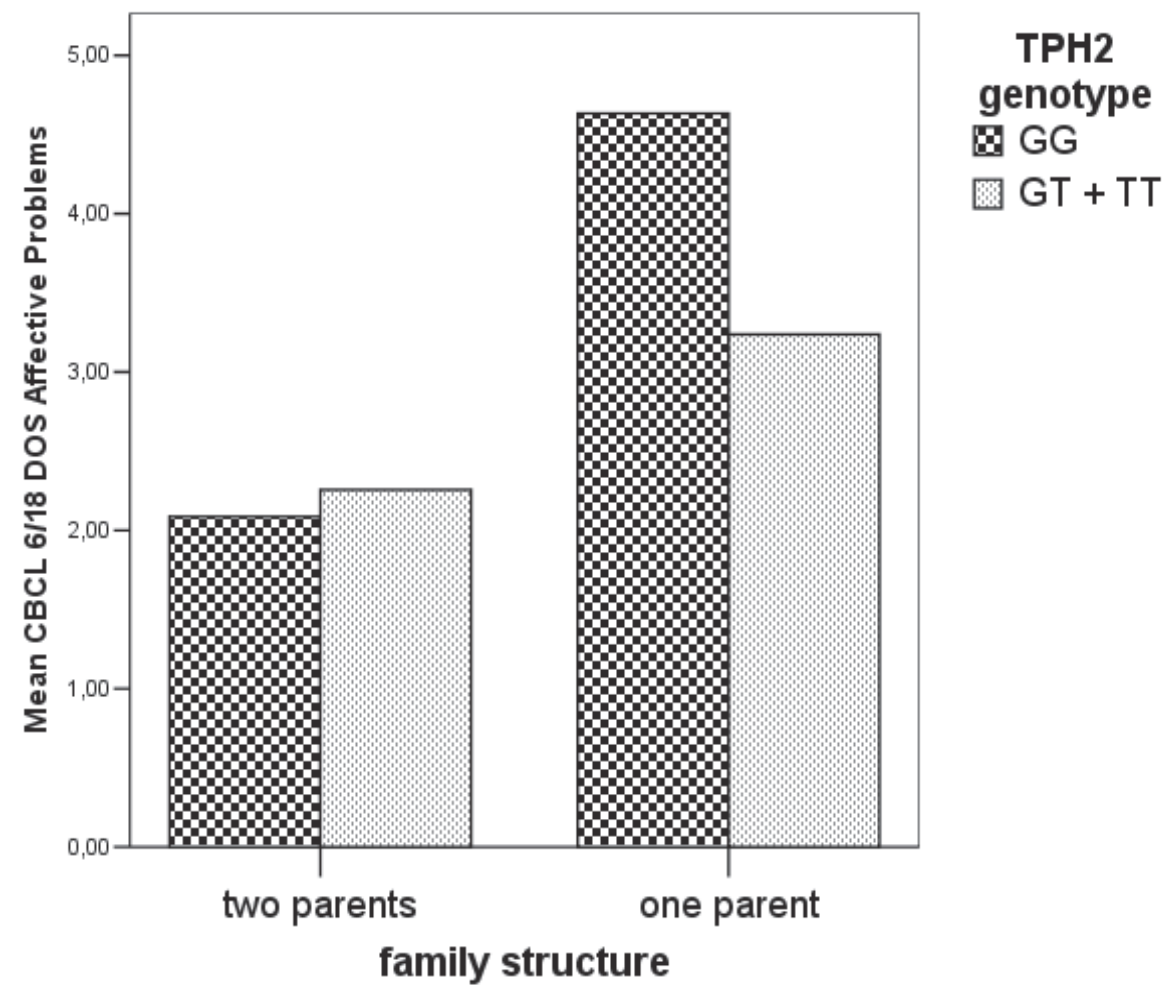


Figure 1b. CBCL 6/18 Affective Problems DOS according to family structure x 5-HTTLPR genotype $(p=0.042)$.

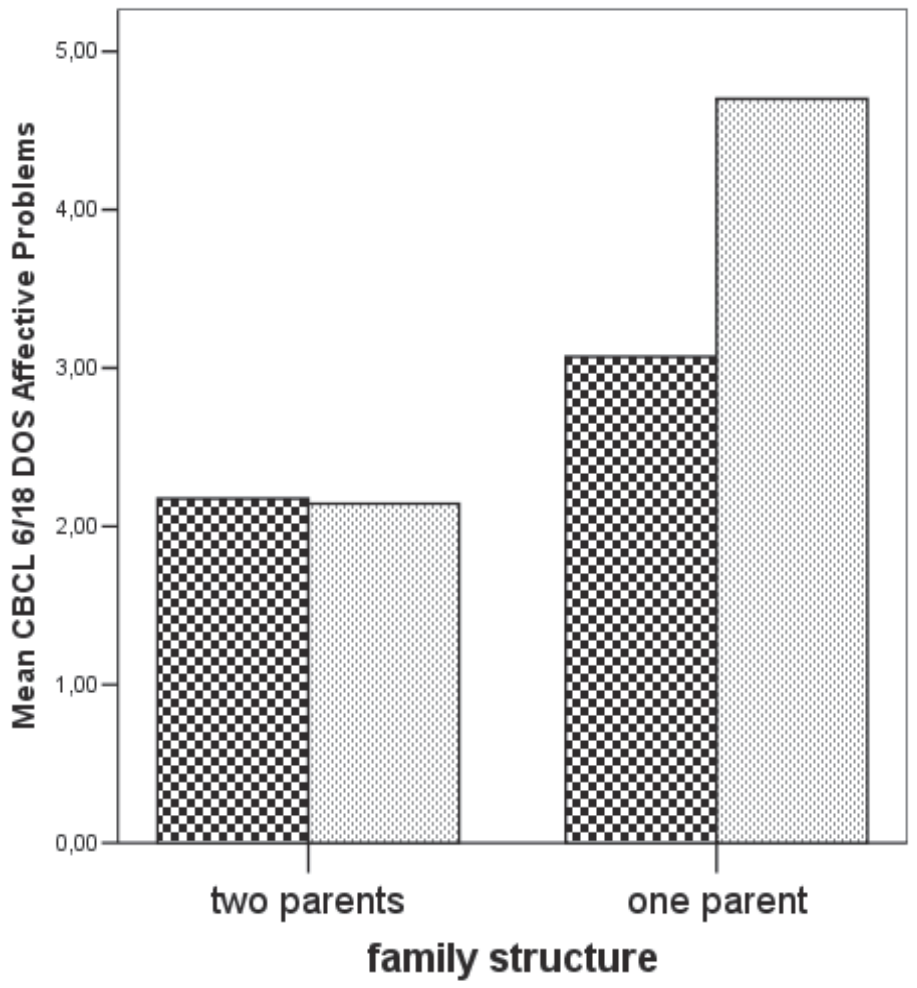

5-HTTLPR genotype B LL 图 LS+SS 


\section{REFERENCES}

Achenbach, T.M., Rescorla, L.A.(2001). Manual for the ASEBA Schoolage Forms and Profiles. Burlington VT: University of Vermont, Department of Psychiatry.

Battaglia, M., Pesenti-Gritti, P., Spatola, C.A.M., Ogliari, A., Tambs, K.(2007). A Twin Study of the Common Vulnerability Between Heightened Sensitivity to Hypercapnia and Panic Disorder. American Journal of Medical Genetics-Neuro-Psychiatric

Genetics [DOI:10.1002/ajmg.b.30647/PMID: 18040986].

Bramlett, M.D., Blumberg, S.J.(2007). Family structure and children's physical and mental health. Health Affairs, 26,549-58.

Brown, S.M., Peet, E., Manuck, S.B., Williamson, D.E., Dahl, R.E., Ferrell, R.E., Hariri, A.R.(2005). A regulatory variant of the human tryptophan hydroxylase-2 gene biases amygdala reactivity. Molecular Psychiatry, 10,884-888.

Caspi, A., Sugden, K., Moffitt, T.E., Taylor, A., Craig, I.W., Harrington, H., McClay, J., Mill, J., Martin, J., Braithwaite, A., Poulton, R.(2003). Influence of life stress on depression: moderation by a polymorphism in the 5-HTT gene. Science, 301,386-9.

Cuffe, S.P., McKeown, R.E., Addy, C.L., Garrison, C.Z.(2005). Family and psychosocial risk factors in a longitudinal epidemiological study of adolescents. Journal of American Academy of Child and Adolescent Psychiatry,44,121-9

D’Onofrio, B.M., Turkheimer, E., Emery, R.E., Slutske, W.S., Heath, A.C., Madden, P.A., Martin, N.G.(2005). A genetically informed study of marital instability and its association with offspring psychopathology. Journal of Abnormal Psychology, 114,570-86.

D'Onofrio, B.M., Turkheimer, E., Emery, R.E., Slutske, W.S., Heath, A.C., Madden, P.A., Martin, N.G.(2006). A genetically informed study of the processes underlying the association between parental marital instability and offspring adjustment. Developmental Psychology, 42,486-99.

D'Onofrio, B.M., Turkheimer, E., Emery, R.E., Maes, H.H., Silberg, J., Eaves, L.J.(2007). A Children of Twins Study of parental divorce and offspring psychopathology. Journal of Child Psychology and Psychiatry, 48,667-75. 
Eaves, L.J.(2006). Genotype x Environment interaction in psychopathology: fact or artifact? Twin Research and Human Genetics, 9,1-8.

Eaves, L., Silberg, J., Erkanli, A.(2003). Resolving multiple epigenetic pathways to adolescent depression. Journal of Child Psychology and Psychiatry, 44,1006-14.

Eley, T.C., Sugden, K., Corsico, A., Gregory, A.M., Sham, P., McGuffin, P., Plomin, R,, Craig, I.W.(2004). Gene-environment interaction analysis of serotonin system markers with adolescent depression. Molecular Psychiatry, 9,908-15.

Ferdinand R.F.(2008). Validity of the CBCL/YSR DSM-IV scales Anxiety Problems and Affective Problems. Journal of Anxiety Disorders, 22,126-34.

Fergusson, D.M., Boden, J.M., Horwood, L.J.(2007). Exposure to single parenthood in childhood and later mental health, educational, economic, and criminal behavior outcomes. Archives of General Psychiatry, 64,1089-95.

Frigerio, A., Cattaneo, C., Cataldo, M.G., Schiatti, A., Molteni, M., Battaglia, M.(2004). Behavioral and Emotional Problems Among Italian Children and Adolescents Aged 4 to 18 Years as Reported by Parents and Teachers. European Journal of Psychological Assessment, 20,124-133.

Frigerio, A., Vanzin, L., Pastore, V., Nobile, M., Giorda, R., Marino, C, et al.(2006). The Italian preadolescent mental health project (PrISMA): rationale and methods. International Journal of Methods in Psychiatric Research, 15,22-35.

Gutknecht, L., Jacob, C., Strobel, A., Kriegebaum, C., Muller, J. et al.(2007). Tryptophan hydroxylase-2 gene variation influences personality traits and disorders related to emotional dysregulation. International Journal of Neuropsychopharmacology,10,309-20.

Hetherington, E.M., Bridges, M., Insabella, G.M.(1998) What matters? What does not? Five perspectives on the association between marital transitions and children's adjustment. American Psychologist, 53,167-84.

ISTAT (2006). Rapporto annuale 2005. Istituto Nazionale di Statistica. Roma. http://www.istat.it/dati/catalogo/20060524_00/

Jaffee, S.R., Moffitt, T.E., Caspi, A., Fombonne, E., Poulton, R., Martin, J.(2002). Differences in early childhood risk factors for juvenile-onset and adult-onset depression. Archives of General Psychiatry, 59,215-22. 
Kaufman, J., Yang, B.Z., Douglas-Palumberi, H., Houshyar, S., Lipschitz, D., Krystal, J.H., Gelernter, J.(2004). Social supports and serotonin transporter gene moderate depression in maltreated children. Proceedings of the National Academy Sciences of the USA,101,17316-21.

Lau, J.Y., Eley, T.C.(2008). Disentangling gene-environment correlations and interactions on adolescent depressive symptoms. Journal of Child Psychology and Psychiatry,49,142-150.

Lesch, K.P., Bengel, D., Heils, A., Sabol, S.Z., Greenberg, B.D., Petri, S., Benjamin, J., Muller, C.R., Hamer, D.H., Murphy, D.L.(1996). Association of anxiety-related traits with a polymorphism in the serotonin transporter gene regulatory region. Science,274,1527-31.

Lesch, K.P.(2003). Neuroticism and serotonin: a developmental genetic perspective. In: R. Plomin, J.C. DeFries, I.W. Craig, P. McGuffin (Eds.). Behavioral Genetics in postgenomic era(p.389-423). Washington DC: American Psychological Association.

Luby, J.L., Belden, A.C., Spitznagel, E.(2006). Risk factors for preschool depression: the mediating role of early stressful life events. Journal of Child Psychology and Psychiatr,47,1292-1298.

Meltzer, H., Gatward, R., Corbin, T., Goodman, R., Ford, T.(2003). Persistence, onset, risk factors and outcomes of childhood mental disorders. National Statistics.

Moffitt, T.E., Caspi, A., Rutter, M.(2006). Measured Gene-Environment Interactions in Psychopathology. Perspectives on Psychological Science, 1,5-27.

Munafo, M.R., Clark, T.G., Moore, L.R., Payne, E., Walton, R., Flint, J.(2003). Genetic polymorphisms and personality in healthy adults: a systematic review and meta-analysis. Molecular Psychiatry,8,471-484.

Neuman, R.J., Geller, B., Rice, J.P., Todd, R.D.(1997). Increased prevalence and earlier onset of mood disorders among relatives of prepubertal versus adult probands. Journal of American Academy of Child and Adolescent Psychiatry,36,466-473.

Nobile, M., Begni, B., Giorda, R., Frigerio, A., Marino, C. et al.(1999). Effects of serotonin transporter promoter genotype on platelet serotonin transporter functionality in depressed children and adolescents. Journal of the American Academy of Child and Adolescent Psychiatry,38,1396-402.

Nobile, M., Giorda, R., Marino, C., Carnet, O., Pastore, V. Vanzin, L., 
Bellina, M., Molteni, M., Battaglia M.(2007). Socioeconomic status mediates the genetic contribution of the DRD4 and 5-HTTLPR polymorphisms to externalization in pre-adolescence. Development and Psychopatholgy.19:1145-1158

O'Connor, T.G., Caspi, A., DeFries, J.C., Plomin, R.(2000). Are associations between parental divorce and children's adjustment genetically mediated? An adoption study. Developmental Psychology, 36,429-37.

O'Connor, T.G., Dunn, J., Jenkins, J.M., Pickering, K., Rasbash, J.(2001). Family settings and children's adjustment: differential adjustment within and across families. British Journal of Psychiatry, 179,110-115.

O'Connor, T.G., Caspi, A., Defries, J.C., Plomin, R.(2003).Genotypeenvironment interaction in children's adjustment to parental separation. Journal of Child Psychology and Psychiatry, 44,849-856.

Rutter, M.(2005).Environmentally mediated risks for psychopathology: research strategies and findings. Journal of the American Academy of Child and Adolescent Psychiatry,44,3-18

Rutter, M., Moffitt, T.E., Caspi, A.(2006). Gene-environment interplay and psychopathology: multiple varieties but real effects. Journal of Child Psychology and Psychiatry,47,226-61.

Scheuch, K., Lautenschlager, M., Grohmann, M., Stahlberg, S., Kirchheiner, J., Zill, P., Heinz, A., Walther, D.J., Priller, J.(2007). Characterization of a Functional Promoter Polymorphism of the Human Tryptophan Hydroxylase 2 Gene in Serotonergic Raphe Neurons. Biological Psychiatry,62,1288-94.

Spatola, C.A., Fagnani, C., Pesenti-Gritti, P., Ogliari, A., Stazi, M.A., Battaglia, M.(2007). A general population twin study of the CBCL/6-18 DSM-oriented scales. Journal of the American Academy of Child and Adolescent Psychiatry,46,619-27.

Thapar, A., McGuffin, P.(1994), A twin study of depressive symptoms in childhood. Br Journal of Psychiatry,165,259-65.

Zammit, S., Owen, M.J.(2006). Stressful life events, 5-HTT genotype and risk of depression. The British Journal of Psychiatry,188,199-201.

Zhang, X., Beaulieu, J.M., Gainetdinov, R.R., Caron, M.G.(2006). Functional polymorphisms of the brain serotonin synthesizing enzyme tryptophan hydroxylase-2. Cellular and Molecular Life Sciences,63,6-11. 
Zhou, Z., Roy, A., Lipsky, R., Kuchipudi, K., Zhu, G., Taubman, J., Enoch, M.A., Virkkunen, M., Goldman D.(2005). Haplotype-based linkage of tryptophan hydroxylase 2 to suicide attempt, major depression, and cerebrospinal fluid 5-Hydroxyindoleacetic Acid in 4 populations. Archives of General Psychiatry,62,1109-1118. 


\section{CHAPTER 6}

\section{Socio-economic status moderates the genetic contribution of the dopamine receptor D4 and 5-HTTLPR polymorphisms to externalization in preadolescence}

Maria Nobile, Roberto Giorda, Cecilia Marino, Ombretta Carlet, Valentina Pastore, Laura Vanzin, Monica Bellina, Massimo Molteni and Marco Battaglia

Developmental Psychopathology. 2007 Fall; 19(4): 1147-60. 


\begin{abstract}
The impact of Socioeconomic Status (SES) and of some genetic polymorphisms upon individual differences for externalized behaviors have often been investigated separately in studies of children and adults. In a general population sample of 607 Italian pre-adolescents, we examined the independent and joint effects of SES and of the DRD4 and 5-HTTLPR polymorphisms upon Rule-Breaking and Aggressive behaviors measured with the Child Behavior CheckList/6-18.

We found evidence -based on both one locus- and two loci genotype analyses- that low SES, the DRD4 'long'- and the 5-HTTLPR 'long' alleles, both alone and in interaction, are associated with higher Aggressive behaviors scores. The effects were similar, but more modest and limited to one locus genotype analyses for Rule-Breaking behavior. Consistent with studies which showed the effects of societal moderators upon heritability of externalized behaviors across different segments of the population, we suggest that diminished social constraints associated with low parental SES may act as enhancers of the genetic influence of specific DRD4 and 5-HTTLPR alleles over aggressive behaviors in preadolescence.
\end{abstract}




\section{INTRODUCTION}

Childhood and adolescence externalizing behaviors -encompassing aggressive, destructive, oppositional, impulsive and delinquent conductsare frequent precursors of serious psychopathology later in life (Loeber, 1991, Moffitt, 1993). Genetic influences, as well as environmental factors -both unique and family-shared (Caspi, McClay, Moffitt, Mill, Martin, Craig et al., 2002; DiLalla, 2002, Van Beijsterveldt, Bartels, Hudziak \& Boomsma, 2003; Wadsworth \& Achenbach, 2005) - are recognized determinants of individual differences along the complex phenotype of developmental externalization.

Twin and adoptive studies with the Achenbach (1991) Child Behavior CheckList/4-18 (CBCL/4-18) found moderate-to-substantial genetic contributions to Externalizing behaviors, with heritability estimates ranging from .51 to .65 (Deater-Deckard \& Plomin 1999; Edelbrock, Rende, Plomin \& Thompson, 1995; Hudziak, Rudiger, Neale, Heath \& Todd, 2000; Schmitz, Fulker \& Mrazek, 1995; Van den Oord, Boomsma \& Verhulst, 1994). The psychometric facets of CBCL-4/18-defined Externalization, however, may be differently heritable: the Aggressive component has been found to have higher heritability than the Rule-Breaking component, while shared environmental factors appear to have greater influence over the latter, than the former (Eley, Lichtenstein \& Stevenson, 1999; Eley, Lichtenstein \& Moffitt, 2003).

Amongst the relatively few studies which investigated the nature of timestability of different Externalized behaviors from early childhood into adolescence, at least four revealed that both genetic and shared environmental influences are important causal agents of continuity. In a twin study, Van der Valk, van den Oord, Verhulst \& Boomsma (2003) showed that phenotypic stability from age 3 to 7 in CBCL-defined Externalization was explained for $55 \%$ by genetic factors, while the same shared environmental factors influenced these behaviors at both time points. A twin-family study of antisocial behaviors (O'Connor, Neiderhiser, Reiss, Hetherington \& Plomin, 1998) of children between 10 and 18 years showed that $54 \%$ of phenotypic stability was attributable to continuing genetic influences and $30 \%$ to continuing shared environmental factors. More recently, Haberstick, Schmitz, Young \& Hewitt (2005) found a single common genetic factor -whose effects may act pleiotropically at each age in the presence of unique environmental influences- as the main cause of continuity of externalization from childhood into adolescence. Finally, a large twin study of problem behaviors at age 3, 7, 10 and 12 (Bartels, van den Oord, Hudziak, Rietveld, van Beijsterveldt \& Boomsma, 2004) found 
that a subset of genes expressed early in life, and remaining expressed at the next time point, contributed to $60 \%$ of CBCL-defined Externalization, while a common set of shared environmental factors operated at all ages, and accounted for $34 \%$ of time-stable Externalized behaviors.

Moving on from estimations of general causal effects detectable via model fitting analyses and maximum likelihood theory, some identified environmental and genetic causal factors have been associated with Externalization.

Well before the advent of the genomic- and post-genomic era, several neurochemical indices have been studied in relation to a host of broadlyintended externalized behaviors, yielding evidence of altered dopaminergic and serotonergic functions in aggression, impulsivity and antisocial behaviors (Lesch \& Merschdorf, 2000; Swann, 2003). Although several different known genes contribute to regulate the dopaminergic and serotonergic functions and signaling patterns, the Dopamine D4 receptor (DRD4) gene and the Serotonin transporter (5-HTT) gene have been widely explored -alone or in combination- as possible contributors of variation along normative and psychopathological traits in adults and children (Ebstein, Benjamin \& Belmaker, 2000; Oak, Oldenhof \& Van Tol, 2000; Reif \& Lesch, 2003).

The DRD4 is a G-protein coupled receptor belonging to the D2 receptors' family which exerts an inhibitory effect on the adenylate cyclase-mediated secondary messenger pathway (Kandel 2000). The DRD4 gene is situated on the long arm of chromosome 11 (Gelertner, Kennedy, Van Tol, Civelli \& KIdd, 1992; Petronis, Van Tol, Lichter, Livak \& Kennedy, 1993), with a $48 \mathrm{bp}$ VNTR polymorphism in the third exon constituting the main focus of attention. Between 2 and 11 repeated elements have been reported in the literature, although the two predominant alleles in Caucasians consist of four (4R) and seven (7R) repeats (Ding, Chi, Grady, Morishima, Kidd, Kidd et al., 2002; Lichter, Barr, Kennedy, Van Tol, Kidd \& Livak, 1993; Van Tol, Wu, Guan, Ohara, Bunzow, Civelli et al., 1992). The polymorphic repeated segment codes for aminoacids in the third intracytoplasmic loop of the receptor, a region that couples to Gprotein and thus mediates intracellular signaling (Asghari, Sanyal, Buchwaldt, Paterson, Jovanovic, Van Tol 1995). There is some evidence that the long $(L)$ and the short $(S)$ forms of this protein have functional significance (Asghari, Schoots, van Kats, Ohara, Jovanovic, Guan, et al., 1994, Asghari et al., 1995), although more recent data suggest that the polymorphic region of the loop may not affect the specificity- or the efficiency- of G(i)alpha coupling (Kazmi, Snyder, Cypess, Graber \& Sakmar, 2000). 
These variants of the dopamine D4 receptor have been linked to human Novelty Seeking (Benjamin, Li, Patterson, Greenberg, Murphy \& Hamer 1996; Ebstein, Novick, Umansky, Priel, Osher, Blaine, et al., 1996), a substantially heritable temperamental dimension encompassing individual dispositions towards exploratory excitability, impulsivity and sensationseeking behaviors which can be broadly defined as externalized (Battaglia, Przybeck, Bellodi \& Cloninger, 1996). The association between DRD4 gene variants and phenotypic variation along human NS has been confirmed by several, but not all (see Kluger, Siegfried \& Ebstein, 2002 for a meta-analytic approach to the issue, and Savitz \& Ramesar, 2004 for review), subsequent studies.

The serotonin transporter (5-HTT) has received particular attention because it is involved in the re-uptake of serotonin at brain synapses and is the target of SSRIs (Selective Serotonin Reuptake Inhibitors) antidepressants. The promoter activity of the 5 -HTT gene is regulated by a deletion/insertion polymorphism in the proximal 5' promoter region, designated the 5HTT gene-linked polymorphic region (5-HTTLPR). The short (S) allele in the 5-HTTLPR is associated with lower transcriptional efficiency of the promoter compared with the long (L) allele (Lesch, Bengel, Heils, Sabol, Greenberg, Petri et al., 1996). Both adults and children and adolescents with the $L-L$ genotype have significantly higher serotonin uptake compared to those with L-S or S-S genotypes (Greenberg, Tolliver, Huang, Li, Bengel \& Murphy, 1999; Nobile, Begni, Giorda, Frigerio, Marino, Molteni et al., 1999). This genetically-influenced functional difference in serotonin uptake appears to influence a significant proportion of phenotypic variation along several human behaviors, including negative emotionality, proneness to anxiety/depression, interpersonal hostility, and aggressiveness (see e.g., Battaglia, Ogliari, Zanoni, Citterio, Pozzoli, Maffei et al., 2005; Nobile, Cataldo, Giorda, Battaglia, Baschirotto, Bellina et al., 2004, and Lesch, 2002 and Munafò, Clark, Moore, Payne, Walton \& Flint, 2003 for reviews). However, association studies of 5-HTTLPR and aggressiveness in the developmental years provided conflicting results. For instance, Gerra, Garofano, Castaldini, Rovetto, Zaimovic, Moi and colleagues (2005) found an association between the $-S$ allele and aggressive behaviors within a group of adolescent drug abusers, and Sakai, Young, Stalling, Timberlake, Smolen, Stetler \& Crowley (in press) found a within-family association between the $-\mathrm{S}$ allele and conduct disorder. However, except for teacher-rated aggressive behavior, the same association was not found in a sample of younger children (Haberstick, Smolen \& Hewitt, 2006), and two other studies (Beitchman, Davidge, Kennedy, Atkinson, 
Lee, Shapiro et al., 2003; Davidge, Atkinson, Douglas, Lee, Shapiro, Kennedy et al., 2004) found no association at all with the 5-HTTLPR and aggressive/externalized behaviors.

Such conflicting results with DRD4 and 5-HTTLPR in developmental Externalization might be at least partially accounted for by two important factors, namely interactions among genes, and interaction between genes and the environment.

There are several hints that interactions among genes -a phenomenon often referred to as 'epistasis'- may apply to the combined effects of the DRD4 and the 5-HTTLPR over externalized behaviors both in childhood (Auerbach, Geller, Lezer, Shinwell, Belmaker, Levine et al., 1999; Auerbach, Faroy, Ebstein, Kahana \& Levine, 2001; Ebstein, Levine, Geller, Auerbach, Gritsenko \& Belmaker, 1998; Lakatos, Nemoda, Birkas, Ronai, Kovacs, Ney et al., 2003) and adulthood (Benjamin, Osher, Kotler, Gritsenko, Nemanov, Belmaker et al., 2000; Strobel, Lesch, Jatzke, Paetzold \& Brocke, 2003). In particular, Benjamin et al. (2000) suggested that the short allele of 5-HTTLPR and the long allele of DRD4 oppose each other's effects inasmuch as approaching behaviors (e.g., Orientation towards environmental stimuli in infants and Novelty Seeking in adults) are promoted by the long DRD4 allele and the short allele of 5-HTTLPR promotes avoidant behaviors.

Since a variety of often-uncontrolled environmental factors (both familyshared and idiosyncratic, see e.g.: Burt, et al, 2003; Caspi et al., 2002; Jaffee, Moffitt, Caspi, Taylor \& Arseneault, 2002; Manly, Kim, Rogosch \& Cicchetti, 2001; Rutter, Moffitt \& Caspi, 2006; Shonk \& Cicchetti, 2001) moderate the expression of externalized behaviors and the amount of measured genetic influence (i.e., the heritability), interaction with the environment can be another, non mutually exclusive, potential explanation for inconsistent results with DRD4 and 5-HTTLPR in Externalization.

Parental socio-economic status (SES) could be one such environmental factor. Although limited by the fact of being a generic, broad, distal risk variable which is measured at a family-wide rather than at a child-specific level, SES is a powerful predictor of Externalization (Barry, Dunlap, Cotten, Lochman \& Wells, 2005; Dodge, Petit \& Bates, 1994; Keiley, Bates, Dodge \& Pettit, 2000; Loeber, Green, Keenan \& Lahey, 1995; Wadsworth \& Achenbach, 2005; Zukauskiene, Ignataviciene \& Daukantaite, 2003). The impact of socio-economic disadvantage can be negative both crosssectionally and in the longer term: low SES has been linked to higher prevalence of conduct disorder (Steiner \& Dunne, 1997), to both motherand teacher reported aggression and delinquency on the Child Disruptive 
Behavior Scale (Barry et al., 2005), as well as to poor academic performance and severe disciplinary problems during adolescence (DuBois, Felner, Meares \& Krier, 1994). Low SES may contribute to these psychopathologies either directly or indirectly, through negative effects onto more proximal child-specific factors, such as parenting (Conger, Wallace, Sun, Simons, McLoyd \& Brody, 2002) or exposure to trauma (Egeland, 1997). However, no study has so far analyzed the possible impact of SES in mediating the genetic contribution of the DRD4 and 5HTTLPR polymorphisms to childhood Externalization.

In the present study we examined the independent and joint effects of three potential, identified genetic (the DRD4 and 5-HTTLPR polymorphisms) and environmental (parental SES) causes of developmental Externalization in a general population sample of Italian children and adolescents.

\section{MATERIALS AND METHOD}

\section{Subjects}

Participants in this study were subjects involved in two epidemiological studies of mental health in youth. Subjects from sample $1(n=442)$ were recruited by our group as a collaborating center of the Italian Project on Pre-adolescent Mental Health (the PrISMA project -Progetto Italiano Salute Mentale Adolescenti) (Frigerio, Vanzin, Pastore, Nobile, Giorda, Marino, et al., 2006). The PrISMA project was designed to estimate the prevalence of behavioral problems in a National probability sample of pre-adolescents (10-14 years old) living and attending secondary schools in 7 medium-tolarge Italian urban areas (Milan, Rimini, Lecco and Conegliano located in the north of Italy, Rome and Pisa in the center- and Cagliari in the south of the Italian peninsula). Psychometric indexes were obtained through parental assessments of children's behavior with the CBCL/6-18 (Achenbach \& Rescorla, 2001) and the overall participation rate of the complete PrISMA sample was $61 \%$ of eligible subjects (Frigerio et al., 2006). The mean values of the CBCL/6-18 subscales did not differ significantly across these seven urban areas (data available from authors upon request).

Amongst the seven PrISMA participating units, two (respectively based in Bosisio Parini near Lecco, and Conegliano) have interests in behavioral genetics, together with the suitable technology for DNA collection and molecular genetic analyses. Therefore, for children living in Lecco and Conegliano, in addition to demographic and psychometric information, 
we asked for DNA collections, which were allowed by parental written informed consent for 442 of 1211 (36\%) eligible children.

Subjects from sample 2 belong to a relatively small suburban community (Ponte Lambro -PL-, inhabitants 4065) currently involved in an ongoing longitudinal study of emotional and behavioral problems, which encompasses the assessment of behavioral data with the CBCL/6-18 (Achenbach \& Rescorla 2001) and simultaneous DNA collection. The DNA of 165 of 317 (52\%) eligible pre-adolescents living in PL and aged 10-14, was made available after parental written informed consent. The $\mathrm{PL}$ and PrISMA samples have no overlapping.

Since the inclusion- (age between 10 and 14 years, regular school attendance, parental written informed consent) and exclusion(certification of mental handicap, which was present in $0.3 \%$ of eligible participants) criteria, and the psychometric instrument (parental assessments of children behavior through the CBCL/6-18) - were the same for the PriSMA and the PL, subjects of both epidemiological samples were pooled together for the present study, to increase the statistical power after controlling for the homogeneity of demographic and behavioral variables (Table 1).

Genetic data of both samples are shown here for the first time and analyzed in conjunction with demographic and clinical information, as relevant to genetic and gene-environment interaction effects upon the externalizing behaviors explored by this study.

\section{Procedures}

The study protocols were approved by the 'Eugenio Medea' Scientific Institute Ethical Committee.

\section{Behavioral Assessment}

The CBCL/6-18 (Achenbach \& Rescorla 2001) is an empirically-based checklist of social competence and behavioral problems filled out by parents of children and adolescents aged $6-18$ years. The CBCL/6-18 is divided into two major factors: the Internalizing- (with the AnxiousDepressed, Withdrawn and Somatic Complaints subscales) and the Externalizing Scale, which consists of 35 items and two subscales: RuleBreaking- and Aggressive Behavior. We employed parental employment as a measure of socio-economic status (SES) coded according to the Hollingshead (1975) 9-point scale for parental occupation. A score (from 1 to 9 ) was assigned to each parental job; when both parents were employed the highest of the two scores was used. Since low SES -in contrast to medium and high SES- has been identified as a specific risk 
factor for both Aggressive and Rule-Breaking Behavior (Barry et al., 2005; Dodge et al., 1994; Keiley et al., 2000;Loeber et al., 1995; Wadsworth \& Achenbach 2005; Zukauskiene et al., 2003), we split SES into two classes of risk, namely 'low' (SES 1-3) and 'medium-to-high' (SES 4-9).

\section{DNA collection and extraction}

Genomic DNA was extracted from mouthwash samples collected in 4\% sucrose using the DNAzol Genomic DNA Isolation reagent (Molecular Research Center, Cincinnati).

The methods for determining the DRD4/48bp-repeat and 5-HTTLPR polymorphisms were the same as described by Macciardi, Petronis, Van Tol, Marino, Cavallini, Smeraldi \& Kennedy (1994), and Lesch et al. (1996), respectively.

All amplification reactions were performed on a Mastercycler thermocycler (Eppendorf). The amplified products were analyzed on 2\% agarose gels.

\section{Statistical analyses}

The DRD4-exon-III polymorphism was classified according to the short (2-5 repeats; S) vs. long (6-8 repeats; L) scheme (Benjamin et al., 1996; Ebstein et al.,1996), so that subjects could be split into DRD4-S-S vs. DRD4-L (encompassing L-S and L-L subjects) carriers. For the 5HTTLPR genotype we split the sample into S-allele carriers (encompassing SS and LS subjects) and LL subjects.

Demographic and behavioral variables were preliminarily tested by ANOVA.

Since in the PrISMA project parents were let free to participate through simple behavioral assessments or behavioral assessment plus DNA collection, for sample 1 it was possible to control for possible participation biases. When we compared the CBCL 'Externalizing-','Rule-Breaking-' and 'Aggressive Behavior' scores of PrISMA children belonging to families who agreed- vs. those belonging to families who did not agree to participate in the genetic study, we found that there were no significant differences (respectively: Externalization: $5.84 \pm 5.57$ vs. $6.2 \pm 5.04, \mathrm{t}=-$ 1.0, $\mathrm{p}=0.32$; Rule-Breaking: $1.43 \pm 1.95$ vs. $1.37 \pm 1.62, \mathrm{t}=0.47, \mathrm{p}=0.64$; 'Aggressive: $4.41 \pm 4.08$ vs. $4.83 \pm 3.83$; $t=-1.553, p=0.12$ ). Moreover, there were no significant differences owing to SES (respectively $58.84 \pm$ 22.25 vs. $57.69 \pm 23.62, t=-0.72, p=0.47$ ) or age (respectively: $12.14 \pm 0.89$ vs. $12.05 \pm 0.95, t=-1.34, p=0.18$ ) between PrISMA children belonging to families who agreed- vs. those belonging to families who did not agree to participate in the genetic study

After controlling for independence of genotypes' and SES classes' 
distribution, the DRD4 and 5-HTTLPR genotypes and SES (divided into 'low' and 'medium-to-high') were entered simultaneously as independent variables -while the CBCL/6-18 'Rule-Breaking-' and 'AggressiveBehavior' scores were the dependent variables- in a MANCOVA, with gender and age as co-variates. Two ANCOVAs were subsequently run to estimate the effect of the independent variables on Aggressive and RuleBreaking Behavior separately.

Furthermore, to investigate the effect of specific combinations of genotypes and SES upon 'Rule-Breaking' and 'Aggressive' behaviors, we performed a two-loci genotype analysis whereby each subject was uniquely classified as belonging in one of four genetic variants -DRD4 (SS)-5-HTT (L-L) ; DRD4 (S-S)-5-HTT (S-carrier) ;DRD4 (L-carrier)-5-HTT (LL); DRD4 (L-carrier)-5-HTT (S-carrier)- and in one of the two SES categories, again with age- and sex as covariates, in two separate ANCOVAs (one for 'Rule-Breaking' and one for 'Aggressive' behaviors). All analyses were performed using the Statsoft Statistica package (Version 6.0, 1997).

\section{RESULTS}

Table 1 shows the demographic and behavioral variables in the two original epidemiological samples and in the combined sample. More than $95 \%$ of participating children were Caucasian and of Italian ancestry. Although attending the same school grade, children in the PrISMA sample were slightly but significantly older than children in the PL sample (F= 3.75 , d.f. $=1,605, p=0.053$ ), due to a modest difference in the timing of recruitment of the two samples (winter for the PrISMA sample and fall for the PL Sample). The total score of Externalizing ('Rule-Breaking' plus 'Aggressive') behavior was significantly higher in boys ( $F=13.45$; d.f. $=1,605, p<.001)$ than girls; likewise, both 'Rule-Breaking' and 'Aggressive' behaviors were significantly higher in boys than girls (respectively: $F=20.76$, d.f. $=1,605 ; p<.001 ; F=8.19$ d.f.1,605, $p<.004$ ) in the total sample, without significant differences between the PrISMA and the PL sub-samples. These results are consistent with previous studies investigating externalizing behavior in children and adolescents (BengiArslan, Verhulst, Van der Ende \& Erol, 1997; Collett, Ohan \& Myers, 2003; Fitzpatrick \& Deehan, 1999, Frigerio, Cattaneo, Cataldo, Schiatti, Molteni \& Battaglia, 2004; Lambert, Knight, Taylor \& Achenbach, 1994; Larsson \& Frisk, 1999; Liu, Kurita, Guo, Miyake, Ze \& Cao, 1999; MacDonald, Tsiantis, Achenbach, Motti-Stefanidi \& Richardson, 1995; Novik, 1999; 
Roussos, Karantanos, Richardson, Hartman, Karajiannis, Kyprianos, et al., 1999; Steinhausen, Winkler Metzke, Meier \& Kannenberg, 1997).

Genotyping of both the DRD4 and 5-HTTLPR was successful for 589 subjects with complete socio-demographic and behavioral data. Both polymorphisms were in Hardy-Weinberg equilibrium. The 5-HTTLPR genotype frequencies in the total sample were: L/L $33.6 \%$, L/S $48.6 \%$, S/S: $17.8 \%$; and the allele frequencies were $\mathrm{L} 57.9 \%$ and $S 42.1 \%$. The DRD4 genotype frequencies were S/S 68.9\%, S/L 25.6\%+ L/L $5.3 \%$; and the allele frequencies were $S 81.8 \%$ and $L 18.2 \%$. Genotypes and allele frequencies were evenly distributed between the PrISMA and the P.L. sub-samples (genotype: 5 -HTTLPR: $c^{2}=0.448$, d.f. $=2, p=0.799$; DRD4: $c^{2}=0.094$, d.f. $=2 p=0.95$; alleles: HTTLPR $c^{2}=0.468$, d.f. $=1, p=0.494$; DRD4 $c^{2}=0.0$ d.f. $=1, p=0.998$ ), and across genders (genotype: 5HTTLPR: $c^{2}=2.128$, d.f. $=2, p=0.345$; DRD4: $c^{2}=0.074$, d.f. $=2, p=0.96$; alleles 5-HTTLPR $\left(2=0.31\right.$, d.f. $=1, p=0.861$, DRD4: $c^{2}=0.697$, d.f. $=1$, $\mathrm{p}=0.712$, ), and similar to those previously reported (Cusin, Serretti, Lattuada, Lilli, Lorenzi \& Smeraldi 2002; Gelernter, Kennedy, van Tol, Civelli \& Kidd, 1992; Lesch et al., 1996;) for Caucasian populations. Among the 183 children who had one- or two DRD4 'L' allele(s), five had the 6 repeat- and four had the 8 repeat- polymorphism.

The frequencies of genotype distribution across the two p-SES categories ('low' vs. 'middle + high') were even for both the DRD4-exon-III- and the 5-HTTLPR polymorphism, with only a mild trend towards having the 'Short' DRD4-exon-III more frequently represented amongst the lower SES (DRD4: $c^{2}=3.11$, d.f. $=1, p=0.09 ; 5$-HTTLPR: $c^{2}=0.23$, d.f. $=1, p=0.64$ ) subjects. Similarly, there were no significant differences when we analyzed the distribution of the two-loci genotypes (DRD4-exon-III by 5HTTTLPR polymorphisms) across p-SES classes ( $c^{2}=3.74$, d.f. $=3$ $\mathrm{p}=0.29$ ).

Table 2 shows the 'Rule-Breaking' and 'Aggressive' Behavior scores grouped by DRD4-exon-III- and 5-HTTLPR genotypes and SES. The three-way MANCOVA (d.f. $=2,578$ ) -with sex- and age as covariatesrevealed significant effects for the DRD4-exon III polymorphism and SES (DRD4: $R=5.14, p=0.006$, partial $c^{2}=.017$, observed power $=.83$; SES: $R=6.46, p=0.002$, partial $c^{2}=.022$, observed power $=.91$ ), and a modest trend for the 5-HTTLPR polymorphism (5-HTTLPR: $R=2.44, p=0.09$ ). There were also significant gene $x$ gene (DRD4 x 5-HTTLPR: $R=5.64$, $p=0.004$ ) and gene $\times$ SES interactions (DRD4 $\times$ SES: $R=7.50, p=0.001$ ), while neither the 5-HTTLPR $\times$ SES- nor the DRD4 $\times 5$-HTTLPR $\times$ SES interactions were significant (respectively: $R=2.54, p=0.08 ; R=1.24$, $p=0.29$ ). 
The two ANCOVA run separately on 'Rule-Breaking' and 'Aggressive' scores showed that only low SES $(F=5.13$, d.f. $=1,579, p<0.024)$ and DRD4 x 5-HTTLPR $(F=6.35$, d.f. $=1,579, p<0.01)$ significantly influenced 'Rule-Breaking' behavior, while 'Aggressive Behavior' was significantly influenced by SES $(F=12.94$, d.f. $=1,579, p<0.001)$, DRD4 $(F=9.36$, d.f. $=1,579, p=0.002), 5-H T T L P R(F=4.87$, d.f. $=1,579, p=0.028)$ and by the following interactions DRD4x 5-HTTLPR $(F=11.09$, d.f. $=1,579$, $p=0.001)$, DRD4 $x$ SES $(F=9.22$, d.f. $=1,579, p=0.002)$ and 5-HTTLPR $x$ SES $(F=5.06$, d.f. $=1,579, p=0.025)$, always in the direction of more aggressive behaviors in subjects carrying an LL 5-HTTLPR genotype, carrying 1-2 'long' copies of the DRD4-exon-III polymorphism, and living in families with low SES (Table 2).

Table 3 shows the Rule-Breaking and Aggressive Behavior scores in children divided according to two-loci genotypes and SES. The ANCOVA (sex- and age as covariates) run on Rule-Breaking Behavior showed a main effect of SES $(F=5.134$, d.f. $=1,579, p=0.024)$, but neither of genotype $(F=2.134$, d.f. $=3,579, p=0.095)$, nor of SES $x$ genotype interaction ( $F=1.074$, d.f. $=3,579, p=0.36)$. The ANCOVA (sex- and age as covariates) run on Aggressive behavior showed the effects of SES $(F=12.943$, d.f. $=1,579, p<0.001)$, genotype $(F=4.876$, d.f. $=3,579$, $p=0.002)$, and SES x Genotype ( $F=4.311$, d.f. $=3,579, p=0.005)$ interaction. Post-hoc analysis for Aggressive behavior showed that children of low SES belonging in the DRD4 L-5HTTLPR-LL two loci genotype group were significantly more aggressive than children in all the other groups (significance range by Tukey HSD: $p=0.025-0.001$ ), with the exception of children of low SES belonging in the DRD4 L5 HTTLPR-S carrier group ( $p<.16$ by Tukey HSD) (Figure 1$)$.

\section{DISCUSSION}

Our findings of a significant effect of DRD4 and 5-HTTLPR on preadolescents' Aggressive Behavior scores are compatible with those of other studies investigating the influence and the relationship of the same polymorphisms upon different measures of externally-oriented behaviors in childhood (Auerbach et al., 1999; Auerbach et al., 2001; Ebstein et al., 1998; Lakatos et al., 2003) and in adulthood (Benjamin et al., 2000; Strobel et al., 2003). Specifically, Benjamin et al. (2000) suggested that the long alleles of DRD4 and the short alleles of 5-HTTLPR oppose each other's effects, in that the DRD4 long alleles promote approach and extraverted behaviors, while the short alleles of 5-HTTLPR promote 
avoidance behaviors. Inasmuch as our data are in keeping with studies of infancy and adulthood which show an interaction between 5-HTTLPR and DRD4 in shaping extraverted and -broadly intended- externalized behaviors (Auerbach et al., 1999; Auerbach et al., 2001; Benjamin et al., 2000; Ebstein et al., 1998; Lakatos et al., 2003; Strobel et al., 2003), they add evidence to the hypothesis that this antagonistic interaction mechanism may be present across the whole span of human life.

Our results are also consistent with previous studies showing that SES per se is a predictor of externalization (Barry et al., 2005; Dodge, Pettit \& Bates, 1994; Loeber et al., 1995; Keiley et al., 2000; Wadsworth \& Achenbach, 2005; Zukauskiene et al.,2003).

Of specific relevance to the topic of this Special Issue, i.e., geneenvironment interaction in developmental psychopathology, we also showed that the co-presence of identified alleles of the DRD4 and 5HTTLPR genes with low SES multiplies the risk for aggressive behaviors. Based on the empirical finding that the measured heritability of given behavioral traits can vary in time, or across social strata, a new generation of behavioral genetic studies (reviewed by Rutter \& Silberg, 2002 and Rutter et al., 2006) is now addressing the influence of societal moderators upon heritability of externalized behaviors across different segments of the population. Specifically, it has been shown that in presence of familial moderators (such as religious upbringing) or societal constraints (such as social undesirability) the heritability of -respectively- disinhibited behaviors (Boomsma, de Geus, van Baal \& Koopmans, 1999) and cigarette smoking (Kendler, Thornton \& Pedersen, 2000) can be low, or even undetectable. On the opposite side, low social control associated with living in urban areas, and the secular trend towards sexual tolerance appeared to enhance the genetic influence over adolescent alcohol use (Dick, Rose, Viken, Kaprio \& Koskenvuo, 2001; Rose, Dick, Viken \& Kaprio, 2001) and variance in the age at first intercourse (Dunne, Martin, Statham, Slutske, Dinwiddie, Bucholz, et al., 1997) in cohorts which differed respectively for geographic location or age. While the major drawback of these studies is that the degree of social control is induced -rather than measured directly- across social strata, our results can be interpreted in a similar fashion, i.e., by suggesting that diminished social constraints associated with low SES may act as enhancers of the genetic influence of DRD4 and 5-HTTLPR 'risk' alleles over aggressive behaviors in pre-adolescence.

Our results should also be regarded with some limitations in mind, both of general and specific relevance. There is now a clear contrast between the enthusiasm elicited by behavioral studies which suggest interactions 
between identified candidate genes and specific environmental factors, and the sobriety induced by simulated data analyses studies, such as those failing to find significant $G \times E$ interaction for liability to dichotomously-defined depression or antisocial disorder (Eaves, 2006). Such divergence of results suggests prudence, since there might be risks of oversimplification, and inflation of significance in virtually any analysis of variance focused on a limited pool of polymorphisms and environmental risk factors for a single/few behavioral variable(s).

We can then add at least four, additional specific caveats for the reader. First, although this study is based on a genetically homogeneous sample (more than $95 \%$ of Caucasian children of Italian ancestry), the stratification bias typical of population-based association studies is still possible, and our results need independent replication in extended familybased studies. Moreover, since our population is primarily Caucasian, the implications of our results may not be extended to other ethnic groups with different allele frequencies or environmental and social factors which may impinge differently upon externalizing behaviors.

Second: while the sample size of about 600 subjects is well within the range of other similar studies, one has to consider that for every common polymorphism -or environmental factor- of known effect, the impact over phenotypic variance is expected to be modest (most usually $<5 \%$ ), which leads to a relatively small effect size. Small effect size, thus, are typical of multifactorial conditions (see e.g. Kendler ,1995) and within the expectations of psychiatric genetic epidemiology

Third, we had a less than optimal participation rate. However, our participation figures are within the average reported for population-based investigations of mental health in several European countries including Norway (Harris, Magnus \& Tambs, 2002; Battaglia, Ogliari, Harris, Spatola, Pesenti-Gritti, Reichborn-Kjennerud et al., submitted) and Italy, (Ogliari, Citterio, Zanoni, Fagnani, Patriarca, Cirrincione et al., 2006). This seems to be especially true when when DNA sampling is added to the collection of psychometric variables in children. However, we found no evidence for selection effects owing to CBCL symptoms, SES, or age, at least for children in sample 1, who -in turn- had the same CBCL scores as children in sample 2 .

Fourth, the study is based on parent-rated CBCL externalized behaviors only. Although parental reports are often used for assessing problem behaviors and psychiatric disorders in children, and externalized behaviors typically provide good replicability across different observers (Achenbach McConaughy \& Howell, 1987; Collett et al., 2003), direct assessments through direct interviews are by definition more informative 
and reliable.

In conclusion, this first report of a significant interaction between the DRD4 and 5-HTTLPR genes and low SES in influencing pre-adolescent aggressive behaviors is consistent with a considerable body of literature which analyzed identified functional genetic polymorphisms or environmental risk factors separately. While it is becoming increasingly clear that specified genetic polymorphisms -as well as identified environmental conditions- affect the risk for psychopathology in development, a co-joint analysis of genetic determinants and environmental risk factors appears to be a more ecological and promising approach than studying genes and hazardous environments separately. Since functional variation at a given polymorphism ultimately supports evolutionary tolerance (i.e., lack of negative selective pressure/adaptive advantage) for alternative genetic expressions in at least some ecological niches, the finding that an identified environmental variable mediates the contribution of one -or more- genetic polymorphisms to human variability in aggressiveness is well within the expectations of the discipline of behavioral genetics.

Future investigations may better clarify which elements of the generic and distal risk variable identified with 'low SES' influence at a childspecific level the individual risk to be more aggressive in the pre-adolescence years.

\section{Acknowledgments}

This study was supported by Grant R.F.2002-2003 N.182 from the Italian Ministry of Health. 
CHAPTER 6

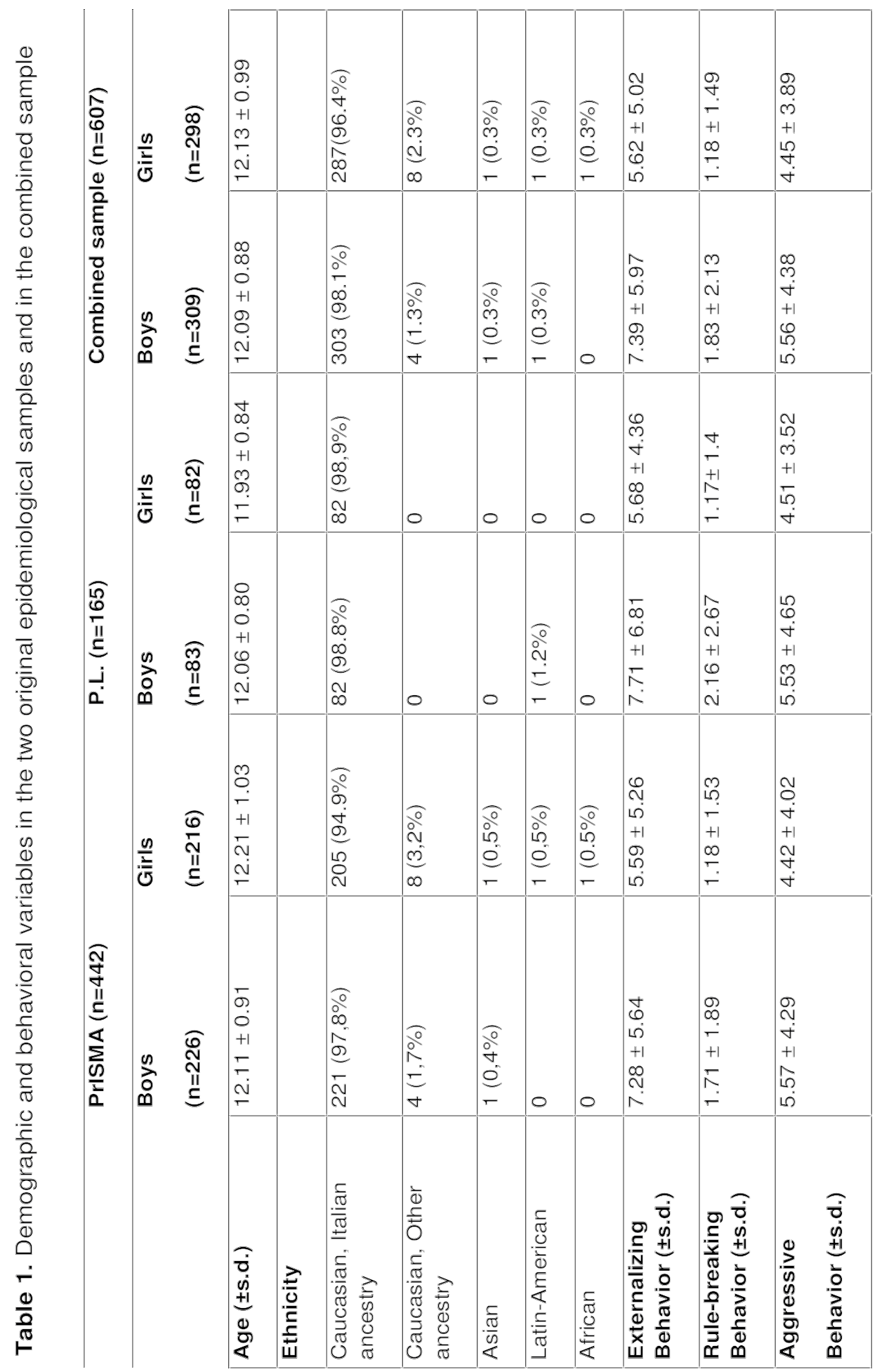




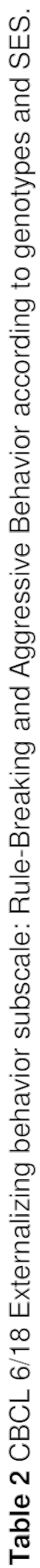

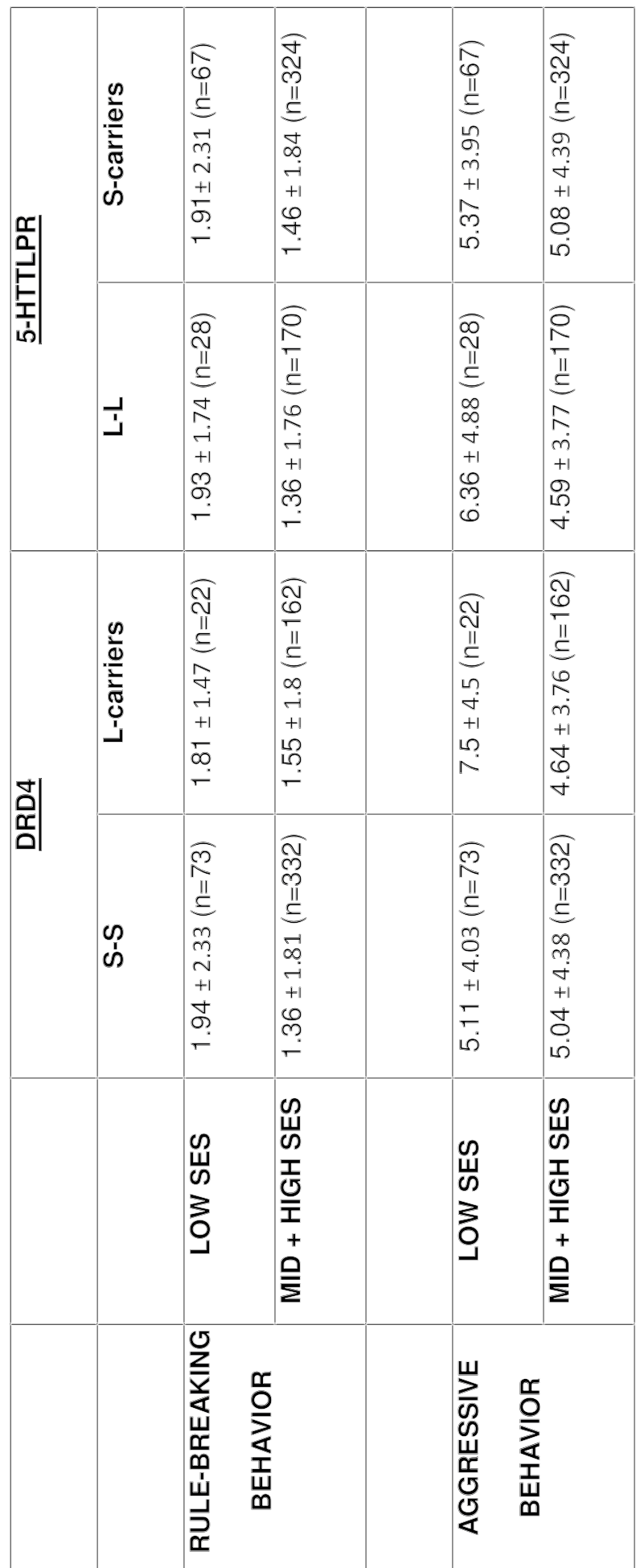


CHAPTER 6
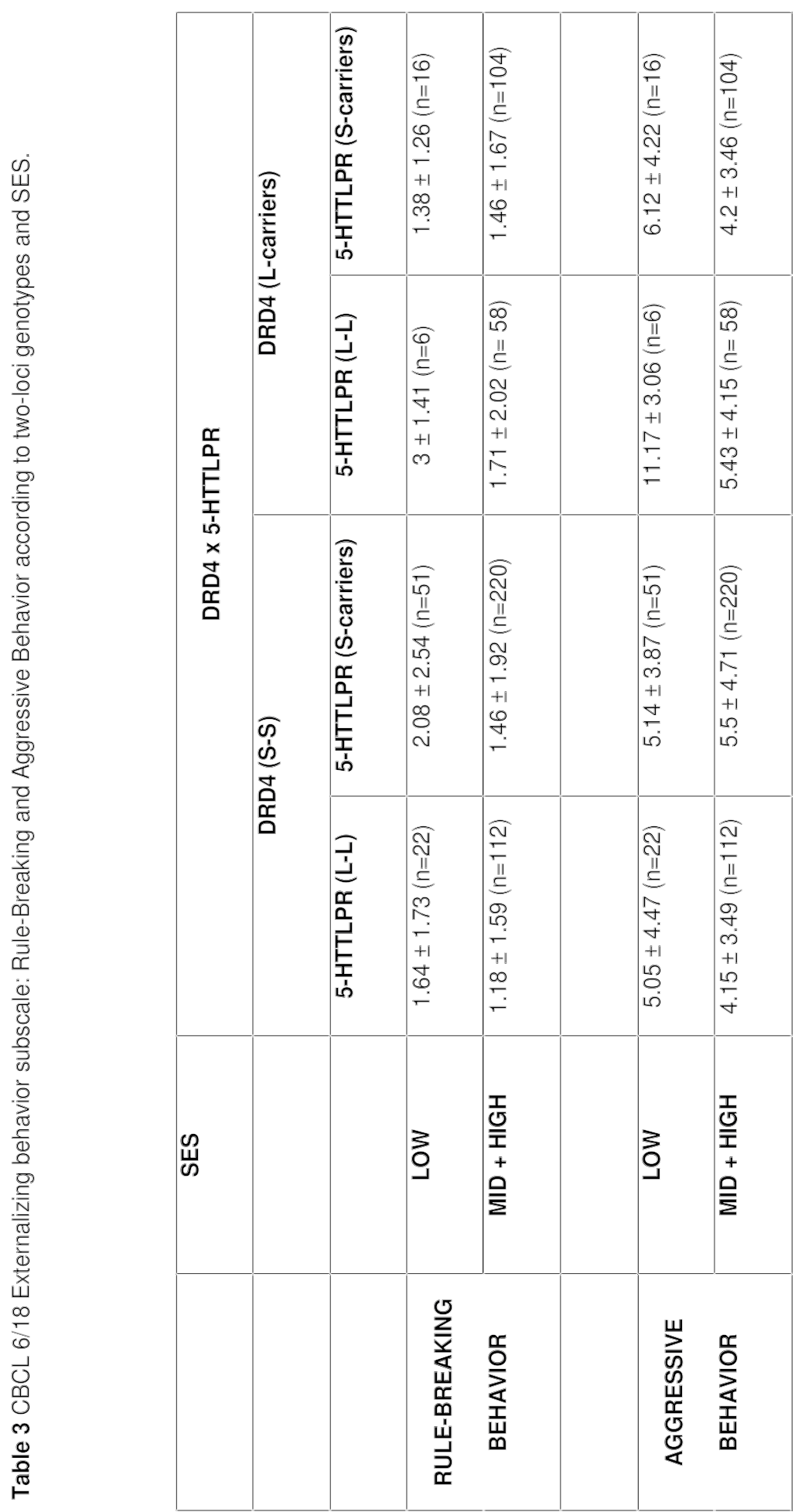
Figure 1

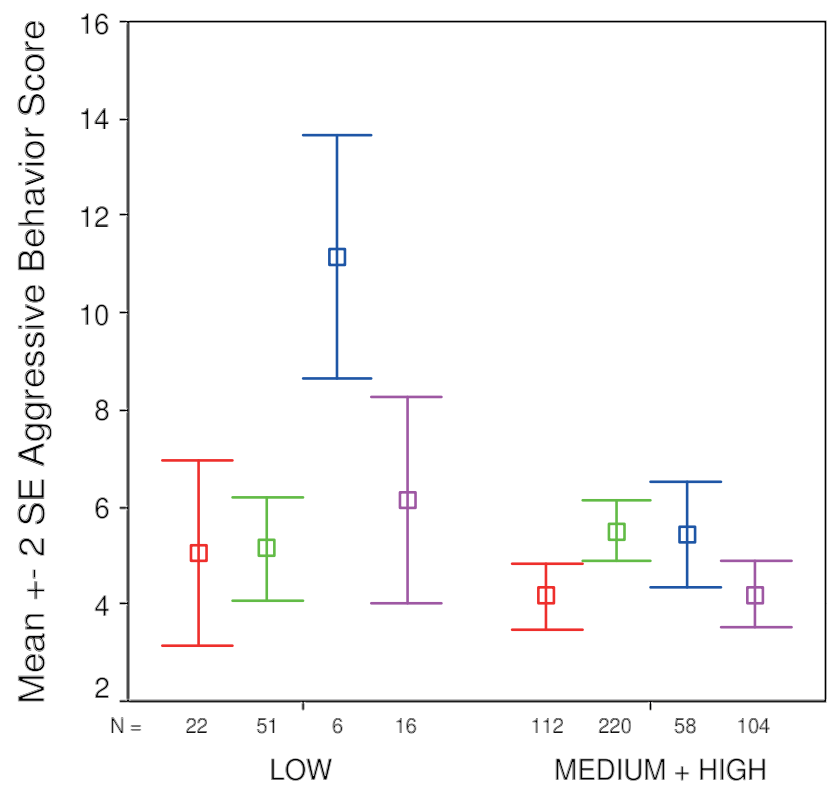

parental socioeconomic status (SES) two-loci genotype

I

DRD4 (S-S)

ㄷTTLLPR (L-L)

I

DRD4 (S-S)

$\square$ 5HTTLPR (S-carriers)

I

DRD4 (L-carriers)

口 5 HTTLPR (L-L)

I

DRD4 (L-carriers)

$\square$ SHTTLPR (S-carriers)

Figure 1. Aggressive Behavior Score according to SES and two-loci genotype 


\section{REFERENCES}

Achenbach T.M., McConaughy S.H.\& Howell C.T.(1987). Child/adolescent behavioral and emotional problems: Implications of cross-informant correlations for situation specificity. Psychological Bulletin, 101: 213-232.

Achenbach TM. (1991). Manual for the Child Behavior Checklist/4-18 and 1991 Profiles. Burlington, VT: University of Vermont, Department of Psychiatry.

Achenbach T.M. \& Rescorla L.A. (2001). Manual for the ASEBA Schoolage Forms and Profiles. Burlington, VT: University of Vermont, Department of Psychiatry.

Asghari V., Schoots O., van Kats S., Ohara K., Jovanovic V., Guan H.C., Bunzow J.R., Petronis A., Van Tol H.H. (1994). Dopamine D4 receptor repeat: analysis of different native and mutant forms of the human and rat genes. Molecular Pharmacology, 46, 364-73.

Asghari V., Sanyal S., Buchwaldt S., Paterson A., Jovanovic V., Van Tol H.H. (1995). Modulation of intracellular cyclic AMP levels by different human dopamine D4 receptor variants. Journal of Neurochemistry 65, 1157-1165.

Auerbach J.G., Geller V., Lezer S., Shinwell E., Belmaker R.H., Levine J., Ebstein R. (1999). Dopamine D4 receptor (DRD4) and serotonin transporter promoter (5-HTTLPR) polymorphisms in the determination of temperament in 2-month-old infants. Molecular Psychiatry, 4, 369-373.

Auerbach J.G., Faroy M., Ebstein R., Kahana M., Levine J. (2001). The association of the dopamine D4 receptor gene (DRD4) and the serotonin transporter promoter gene (5-HTTLPR) with temperament in 12-monthold infants. Journal of Child Psychology and Psychiatry, 42, 777-783.

Barry T.D., Dunlap S.T., Cotten S.J., Lochman J.E., Wells K.C. (2005). The influence of maternal stress and distress on disruptive behavior problems in boys. Journal of the American Academy of Child and Adolescent Psychiatry, 44, 265-273.

Bartels M., van den Oord E.J., Hudziak J.J., Rietveld M.J., van Beijsterveldt C.E., Boomsma D.I. (2004). Genetic and environmental mechanisms underlying stability and change in problem behaviors at ages 3, 7, 10, and 12. Developmental Psychology, 40, 852-867.

Battaglia M., Przybeck T.R., Bellodi L., Cloninger C.R. (1996). Temperament dimensions explain the comorbidity of psychiatric disorders. 
Comprehensive Psychiatry, 37, 292-298.

Battaglia M, Ogliari A, Zanoni A., Citterio A, Pozzoli U., Maffei C., Giorda R., Marino C. (2005). Influence of the Serotonin Transporter Promoter Gene and Shyness on Children's Cerebral Responses to Facial Expressions. Archives of General Psychiatry, 62: 85-94.

Battaglia M, Ogliari A, Harris J, Spatola CAM, Pesenti-Gritti P, ReichbornKjennerud T, Torgersen S, Kringlen E, Tambs K (submitted). A Genetic Study of the Acute Anxious Response to Carbon Dioxide Stimulation in Man.

Beitchman J.H., Davidge K.M., Kennedy J.L., Atkinson L., Lee V., Shapiro S., Douglas L. (2003) The serotonin transporter gene in aggressive children with and without ADHD and nonaggressive matched controls. Annals of the New York Academy of Sciences, 1008, 248-251.

Benjamin J., Li L., Patterson C., Greenberg B.D., Murphy D.L., Hamer D.H. (1996). Population and familial association between the D4 dopamine receptor gene and measures of Novelty Seeking. Nature Genetics, 12, 81-84.

Benjamin J., Osher Y., Kotler M., Gritsenko I., Nemanov L., Belmaker R.H., Ebstein R.P. (2000). Association between tridimensional personality questionnaire (TPQ) traits and three functional polymorphisms: dopamine receptor D4 (DRD4), serotonin transporter promoter region (5-HTTLPR) and catechol O-methyltransferase (COMT). Molecular Psychiatry, 5, 96-100.

Bengi-Arslan, L., Verhulst, F.C., Van der Ende, J., \& Erol, N. (1997). Understanding childhood (problem) behaviors from a cultural perspective: Comparison of problem behaviors and competencies in Turkish immigrant, Turkish, and Dutch children. Social Psychiatry and Psychiatric Epidemiology, 32, 477-484.

Boomsma D.I., de Geus E.J., van Baal G.C., Koopmans J.R. (1999). A religious upbringing reduces the influence of genetic factors on disinhibition: evidence for interaction between genotype and environment on personality. Twin Research 2, 115-125.

Burt S.A., Krueger R.F., McGue M., lacono W. (2003). Parent-child conflict and the comorbidity among childhood externalizing disorders. Archives of General Psychiatry 60, 505-513.

Caspi A., McClay J., Moffitt T.E., Mill J., Martin J., Craig I.W., et al (2002). Role of genotype in the cycle of violence in maltreated children. Science, 297, 851-854. 
Collett B.R., Ohan J.L., Myers K.M. (2003) Ten-year review of rating scales. VI: scales assessing externalizing behaviors. Journal of the American Academy of Child and Adolescent Psychiatry, 42, 1143-1170.

Conger R.D., Wallace L.E., Sun Y., Simons R.L., McLoyd V.C., Brody G.H. (2002). Economic pressure in African American families: a replication and extension of the family stress model. Developmental Psychology, 38, 179193.

Cusin C., Serretti A., Lattuada E., Lilli R., Lorenzi C., Smeraldi E. (2002). Association study of MAO-A, COMT, 5-HT2, DRD2, and DRD4 polymorphism with time course in mood disorders. American Journal of Medical Genetic, 114, 380-390.

Davidge K.M., Atkinson L., Douglas L., Lee V., Shapiro S., Kennedy J.L., Beitchman J.H. (2004). Association of the serotonin transporter and 5HT1Dbeta receptor genes with extreme, persistent and pervasive aggressive behavior in children. Psychiatric Genetics, 14, 143-146.

Deater-Deckard K., Plomin R. (1999) An adoption study of the etiology of teacher and parent reports of externalizing behavior problems in middle childhood. Child Development, 70(1), 144-154.

Dick D.M., Rose R.J., Viken R.J., Kaprio J., Koskenvuo M. (2001). Exploring gene-environment interactions: socioregional moderation of alcohol use. Journal of Abnormal Psychology, 110, 625-632.

DiLalla LF. (2002). Behavior genetics of aggression in children: Review and future directions. Developmental Review, 22, 593- 622.

Ding Y.C., Chi H.C., Grady D.L., Morishima A., Kidd J.R., Kidd K.K., Flodman P., Spence M.A., Schuck S., Swanson J.M., Zhang Y.P., Moyzis R.K.(2002). Evidence of positive selection acting at the human dopamine receptor D4 gene locus. Proceedings of the National Academy of Sciences U S A, 99, 309-314.

Dodge K.A., Pettit G.S., Bates J.E. (1994). Socialization mediators of the relation between socioeconomic status and child conduct problems. Child Development, 65, 649-665.

DuBois D.L., Felner R.D., Meares H., Krier M. (1994). Prospective investigation of the effects of socioeconomic disadvantage, life stress, and social support on early adolescent adjustment. Journal of Abnormal Psychology, 103, 511-522.

Dunne, M. P., Martin, N. G., Statham, D. J., Slutske, W. S., Dinwiddie S.H., 
Bucholz K.K. \& al. (1997). Genetic and environmental contributions to variance in age at first sexual intercourse. Psychological Science, 8, 211216.

Eaves L.J. (2006) Genotype x Environment interaction in psychopathology: fact or artifact? Twin Research and Human Genetics, 9, 1-8.

Ebstein R.P., Novick O., Umansky R., Priel B., Osher Y., Blaine D., Bennett E.R., Nemanov L., Katz M., Belmaker R.H. (1996). Dopamine D4 receptor (D4DR) exon III polymorphism associated with the human personality trait of Novelty Seeking. Nature Genetics 12, 78-80.

Ebstein R.P., Levine J., Geller V., Auerbach J., Gritsenko I., Belmaker R.H. (1998). Dopamine D4 receptor and serotonin transporter promoter in the determination of neonatal temperament. Molecular Psychiatry, 3, 328-346.

Ebstein R., Benjamin J., Belmaker R.H. (2000). Personality and polymorphisms of gene involved in aminergic neurotransmission. European Journal of Pharmacology, 410, 205-214.

Edelbrock C, Rende R, Plomin R, Thompson LA. (1995). A twin study of competence and problem behavior in childhood and early adolescence. Journal of Child Psychology and Psychiatry, 36, 775-785.

Egeland B. (1997). Mediators of the effect of child maltreatment on developmental adaptation in adolescence. In D. Cicchetti \& S.L. Toth (Eds), Developmental perspectives on trauma: Theory, research, and intervention. (pp. 403-434), Rochester, NY: University of Rochester Press.

Eley TC., Lichtenstein P., Stevenson J. (1999). Sex differences in the etiology of aggressive and nonaggressive antisocial behavior: results from two twin studies. Child Development, 70,155-68.

Eley TC., Lichtenstein P., Moffitt TE. (2003). A longitudinal behavioral genetic analysis of the etiology of aggressive and nonaggressive antisocial behavior. Development and Psychopathology. 15, 383-402.

Fitzpatrick C. \& Deehan A. (1999). Competencies and problems of Irish children and adolescents. European Child and Adolescent Psychiatry, 8, 17-23.

Frigerio A., Cattaneo C., Cataldo M.G., Schiatti A., Molteni M., Battaglia M. (2004). Behavioral and Emotional Problems Among Italian Children and Adolescents Aged 4 to 18 Years as Reported by Parents and Teachers. European Journal of Psychological Assessment, 20, 124-133. 
Frigerio A., Vanzin L., Pastore V., Nobile M., Giorda R., Marino C., Molteni M., Rucci P., Ammaniti M., Lucarelli L., Lenti C., Walder M., Martinuzzi A., Carlet O., Muratori F., Milone A., Zuddas A., Cavolina P., Nardocci F., Tullini A., Morosini P., Polidori G., De Girolamo G. (2006). The Italian preadolescent mental health project (PrISMA): rationale and methods. International Journal of Methods in Psychiatric Research, 15, 22-35.

Gelernter J., Kennedy J.L., van Tol H.H., Civelli O., Kidd K.K. (1992). The D4 dopamine receptor (DRD4) maps to distal $11 p$ close to HRAS. Genomics, 13, 208-10

Gerra G., Garofano L., Castaldini L., Rovetto F., Zaimovic A., Moi G., Bussandri M., Branchi B., Brambilla F., Friso G., Donnini C. (2005). Serotonin transporter promoter polymorphism genotype is associated with temperament, personality traits and illegal drugs use among adolescents. Journal of Neural Transmission, 112, 1397-1410.

Greenberg B.D., Tolliver T.J., Huang S.J., Li Q., Bengel D., Murphy D.L. (1999). Genetic variation in the serotonin transporter promoter region affects serotonin uptake in human blood platelets. American Journal of Medical Genetics, 88, 83-87.

Haberstick B.C., Schmitz S., Young S.E., Hewitt J.K. (2005). Contributions of genes and environments to stability and change in externalizing and internalizing problems during elementary and middle school. Behavior Genetics, 35, 381-96.

Haberstick B.C., Smolen A., Hewitt J.K. (2006). Family-based association test of the 5HTTLPR and aggressive behavior in a general population sample of children. Biological Psychiatry, 59, 836-843.

Harris JR, Magnus P, Tambs K (2002). The Norwegian Institute of Public Health Twin Panel: a description of the sample and program of research. Twin Research, 5, 415-423.

Hollingshead A.B. (1975). Four factor index of social status. Unpublished Manuscript. New Haven, CT: Yale University, Department of Sociology.

Hudziak JJ, Rudiger LP, Neale MC, Heath AC, Todd RD. (2000). A twin study of inattentive, aggressive, and anxious/depressed behaviors. Journal of American Academy of Child and Adolescent Psychiatry, 39, 469-476.

Jaffee S.R., Moffitt T.E., Caspi A., Taylor A., Arseneault L. (2002). Influence of adult domestic violence on children's internalizing and externalizing problems: an environmentally informative twin study. Journal of American 
Academy of Child and Adolescent Psychiatry, 41, 1095-1103.

Kandel E.R. (2000). Disorders of thought and volition: Schizophrenia. In E.R. Kandel, J.H. Schwartz, T.M. Jessel (Eds). Principles of neural science . $4^{\text {th }}$ edition. (pp. 1188-1208). New York: McGraw-Hill.

Kazmi M.A., Snyder L.A., Cypess A.M., Graber S.G., Sakmar T.P. (2000). Selective reconstitution of human $\mathrm{D} 4$ dopamine receptor variants with $\mathrm{Gi}$ alpha subtypes. Biochemistry, 39, 3734-3744.

Keiley M.K., Bates J.E., Dodge K.A., Pettit G.S. (2000). A cross-domain growth analysis: externalizing and internalizing behaviors during 8 years of childhood. Journal of Abnormal Child Psychology, 28, 161-179.

Kendler K.S., Thornton L.M., Pedersen N.L. (2000). Tobacco consumption in Swedish twins reared apart and reared together. Archives of General Psychiatry, 57, 886-892.

Kendler KS. (1995) Genetic epidemiology in psychiatry. Taking both genes and environment seriously. Archives of General Psychiatry 52, 895-899.

Kluger A.N., Siegfried Z., Ebstein R.P. (2002). A meta-analysis of the association between DRD4 polymorphism and novelty seeking. Molecular Psychiatry 7, 712-717.

Lakatos K., Nemoda Z., Birkas E., Ronai Z., Kovacs E., Ney K., Toth I., Sasvari-Szekely M., Gervai J. (2003). Association of D4 dopamine receptor gene and serotonin transporter promoter polymorphisms with infants' response to novelty. Molecular Psychiatry 8, 90-97.

Lambert M.C., Knight F., Taylor R., Achenbach T. (1994). Epidemiology of behavioral and emotional problems among children of Jamaica and the United States: Parent reports for ages 6 to 11. Journal of Abnormal Child Psychology, 22, 113-128.

Larsson B., Frisk M. (1999). Social competence and emotional/behavior problems in 6-16-year-old Swedish school children. European Child and Adolescent Psychiatry, 8, 24-33.

Lesch K.P., Bengel D., Heils A., Sabol S.Z., Greenberg B.D., Petri S., Benjamin J., Muller C.R., Hamer D.H., Murphy D.L. (1996). Association of anxiety-related traits with a polymorphism in the serotonin transporter gene regulatory region. Science, 274, 1527-1531.

Lesch K.P. \& Merschdorf U. (2000). Impulsivity, aggression, and serotonin: a molecular psychobiological perspective. Behavioral Sciences \& The 
Law,18, 581-604.

Lesch K.P. (2002). Neuroticism and serotonin: A developmental genetic perspective. In R. Plomin, J.C. DeFries, I.W. Craig \& P. McGuffin (Eds.), Behavioral genetics in the postgenomic era. Washington, DC: A.P.A.

Lichter J.B., Barr C.L., Kennedy J.L., Van Tol H.H., Kidd K.K., Livak K.J. (1993). A hypervariable segment in the human dopamine receptor D4 (DRD4) gene. Human Molecular Genetics, 2, 767-73.

Liu X., Kurita H., Guo C., Miyake Y., Ze., Cao H. (1999). Prevalence and risk factors of behavioral and emotional problems among Chinese children aged 6 through 11 years. Journal of American Academy of Child and Adolescent Psychiatry, 38, 708-715.

Loeber R. (1991). Antisocial behavior: more enduring than changeable? Journal of American Academy of Child and Adolescent Psychiatry, 30, 393397.

Loeber R., Green S.M., Keenan K., Lahey B.B. (1995). Which boys will fare worse? Early predictors of the onset of conduct disorder in a six-year longitudinal study. Journal of American Academy of Child and Adolescent Psychiatry, 34, 499-509.

Macciardi F., Petronis A., Van Tol H.H., Marino C., Cavallini M.C., Smeraldi E., Kennedy J.L. (1994). Analysis of the D4 dopamine receptor gene variant in an Italian schizophrenia kindred. Archives of General Psychiatry, 51, 288-293.

MacDonald V.M., Tsiantis J., Achenbach T.M., Motti-Stefanidi F., Richardson S.C. (1995). Competencies and problems reported by parents of Greek and American children, ages 6-11. European Child and Adolescent Psychiatry, 4, 1-13.

Manly J.T., Kim J.E., Rogosch F.A., Cicchetti D. (2001). Dimensions of child maltreatment and children's adjustment: contributions of developmental timing and subtype. Development and Psychopatholy, 13, 759-782.

Moffitt TE. (1993). Adolescence-limited and life-course-persistent antisocial behavior: a developmental taxonomy. Psychological Review, 100, 674701.

Munafo M.R., Clark T.G., Moore L.R., Payne E., Walton R., Flint J. (2003). Genetic polymorphisms and personality in healthy adults: a systematic review and meta-analysis. Molecular Psychiatry, 8, 471-484. 
Nobile M., Begni B., Giorda R., Frigerio A., Marino C., Molteni M., Ferrarese C., Battaglia M. (1999). Effects of serotonin transporter promoter genotype on platelet serotonin transporter functionality in depressed children and adolescents. Journal of American Academy of Child and Adolescent Psychiatry, 38, 1396-1402.

Nobile M, Cataldo MG, Giorda R, Battaglia M, Baschirotto C, Bellina M, Marino C, Molteni M (2004). A case-control and family-based association study of the 5-HTTLPR in pediatric-onset depressive disorders. Biological Psychiatry, 56: 292-295.

Novik, T.S. (1999). Validity of the Child Behavior Checklist in a Norwegian sample. European Child and Adolescent Psychiatry, 8, 247-254.

Oak J.N., Oldenhof J., Van Tol H.H. (2000). The dopamine D(4) receptor: one decade of research. European Journal of Pharmacology, 405, 303-27.

O'Connor T.G., Neiderhiser J.M., Reiss D., Hetherington E.M., Plomin R. (1998). Genetic contributions to continuity, change, and co-occurrence of antisocial and depressive symptoms in adolescence. Journal of Child Psychology and Psychiatry, 39, 323-36.

Ogliari A, Citterio A, Zanoni A., Fagnani C, Patriarca V, Cirrincione R, Stazi MA, Battaglia M (2006). Genetic and Envrionmental Infuences on Anxiety Dimensions in Italian Twins Evaluated with the SCARED Questionnaire. Journal of Anxiety Disorders, 20, 760-77.

Petronis A, Van Tol HH, Lichter JB, Livak KJ, Kennedy JL (1993): The D4 dopamine receptor gene maps on $11 p$ proximal to HRAS. Genomics, 18, 161-3.

Reif A., Lesch K.P. (2003). Toward a molecular architecture of personality. Behavioural Brain Research, 139, 1-20.

Rose R.J., Dick D.M., Viken And R.J., Kaprio J. (2001). Gene-environment interaction in patterns of adolescent drinking: regional residency moderates longitudinal influences on alcohol use. Alcoholism Clinical and Experimental Research, 25, 637-643.

Roussos A., Karantanos G., Richardson C., Hartman C., Karajiannis D., Kyprianos S., Lazaratou H., Mahaira O., Tassi M., Zoubou, V. (1999). Achenbach's Child Behavior Checklist and Teacher's Report Form in a normative sample of Greek children 6-12 years old. European Child and Adolescent Psychiatry, 8, 165-172. 
Rutter M., Moffitt T.E., Caspi A. (2006). Gene-environment interplay and psychopathology: multiple varieties but real effects. Journal of Child Psychology and Psychiatry, 47, 226-261.

Rutter M, Silberg J. (2002). Gene-environment interplay in relation to emotional and behavioral disturbance. Annual Review of Psychology, 53, 463-490.

Sakai J.T., Young S.E., Stalling M.C., Timberlake D., Smolen A., Stetler G.L., Crowley T.J. (in press). Case-control and within-family test for an association between conduct disorder and 5-HTTLPR. American Journal of Medical Genetics, Part B. Neuropsychiatric Genetics.

Savitz J.B \& Ramesar R.S. (2004). Genetic variants implicated in personality: a review of the more promising candidates. American Journal of Medical Genetics, Part B. Neuropsychiatric Genetics, 131, 20-32.

Schmitz S, Fulker DW, Mrazek DA. (1995). Problem behavior in early and middle childhood: an initial behavior-genetic analysis. Journal of Child Psychology and Psychiatry, 36, 1448-1458.

Shonk S.M. \& Cicchetti D. (2001). Maltreatment, competency deficits, and risk for academic and behavioral maladjustment. Developmental Psychology, 37, 3-17.

Steiner H. \& Dunne J.E. (1997). Summary of the practice parameters for the assessment and treatment of children and adolescents with conduct disorder. Journal of American Academy of Child and Adolescent Psychiatry, 36, 1482-1485.

Steinhausen H.C., Winkler Metzke C., Meier M., Kannenberg R. (1997). Behavioral and emotional problems reported by parents for ages 6 to 17 in a Swiss epidemiological study. European Child and Adolescent Psychiatry, 6, 136-141.

Strobel A., Lesch K.P., Jatzke S., Paetzold F., Brocke B. (2003). Further evidence for a modulation of Novelty Seeking by DRD4 exon III, 5HTTLPR, and COMT val/met variants. Molecular Psychiatry, 8, 371-372.

Swann AC. (2003). Neuroreceptor mechanisms of aggression and its treatment. Journal of Clinical Psychiatry, 64, 26-35.

Van Beijsterveldt CEM, Bartels M, Hudziak JJ, Boomsma DI. (2003). Causes of stability of aggression from early childhood to adolescence: A longitudinal genetic analysis in Dutch twins. Behavior Genetics, 33, 591605. 
Van den Oord EJ, Boomsma DI, Verhulst FC. (1994). A study of problem behaviors in 10- to 15-year-old biologically related and unrelated international adoptees. Behavior Genetics, 24, 193-205.

Van der Valk JC., van den Oord EJ., Verhulst FC., Boomsma DI. (2003). Genetic and environmental contributions to stability and change in children's internalizing and externalizing problems. Journal of American Academy of Child and Adolescent Psychiatry, 42, 1212-20.

Van Tol H.H., Wu C.M., Guan H.C., Ohara K., Bunzow J.R., Civelli O., Kennedy J., Seeman P., Niznik H.B., Jovanovic V. (1992). Multiple dopamine D4 receptor variants in the human population. Nature, 358, 149-52

Wadsworth ME, Achenbach TM. (2005). Explaining the link between low socioeconomic status and psychopathology: testing two mechanisms of the social causation hypothesis. Journal of Consulting and Clinical Psychology. 73, 1146-53.

Zukauskiene R., Ignataviciene K., Daukantaite D. (2003). Subscales scores of the Lithuanian version of $\mathrm{CBCL}$-preliminary data on the emotional and behavioral problems in childhood and adolescence. European Child and Adolescent Psychiatry, 12, 136-143. 


\section{CHAPTER 7}

\section{The moderation by the serotonin transporter gene on the continuity/discontinuity of internalizing problems throughout adolescence and the role of family structure}

Maria Nobile, Paola Colombo, Valentina Bianchi, Monica Bellina, Andrea Greco, Eric Griez, Dario Monzani, Ombretta Carlet, Massimo Molteni and Giampaolo Perna 


\section{ABSTRACT}

Background. Lots of recent studies suggested that a functional polymorphism in the promoter region of the serotonin transporter gene (5HTTLPR) could be a genetic substrate for the stable trait of negative affectivity and that this trait is converted to psychopathology only under condition of stress, thus suggesting a moderating role of the 5-HTTLPR polymorphism in the relationship between environmental adversities and anxiety/depression. The effect of 5-HTTLPR polymorphism on the stability/instability of internalizing problems throughout critical developmental period like adolescence, taking into account the effects of chronic societal stressors, has yet to be examined. In this study we investigated the moderating role of 5-HTTLPR polymorphism on the stability/instability of internalizing problems throughout adolescence, taking also into account the possible interaction with two chronic societal stressors, namely socioeconomic status and family structure.

Methods. This is a five-years follow-up study of the genetic section of the PrISMA (Progetto Italiano Salute Mentale Adolescenti) project. The final study population included 287 subjects aged 15-19. To investigate the moderating role of 5-HTTLPR polymorphism in the relationships between socioeconomic status, family structure and internalizing problems at the first (W1) and the second wave (W2), a multigroup path analysis was employed, gender and age were included in the model.

Results. Examination of the model yielded interesting group differences: the pathway between internalizing problems and family structure at the first wave was positive and significant $(\beta=0.24, p<0.01)$ only for genotype $S$-allele carriers. Furthermore, based on the results of the Lagrange multiplier test, the two groups showed a significant difference in the pathway between internalizing problems at first and second wave $\left(X^{2}=3.89, p<.05\right)$, suggesting that the direct impact of internalizing problems at $\mathrm{W} 1$ on internalizing problems at W2 was greater for the 5HTTLPR genotype=S-allele carrier group than for 5-HTTLPR $=$ LL sample.

Conclusions. This longitudinal study contributes to the understanding of the processes underlying the continuity/discontinuity of internalizing behaviour during adolescence. We found that 5-HTTLPR polymorphism plays an important role in determining the stability of this psychopathological trait throughout a developmental period (i.e. 
adolescents) during which internalizing problems increase. A moderating role of 5-HTTLPR on the effect of family status in determining the presence of internalizing problems was found only during early adolescence. 


\section{INTRODUCTION}

Internalizing problems, such as anxiety, depression, and withdrawal, increase dramatically from childhood to adolescence, often continue into adulthood and account for a large proportion of mental health problems (Costello et al., 2011). Studies in children (Eley \& Stevenson, 1999; Rice, 2009), adolescents (Rice, 2009) and adults (Fanous \& Kendler, 2004) suggest that genetic risk factors substantially influence not only individual differences in internalizing problems but also stability/instability of anxious and depressive symptoms through different age periods (van der Valk et al., 2003) .

One of the most investigated genetic polymorphisms in internalizing disorder is a functional polymorphism in the promoter region of the serotonin transporter gene (5HTTLPR). The $5 \mathrm{HT}$-transporter (5-HTT) plays an important role in the regulation of $5-\mathrm{HT}$ re-uptake from the intrasynaptic cleft. The promoter activity of the 5-HTT gene is regulated by a deletion/insertion polymorphism in the proximal 5' promoter region, designated the 5HTT gene-linked polymorphic region (5-HTTLPR). The short (" $S$ ") allele in the 5-HTTLPR is associated with lower transcriptional efficiency of the promoter compared with the long (" $L$ ") allele (Lesch et al., 1996). Unaffected adults, children and adolescents with the $L-L$ genotype have been found to have significantly higher maximal uptake of serotonin in platelets compared to subjects with L-S or S-S genotypes (Nobile et al., 1999). The leading theory (Lesch et al.,1996; Jacobs et al., 2006) is that the $5-H T T L P R$ is a genetic substrate for negative affectivity or neuroticism (a latent personality trait). Negative affectivity prospectively predicts risk for all stress-related psychiatric disorders (Krueger at al., 1996). According to this theory, 5- HTTLPR S-carriers are characterized by the stable trait of negative affectivity that is converted to psychopathology only under conditions of stress. Negative affectivity seems to represent the potential for excitability of anxiety and fear neural circuits, and is characterized by an attentional bias toward negatively valenced information and a cognitive sensitivity to perceive threat (Watson \& Clark, 1984). Lots of studies of various stress reactive phenotypes suggest that $S$ carriers should be most reactive to the effects of adverse experience (for a review see Caspi et al., 2010).

Unfortunately, several large studies and two metaanalyses (Risch et al., 2009; Munafò et al., 2009) assessing the moderating role of 5HTTLPR in the relationship between depression and environmental adversities have shown results inconsistent with the previous hypothesis, especially in adolescent samples. However, two consecutive reviews of Uher and McGuffin (2008; 2010) suggest that the method used to assess 
environmental adversities could explain most discrepancies in those results. Studies using objective evidence or detailed interviews to assess environmental adversity consistently found an interaction in the expected direction. Studies relying on brief self-report measures of adversity often showed negative findings. That is, this interaction is revealed by objective indicators of adversity (for example 'family status') and may be attenuated by inaccuracies of retrospective self-report questionnaires. In a very large quantitative metaanalysis (based on 54 studies), Karg et al. (2011) reported strong evidence of genetic moderation of the relationship between stress and depression by 5-HTTLPR with the less functional $S$ allele associated with stress sensitivity. They also identified important study characteristics that influence study outcome, i.e. stressor type and stress assessment method. As underlined before, standard of stress assessment is a critical point: the evidence of genetic moderation was stronger among studies that used objective measures or interpersonal interviews to assess stress than among studies that used self-report questionnaires.

Another potential reason for the difference in stressor subgroup is the actual duration of the stressor: evidence for moderating effect was stronger for chronic stressors. On the other hand, as most of these studies are cross-sectional, we know little about the impact of genetic risk factors over time particularly during childhood and adolescence, which is when levels of internalizing symptoms and prevalence of anxiety and mood disorders change substantially (Costello et al., 2011). Some recent studies suggest that the strength of a genetic effect can vary by age, causing "age-varying associations." If not taken into account during the design and the analysis of a study, age-varying genetic associations can cause non-replication. In a developmental twin study on internalizing symptoms from middle childhood to young adulthood Kendler et al. (2008) found both genetic innovation (i.e. new genes that were previously without effect on a psychopathological trait become active) and genetic attenuation (i.e. genes that impact at one developmental age decline in their influence during the subsequent period).

The moderation of 5-HTTLPR polymorphism on the stability/instability of internalizing problems throughout critical developmental period (i.e. adolescence), taking into account the effects of chronic societal stressors, has yet to be examined. In this study we examined the moderating role of the 5HTTLPR on the relationship among two objective risk factors (namely, low socio economic status and family status) and internalizing symptoms (a broad psychopathological trait including both anxious and depressive symptoms) using time sensitive techniques across adolescence (from early- to late- adolescence). 


\section{METHODS}

\section{Subjects}

This study is a five year follow-up of the genetic section of the PrISMA project and of a longitudinal study on emotional and behavioural problems in a small suburban community (Ponte Lambro, PL), (Frigerio et al., 2006, 2009; Nobile et al., 2007, 2009). The original study population consisted of 607 Italian children (441 of PrISMA Sample and 166 of PL Sample) aged 10-14 years at the time of the first wave study (W1). Participants in the W1 study were invited by mail and/or by telephone to participate in the followup phase (W2). Of the 607 combined sample adolescents who were candidates in the $\mathrm{W} 2,22.4 \%(n=136)$ were no longer available due to change of address, incomplete mail/phone data or relocation. Questionnaires were thus sent in sealed envelopes to the families of the remaining 471 adolescents, with 287 subjects (60.9\%: 50.9\% boys, $49.1 \%$ girls, aged 15-19) accepting participation in the study.

\section{Procedures}

The study protocols were approved by the 'Eugenio Medea' Scientific Institute Ethical Committee. Parents' and adolescents' (when required) written informed consent was obtained for all participants.

Emotional and Behavioural assessment.

Parent-reported Internalizing behaviour was assessed using the Child Behaviour CheckList 6-18 (CBCL/6-18; Achenbach \& Rescorla,2001). This is an empirically-based checklist of social competence and behavioural problems filled out by parents of children and adolescents aged 6-18. According to the Achenbach System of Empirically Based Assessment (ASEBA) the CBCL/6-18 is divided into two major broad band scales: the Internalizing and the Externalizing Scales. The Internalizing Scale consists of 32 items and three subscales: Anxious/Depressed (e.g., "Self-conscious or easily embarrassed"), Withdrawn/Depressed (e.g. "would rather be alone than with others"), and Somatic Complaints (e.g. "overtired without good reason") Scales. All items were scored on a threepoint scale: not true, somewhat or sometimes true, very true or often true. The CBCL is designed to be self-explanatory for parents with reading skills as low as fifth grade level. In the present sample the Internalizing Scale showed an acceptable internal reliability at both waves (Cronbach's $\alpha=0.835$ and $\alpha=0.85$, respectively).

The individual and family characteristics of the sample were gathered by 
an 'ad hoc' form filled in by parents. This was an expanded version of the questionnaires originally employed during the PRISMA and PL W1 assessment that encompassed questions on family socio-demographic data (child's gender and age, number of brothers/sisters, parents' marital status coded as: married, cohabiting, divorced, separated, widowed, single), mother's and father's educational level, child education (school attended, repeated year at school, presence of a remedial teacher), possible contacts with the health services and family socio-economic status (SES) (Frigerio et al., 2006). We used parental employment as a measure of SES coded according to the Hollingshead 9-point scale for parental occupation (Hollingshead, 1975). A score of 1-9 was assigned to each parental job; when both parents were employed, the highest of the two scores was used. Since low SES, in contrast to medium and high SES, has been identified as a specific risk factor for a host of psychopathological behaviours (van Oort et al., 2011; Wadsworth \& Achenbach, 2005), we split SES into two classes of risk: low SES 1-3 (mean=2.89, s.d.=0.41) and medium to high SES 4-9 (mean=6.31, s.d.= 1.53). As adopted by major epidemiological surveys (Great Britain. Office for National Statistics. 2003), the categories of parental marital status were recoded for analysis into two classes of family structure: 'two-parent' (encompassing: married $-92.1 \%$, and cohabiting parents $-0.4 \%$ of the combined sample) and 'one-parent' families (encompassing divorced $-3.6 \%$, separated $-3.2 \%$, and single parents $-0.7 \%$ of the combined sample).

\section{DNA collection and extraction.}

Genomic DNA was extracted from mouthwash samples collected in $4 \%$ sucrose using the DNAzol Genomic DNA Isolation reagent (Molecular Research Center, Cincinnati). The methods for determining 5-HTTLPR polymorphisms were the same as described by Lesch et al. (1996). All amplification reactions were performed on a Mastercycler thermocycler (Eppendorf). The amplified products were analysed on $2 \%$ agarose gels.

\section{Data Analyses}

The 5-HTTLPR genotypes were divided into two groups: S-allele carriers (encompassing SS and LS subjects) and LL subjects. To test for bias due to attrition, socio-demographic and clinical differences between participants and non-participants in the W2 phase were preliminarily analysed by ANOVA or $\chi^{2}$, as required. In order to investigate the possible effect of belonging to PRISMA or PL sample on attrition rate, the variable 'sample' was simultaneously entered as independent variable in ANOVA. $\chi^{2}$ tests were stratified by 'sample' and homogeneity of different samples 
$\chi^{2}$ was tested by Breslow-Day test.

No significant differences were found between participants and non participants, even when stratified according to PL or PRISMA samples for scores at the Internalizing Problems, gender, age and family structure evaluated at W1. A slight but significant difference was found for SES at $W 1\left(\chi^{2}=4.347 ; p=0.041\right)$ with lower SES among non-participants, BreslowDay test of homogeneity was not significant suggesting that the two samples were homogenous for this attrition bias.

Since it has recently been shown that in some cases association between exposure to single parenthood in childhood and psychopathology may be explained by social and/or contextual factors associated with exposure to single parenthood (Fergusson et al., 2007), we preliminarily controlled the possible association of family structure with available socioeconomic measures. By multiple logistic regression analysis we found that class of family structure at $\mathrm{W} 1$ and $\mathrm{W} 2$ could not be predicted by parental SES at W1 and W2, mother's education, or father's education (p-range: 0.34 0.92). Independence of distribution of genotypes in relationship to both gender, family structure and SES was preliminary analyzed by $\chi^{2}$ statistic. The distributions of the Internalizing scale scores at W1 and W2 were square-root transformed to attenuate deviations from normality, which led to acceptable kurtosis $(-0.100$ and 0.372$)$, and skewness $(-0.098$ and $0.225)$ values.

To investigate the moderating role of 5-HTTLPR polymorphism in the relationships between socioeconomic status, family structure and internalizing problems at W1 and W2, a multigroup, path analysis was employed; in order to account for possible gender and age effects, these variables were included in the model. Model fit was firstly evaluated by $\chi^{2}$ statistic. Due to the sensitivity of the $\chi^{2}$ statistic to sample size, other indices were used, based on $\mathrm{Hu}$ and Bentler's (1999) recommendations: the standardized root-mean-square residual (SRMR, whose values $\leq 0.08$ indicate adequate fit), and the root-mean square error of approximation (RMSEA, whose values $\leq 0.06$ indicate adequate fit). In order to test for paths differences across the two levels of 5-HTTLPR polymorphism we used Lagrange multiplier tests (Kline, 1998); path that were significant at least in one path were constrained to increase the model's $\chi^{2}$ with respect to the original. In particular the modification indices were calculated to estimate the benefit of releasing each equality constraint. The statistical significance of the change in model-data-fit, using model $\chi^{2}$ decrease, was used as the criteria to release the constraints.

Data analyses were carried out using SPSS Statistics 17.0 and Mplus program (Version 6.11; Muthen \& Muthen, 1998-2010). 


\section{RESULTS}

\section{Preliminary analysis}

The socio-demographic characteristics of the study group and the raw score (mean \pm s.d.) for the Internalizing scales at both waves are shown in Table 1.

Consistent with previous studies investigating internalizing problems during adolescence (Lau and Eley 2008; Kendler et al 2008) there was a slight but not significant increase in time of the mean scores for Internalizing Problems, with a significant time $x$ gender interaction $(F=20.107 ; p<0.001)$ sustained by a marked increase of scores in time among girls and a slight decrease among boys.

Genotyping of 5-HTTLPR was successful for 274 subjects with complete socio-demographic and behavioural data. The 5-HTTLPR genotype frequencies in the total sample were: L/L $37.2 \%$, L/S $46.4 \%$, S/S $16.4 \%$; and the allele frequencies were: $L 60.4 \%$ and $S 39.6 \%$. The genotype frequencies were in Hardy-Weinberg equilibrium $\left(\chi^{2}=0.26 ; p=n . s\right.$. $)$, and similar to those previously reported (Lesh et al.,1996) for Caucasian populations. Genotype frequencies were evenly distributed, both trichotomously and dichotomously (S-carriers vs LL subjects) across genders $\left(\chi^{2}=1.43, p=n . s\right.$. and $\chi^{2}=1.22, p=n . s$., respectively), family structure at $\mathrm{W} 1\left(\chi^{2}=2.56, p=n . s\right.$. and $\chi^{2}=1.76, p=n . s$., respectively), family structure at $\mathrm{W} 2\left(\chi^{2}=0.97, p=\right.$ n.s. and $\chi^{2}=0.834, p=n . s$., respectively) and SES $\left(\chi^{2}=1.03, p=n s\right.$ and $\chi^{2}=1.00, p=n$. s., respectively).

\section{Path analysis: pattern of influences}

The exploratory model was tested for both levels of 5HTTLPR genotypes. In contrast to our hypotheses, socioeconomic status at W2 was excluded from the model as it has insufficient variance to test a multigroup path model. The two level paths with beta coefficients are shown in Figs. 1 and 2. The model provided an acceptable fit to the data both for the entire sample $\left(X^{2}=18.21, p=n . s\right.$.; $S R M R=0.03$, RMSEA $\left.=0.05\right)$ and also for the two levels of 5-HTTLPR genotypes $\left(X^{2}=12.70, p=n . s\right.$.; $S R M R=0.05$, RMSEA $=0.04$ for LL subjects; $X^{2}=10.19, p=n . s$.; $S R M R=0.03$, RMSEA = 0.00 for $S$-allele carriers) suggesting there was invariance of the model structure across 5HTTLPR genotype.

The results indicate that internalizing problems at W2 was positively influenced by internalizing problems at $\mathrm{W} 1$, and family structure at $\mathrm{W} 2$ was correlated with family structure at W1 for both samples. Nevertheless, no relations were found for either level between: age at $\mathrm{W} 1$ and internalizing problems at $\mathrm{W} 1$, age at $\mathrm{W} 2$ and internalizing problems at $\mathrm{W} 2$, gender and 
internalizing problems at $\mathrm{W} 1$, socioeconomic status at $\mathrm{W} 1$ and internalizing problems at $W 1$, socioeconomic status at $W 1$ and internalizing problems at W2, family structure at $W 1$ and $W 2$ and internalizing problems at W2.

Examination of the model also yielded interesting group differences. Although these paths were similar for both levels of 5HTTLPR genotype, differences were found for two coefficients as follows: -for genotype Sallele carrier, the pathway between internalizing problems at W2 regressing on gender was positive and significant, and the pathway between family structure at W1 and internalizing problems at W1 was positive and significant too; - for genotype=LL these two pathways were not significant.

Furthermore, based on the results of the Lagrange multiplier test, the two groups showed a significant difference in the pathway between internalizing problems at $\mathrm{W} 1$ and internalizing problems at $\mathrm{W} 2\left(X^{2}=3.89\right.$, $p<.05)$, suggesting that the direct impact of internalizing problems at W1 on internalizing problems at W2 was greater for the 5HTTLPR genotype=S-allele carrier group than for 5-HTTLPR =LL sample. However the two groups did not show a significant difference in the pathway between internalizing problems at $\mathrm{W} 2$ and gender and in the pathway between family structure at $\mathrm{W} 1$ and internalizing problems at $\mathrm{W} 1\left(\mathrm{X}^{2}=\right.$ $0.43, p=\mathrm{ns}$ and $\mathrm{X}^{2}=1.29, p=\mathrm{ns}$, respectively).

The model accounted for $24.4 \%$ of the variance in Internalizing problems at W2 for 5HTTLPR genotype= LL (Fig. 1), whereas for 5HTTLPR genotype $=\mathrm{S}$-allele carrier $34.0 \%$ of that same variance was accounted for (Fig. 2).

Finally, we repeated our analyses after recoding children according to the functional variants identified in the 5-HTTLPR L-allele, LA and LG (Hu et al., 2006). Since the $L G$ variant has a level of serotonin transporter expression comparable to the S-allele, and both have lower levels than LA, (Huet al. 2006) we reclassified children dichotomously between LA homozygotes vs. rest of the sample, and re-ran pathway analysis obtaining similar results. Internalizing problems at W2 was positively influenced by internalizing problems at W1 for both groups (5HTTLPR genotype= LaLa: $\beta=.41, p<.001 ; 5$ HTTLPR genotype $=$ Lg- or S-allele carrier: $\beta=.53$, $p<.001)$. Differences between the two groups were found for two coefficients: for 5HTTLPR genotype= Lg- or S-allele carrier, the pathway between internalizing problems at $\mathrm{W} 2$ regressed on gender was significant and positive $(\beta=.19, p<.01)$, and the pathway between family structure at $\mathrm{W} 1$ and internalizing problems at $\mathrm{W} 1$ was significant and positive $(\beta=.24$, $p<.001$ ), whereas these two pathways were not significant for 5HTTLPR 
genotype $=$ LaLa. Based on the results of the Lagrange multiplier test, the two groups showed a significant difference in the pathway between internalizing problems at W1 and internalizing problems at $\mathrm{W} 2\left(X^{2}=6.73\right.$, $p<.05)$, while the two groups did not show a significant difference in the pathway between internalizing problems at W2 and gender and in the pathway between family structure at $\mathrm{W} 1$ and internalizing problems at $\mathrm{W} 1$ $\left(X^{2}=0.66, p=n . s\right.$., and $X^{2}=1.02 p=$ n.s., respectively).

\section{DISCUSSION}

Many studies suggest that genetic factors play an important role in the continuity of internalizing symptoms throughout adolescence, but also that genes could encounter an attenuation or a potentiation of their effects during adolescence. In the same way different types of social adversities could play a different role according to the age period being studied. In this study we evaluated whether 5-HTTLPR moderation could play a role in the continuity of internalizing problems throughout adolescence, at the same time taking into account the interaction with two social adversities. Our data suggest not only that 5-HTTLPR polymorphism is involved in individual differences in anxiety/depression symptoms but also that 5HTTLPR plays an important role in determining the stability of the trait through a developmental period (i.e. adolescents) during which internalizing problems increase, especially in girls. In fact, earlyadolescence internalizing problems were revealed to be strong predictors of internalizing problems in late-adolescents, but in the 5-HTTLPR Scarriers group the relationship between symptoms at different age-stages was significantly higher when the impact of certain social adversities, gender and age was also taken into account. These data are largely in agreement with a bulk of data collected in adult population and suggesting a role of 5-HTTLPR polymorphism in a very stable trait characterized by both anxious and depressive symptoms often under clinical cut-off but that could easily progress towards mental illness under conditions of stress (Caspi et al., 2010). These data also support the validity of this theory in adolescents and in a life course perspective based on time-sensitive modeling techniques.

When we examined the moderating role of 5-HTTLPR on the effect of family status in determining the presence of internalizing problems, we found a significant effect of the family status at W1 on Internalizing problems at W1 in the 5-HTTLPR S-carriers group only. This data suggests a possible $\mathrm{G} \times \mathrm{E}$ interaction of 5-HTTLPR polymorphism and family status 
on internalizing problems during early adolescence. We did not find any effect of family status, assessed during both early- and late adolescence, alone or in interaction with 5-HTTLPR polymorphism, on internalizing problems during late-adolescence. This finding could be due to the progressive lack of influence of the familial background during adolescence, when different external influences, such as peer context or some aspects of neighbourhood, start to exert a greater effects on emotional and behavioural problems. According to this perspective, we could hypothesize that the gene is still active but, from this age onwards, it is going to interact with other kind of environmental adversities.

As adolescence is a period of rapid change in biological functioning, cognitive development and relocation in social roles and social environment, the study regarding gene-environment interaction should also consider the 'area' of social adversities occurrence as an important facets of whether the event is perceived and/or responded to as stressful. A more 'dynamic' $G \times E$ perspective could be useful in study regarding transition period, thus suggesting the use of different measures to assess stressful events in adolescence including dimensions related to family and parent events, but also to other events like, accident and illness events, sexual events, autonomy events, deviance events, relocation events, etc. These findings also suggest that inconsistent data on the moderational role of 5-HTTLPR on the link between environmental adversities and the etiology of mental illness during transition period (such as adolescence and senescence) (Uher \& Mc Guffin, 2010) could be related not only to the quality of environmental exposure measurement or to the type of environment itself, but also to the timing of exposure (Lupien et al., 2009). In contrast to our expectations, we did not find a significant effect of familial Socio-Economic Status on internalizing problems, which could be due to an attrition bias in our sample, leading to a lack of representativeness for low Socio-Economic Status adolescents. On the other hand, these results are in line with other studies evaluating the effects of parental SES on emotional and behavioural problems assessed by CBCL in the Italian population and reporting a significant effect of parental SES on Externalizing problems only (Frigerio et al., 2004, 2008)

There are several limitations in this study. Firstly, we had a less than optimal participation rate. However, participation is within the average reported for population-based investigations of mental health in several European countries including Norway (Battaglia et al., 2007) and Italy (Spatola et al., 2007). Secondly, while the psychometric variables did not affect agreement to participate in the study, non-participants were more likely to belong to socially disadvantaged backgrounds, as suggested by 
the excess of lower SES. The sample may thus not be fully representative of a general population. However, the fact that non-participant adolescents did not differ from participants in terms of internalizing problems suggests that loss from analysis of those subjects is unlikely to have introduced a major bias. Thirdly, in the second wave of this study the only sources on behavioural problems of adolescents were behaviour checklists filled in by parents. Other sources of information, such as the adolescents themselves, could have been beneficial. The use of 'repeated' measures obtained by the same informants (i.e. parents) could, in time, suffer from shared method variance and inflate the estimates of stability of behaviour. Fourthly, family structure is a broad, distal, family-wide risk factor which is likely to encompass -as a probable end-point of many marital relationships gone awry- several other subfactors including parental discord or instability, which can have a variable time effect across different families. Since family structure cannot be considered a simple 'environmental' risk factor, in that environmental and genetic risk factors correlate within families, the possibility remains that what we have interpreted as a geneby-environment interaction is rather a gene-by-gene interaction. Although the prevalence of one-parent families in our sample mirrors the average North-Eastern Italian general population prevalence (ISTAT, 2006), this remains a smaller figure than the average prevalence reported for other European, or North-American cultures. Thus, in this specific culture separation/divorce may index only the most severely dysfunctional families, and the 'one-parent' variable may have acted as a particularly strong enhancer of risk for internalizing symptoms over genotypes.

\section{CONCLUSION}

This longitudinal study contributes to the understanding of the processes underlying the continuity/discontinuity of internalizing behaviour during adolescence. We found that 5-HTTLPR polymorphism plays an important role in determining the stability of this psychopathological trait throughout a developmental period (i.e. adolescents) during which internalizing problems increase. In fact, early-adolescence internalizing problems were revealed to be strong predictors of internalizing problems in lateadolescence, especially in adolescents who carry a specific 5-HTTLPR genotype (i.e. S-allele carriers). In the same group we found a moderating role of 5-HTTLPR on the effect of family status in determining the presence of internalizing problems, but only during early adolescence. Future models of the developmental link between environmental adversities and 
internalizing behaviour therefore needs to consider not only the effect of gene $x$ environment interaction, but also that environmental adversities occurring during different time-frame may be associated with internalizing behaviour via different mechanism and that shifts in the strength of effects should be expected across the development. A more 'dynamic' $G \times E$ perspective could be useful in study regarding transition period, like adolescence, when rapid change in biological functioning, cognitive development and relocation in social roles and social environment are at work. 
Table 1. Socio-demographic and behavioural characteristics of the study group at first and second wave.

\begin{tabular}{|c|c|c|c|}
\hline Characteristics & $\begin{array}{l}\text { Boys } \\
(\mathrm{N}=146)\end{array}$ & $\begin{array}{c}\text { Girls } \\
(\mathrm{N}=141)\end{array}$ & $\begin{array}{l}\text { Total } \\
(\mathrm{N}=287)\end{array}$ \\
\hline \multicolumn{4}{|l|}{ Wave 1} \\
\hline Age $($ mean $\pm S D)$ & $12.10 \pm 0.89$ & $12.08 \pm 0.88$ & $12.09 \pm 0.89$ \\
\hline Family Structure: single parent $(\mathrm{n}, \%)$ & $8(5.50 \%)$ & $7(5.00 \%)$ & $15(5.30 \%)$ \\
\hline SES: Low (n, \%) & $15(10.30 \%)$ & $12(8.50 \%)$ & $27(9.40 \%)$ \\
\hline Internalizing Problems (mean \pm SD) & $7.66 \pm 6.00$ & $6.96 \pm 5.39$ & $7.32 \pm 5.71$ \\
\hline \multicolumn{4}{|l|}{ Wave 2} \\
\hline Age $($ mean $\pm S D)$ & $17.68 \pm 0.89$ & $17.72 \pm 0.92$ & $17.70 \pm 0.91$ \\
\hline Family Structure: single parent $(\mathrm{n}, \%)$ & $11(7.50 \%)$ & $14(9.90 \%)$ & $25(8.70 \%)$ \\
\hline SES: Low (n, \%) & $12(8.30 \%)$ & $10(7.10 \%)$ & $22(7.70 \%)$ \\
\hline Internalizing Problems (mean \pm SD) & $6.38 \pm 5.19$ & $8.65 \pm 7.37$ & $7.47 \pm 6.42$ \\
\hline
\end{tabular}




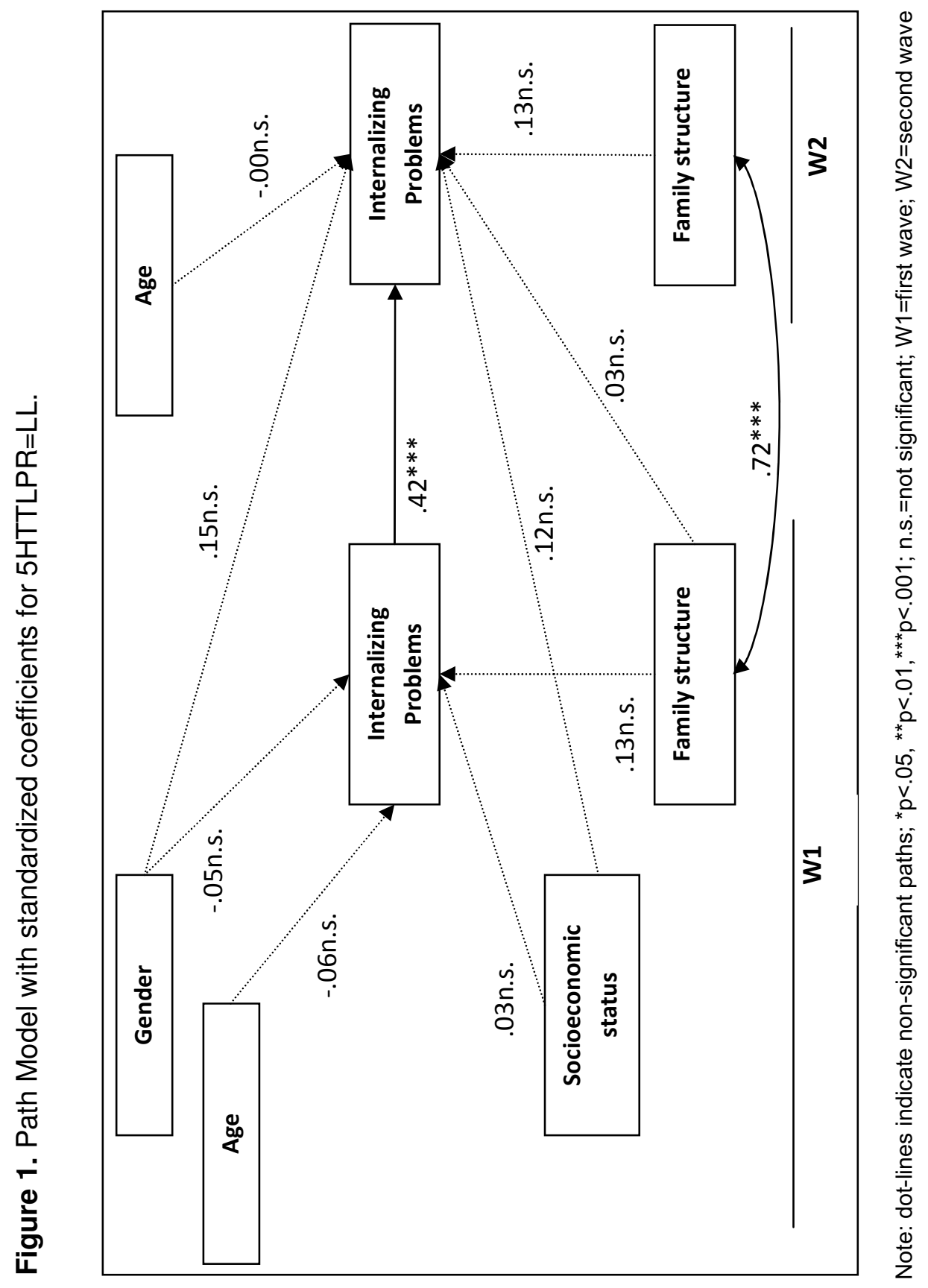




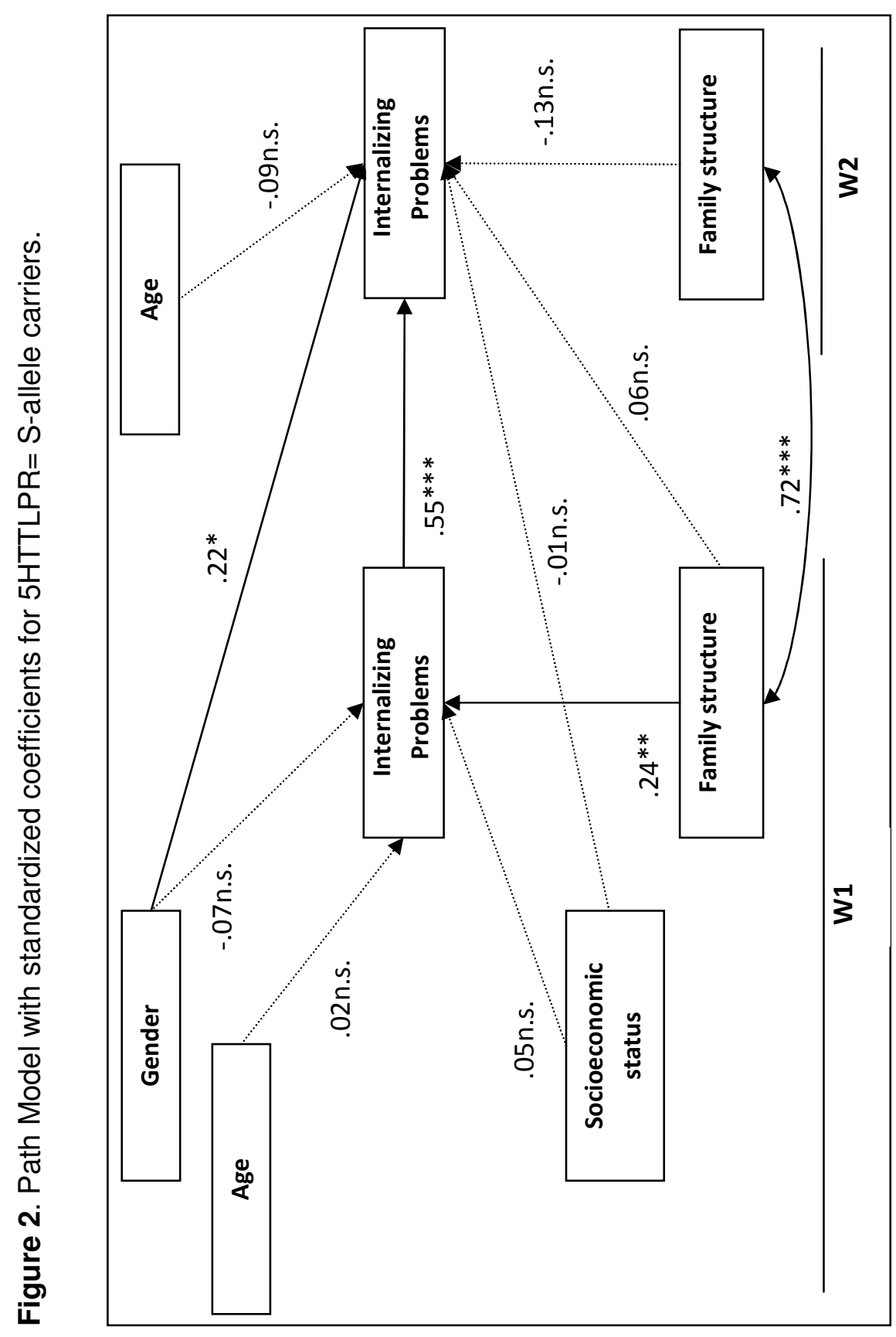

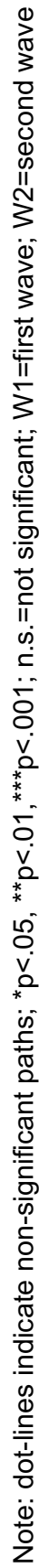




\section{REFERENCES}

Achenbach, T.M., \& Rescorla, L. A. (2001). Manual for the ASEBA schoolage forms and profiles.. University of Vermont, Research Center for Children, Youth, and Families: Burlington, VT.

Angold, A., \& Costello, E. J. (1993). Depressive comorbidity in children and adolescents: Empirical, theoretical, and methodological issues. The American Journal of Psychiatry, 150(12), 1779-1791.

Battaglia, M., Ogliari, A., Harris, J., Spatola, C. A., Pesenti-Gritti, P., Reichborn-Kjennerud, T., et al. (2007). A genetic study of the acute anxious response to carbon dioxide stimulation in man. Journal of Psychiatric Research, 41(11), 906-917.

Birmaher, B., Ryan, N. D., Williamson, D. E., Brent, D. A., \& Kaufman, J. (1996). Childhood and adolescent depression: A review of the past 10 years. part II. Journal of the American Academy of Child and Adolescent Psychiatry, 35(12), 1575-1583.

Birmaher, B., Williamson, D. E., Dahl, R. E., Axelson, D. A., Kaufman, J., Dorn, L. D., et al. (2004). Clinical presentation and course of depression in youth: Does onset in childhood differ from onset in adolescence? Journal of the American Academy of Child and Adolescent Psychiatry, 43(1), 6370.

Caspi, A., Hariri, A. R., Holmes, A., Uher, R., \& Moffitt, T. E. (2010). Genetic sensitivity to the environment: The case of the serotonin transporter gene and its implications for studying complex diseases and traits. The American Journal of Psychiatry, 167(5), 509-527.

Cataldo, M. G., Nobile, M., Lorusso, M. L., Battaglia, M., \& Molteni, M. (2005). Impulsivity in depressed children and adolescents: A comparison between behavioral and neuropsychological data. Psychiatry Research, 136(2-3), 123-133.

Costello, E. J., Copeland, W., \& Angold, A. (2011). Trends in psychopathology across the adolescent years: What changes when children become adolescents, and when adolescents become adults? Journal of Child Psychology and Psychiatry, and Allied Disciplines, 52(10), 1015-1025.

Costello, E. J., Copeland, W., \& Angold, A. (2011). Trends in psychopathology across the adolescent years: What changes when children become adolescents, and when adolescents become adults? 
Journal of Child Psychology and Psychiatry, and Allied Disciplines, 52(10), 1015-1025.

Costello, E. J., Pine, D. S., Hammen, C., March, J. S., Plotsky, P. M., Weissman, M. M., et al. (2002). Development and natural history of mood disorders. Biological Psychiatry, 52(6), 529-542.

Eley, T. C., \& Stevenson, J. (1999). Exploring the covariation between anxiety and depression symptoms: A genetic analysis of the effects of age and sex. Journal of Child Psychology and Psychiatry, and Allied Disciplines, 40(8), 1273-1282.

Fanous, A. H., \& Kendler, K. S. (2004). The genetic relationship of personality to major depression and schizophrenia. Neurotoxicity Research, 6(1), 43-50.

Fergusson, D. M., Boden, J. M., \& Horwood, L. J. (2007). Exposure to single parenthood in childhood and later mental health, educational, economic, and criminal behavior outcomes. Archives of General Psychiatry, 64(9), 1089-1095.

Frigerio, A., Rucci, P., Goodman, R., Ammaniti, M., Carlet, O., Cavolina, P., et al. (2009). Prevalence and correlates of mental disorders among adolescents in italy: The PrISMA study. European Child \& Adolescent Psychiatry, 18(4), 217-226.

Frigerio, A., Vanzin, L., Pastore, V., Nobile, M., Giorda, R., Marino, C., et al. (2006). The italian preadolescent mental health project (PrISMA): Rationale and methods. International Journal of Methods in Psychiatric Research, 15(1), 22-35.

Gotlib, I. H., Lewinsohn, P. M., \& Seeley, J. R. (1995). Symptoms versus a diagnosis of depression: Differences in psychosocial functioning. Journal of Consulting and Clinical Psychology, 63(1), 90-100.

Great Britain. Office for National Statistics. (2003). In Meltzer H. (Ed.), Persistence, onset, risk factors and outcomes of childhood mental disorders. London: TSO.

Hollingshead AB. (1975). Four factor index of social status. Unpublished Document,

Hu, L., \& Bentler, P. M. (1999). Cutoff criteria for fit indexes in covariance structure analysis: Conventional criteria versus new alternatives. Structural Equation Modeling: A Multidisciplinary Journal, 6, 1-55. 
Hu, L. T., Bentler, P. M., \& Kano, Y. (1992). Can test statistics in covariance structure analysis be trusted? Psychological Bulletin, 112(2), 351-362.

ISTAT. (2006). . Roma: Istituto Nazionale di Statistica.

Jacobs, N., Kenis, G., Peeters, F., Derom, C., Vlietinck, R., \& van Os, J. (2006). Stress-related negative affectivity and genetically altered serotonin transporter function: Evidence of synergism in shaping risk of depression. Archives of General Psychiatry, 63(9), 989-996.

Karg, K., Burmeister, M., Shedden, K., \& Sen, S. (2011). The serotonin transporter promoter variant (5-HTTLPR), stress, and depression metaanalysis revisited: Evidence of genetic moderation. Archives of General Psychiatry, 68(5), 444-454.

Kendler, K. S., Gardner, C. O., \& Lichtenstein, P. (2008). A developmental twin study of symptoms of anxiety and depression: Evidence for genetic innovation and attenuation. Psychological Medicine, 38(11), 1567-1575.

Kline, R. B. (1998). Principles and practice of structure equation modeling.. New York: Guilford Press.

Kovacs, M. (1996). Presentation and course of major depressive disorder during childhood and later years of the life span. Journal of the American Academy of Child and Adolescent Psychiatry, 35(6), 705-715.

Krueger, R. F., Caspi, A., Moffitt, T. E., Silva, P. A., \& McGee, R. (1996). Personality traits are differentially linked to mental disorders: A multitraitmultidiagnosis study of an adolescent birth cohort. Journal of Abnormal Psychology, 105(3), 299-312.

Lau, J. Y., \& Eley, T. C. (2008). Disentangling gene-environment correlations and interactions on adolescent depressive symptoms. Journal of Child Psychology and Psychiatry, and Allied Disciplines, 49(2), 142-150.

Lesch, K. P., Bengel, D., Heils, A., Sabol, S. Z., Greenberg, B. D., Petri, S., et al. (1996). Association of anxiety-related traits with a polymorphism in the serotonin transporter gene regulatory region. Science (New York, N.Y.), 274(5292), 1527-1531.

Lewinsohn, P. M., Gotlib, I. H., \& Seeley, J. R. (1995). Adolescent psychopathology: IV. specificity of psychosocial risk factors for depression and substance abuse in older adolescents. Journal of the American Academy of Child and Adolescent Psychiatry, 34(9), 1221-1229.

Lewinsohn, P. M., Rohde, P., \& Seeley, J. R. (1998). Major depressive 
disorder in older adolescents: Prevalence, risk factors, and clinical implications. Clinical Psychology Review, 18(7), 765-794.

Lewinsohn, P. M., Seeley, J. R., Buckley, M. E., \& Klein, D. N. (2002). Bipolar disorder in adolescence and young adulthood. Child and Adolescent Psychiatric Clinics of North America, 11(3), 461-75, vii.

Lewinsohn, P. M., Seeley, J. R., Buckley, M. E., \& Klein, D. N. (2002). Bipolar disorder in adolescence and young adulthood. Child and Adolescent Psychiatric Clinics of North America, 11(3), 461-75, vii.

Lupien, S. J., McEwen, B. S., Gunnar, M. R., \& Heim, C. (2009). Effects of stress throughout the lifespan on the brain, behaviour and cognition. Nature Reviews. Neuroscience, 10(6), 434-445.

Munafo, M. R., Durrant, C., Lewis, G., \& Flint, J. (2009). Gene X environment interactions at the serotonin transporter locus. Biological Psychiatry, 65(3), 211-219.

Muthén, L.K. and Muthén, B.O. (1998-2010). Mplus User's guide. sixth edition. Los Angeles, CA: Muthén \& Muthén.

Newman, D. L., Moffitt, T. E., Caspi, A., Magdol, L., Silva, P. A., \& Stanton, W. R. (1996). Psychiatric disorder in a birth cohort of young adults: Prevalence, comorbidity, clinical significance, and new case incidence from ages 11 to 21. Journal of Consulting and Clinical Psychology, 64(3), 552562.

Nobile, M., Begni, B., Giorda, R., Frigerio, A., Marino, C., Molteni, M., et al. (1999). Effects of serotonin transporter promoter genotype on platelet serotonin transporter functionality in depressed children and adolescents. Journal of the American Academy of Child and Adolescent Psychiatry, 38(11), 1396-1402.

Nobile, M., Giorda, R., Marino, C., Carlet, O., Pastore, V., Vanzin, L., et al. (2007). Socioeconomic status mediates the genetic contribution of the dopamine receptor D4 and serotonin transporter linked promoter region repeat polymorphisms to externalization in preadolescence. Development and Psychopathology, 19(4), 1147-1160.

Nobile, M., Rusconi, M., Bellina, M., Marino, C., Giorda, R., Carlet, O., et al. (2009). The influence of family structure, the TPH2 G-703T and the 5HTTLPR serotonergic genes upon affective problems in children aged 10-14 years. Journal of Child Psychology and Psychiatry, and Allied Disciplines, 50(3), 317-325. 
Nobile, M., Rusconi, M., Bellina, M., Marino, C., Giorda, R., Carlet, O., et al. (2010). COMT Val158Met polymorphism and socioeconomic status interact to predict attention deficit/hyperactivity problems in children aged 10-14. European Child \& Adolescent Psychiatry, 19(7), 549-557.

Rao, U., \& Chen, L. A. (2009). Characteristics, correlates, and outcomes of childhood and adolescent depressive disorders. Dialogues in Clinical Neuroscience, 11(1), 45-62.

Rice, F. (2009). The genetics of depression in childhood and adolescence. Current Psychiatry Reports, 11(2), 167-173.

Risch, N., Herrell, R., Lehner, T., Liang, K. Y., Eaves, L., Hoh, J., et al. (2009). Interaction between the serotonin transporter gene (5-HTTLPR), stressful life events, and risk of depression: A meta-analysis. JAMA : The Journal of the American Medical Association, 301(23), 2462-2471.

Rutter's child and adolescent psychiatry(2008). In Rutter M. (Ed.), (5th ed.). Oxford: Blackwell.

Spatola, C. A., Fagnani, C., Pesenti-Gritti, P., Ogliari, A., Stazi, M. A., \& Battaglia, M. (2007). A general population twin study of the CBCL/6-18 DSM-oriented scales. Journal of the American Academy of Child and Adolescent Psychiatry, 46(5), 619-627.

Uher, R., \& McGuffin, P. (2008). The moderation by the serotonin transporter gene of environmental adversity in the aetiology of mental illness: Review and methodological analysis. Molecular Psychiatry, 13(2), 131-146.

Uher, R., \& McGuffin, P. (2010). The moderation by the serotonin transporter gene of environmental adversity in the etiology of depression: 2009 update. Molecular Psychiatry, 15(1), 18-22.

van der Valk, J. C., van den Oord, E. J., Verhulst, F. C., \& Boomsma, D. I. (2003). Genetic and environmental contributions to stability and change in children's internalizing and externalizing problems. Journal of the American Academy of Child and Adolescent Psychiatry, 42(10), 1212-1220.

van Oort, F. V., van der Ende, J., Wadsworth, M. E., Verhulst, F. C., \& Achenbach, T. M. (2011). Cross-national comparison of the link between socioeconomic status and emotional and behavioral problems in youths. Social Psychiatry and Psychiatric Epidemiology, 46(2), 167-172.

Wadsworth, M. E., \& Achenbach, T. M. (2005). Explaining the link between low socioeconomic status and psychopathology: Testing two mechanisms 
of the social causation hypothesis. Journal of Consulting and Clinical Psychology, 73(6), 1146-1153.

Watson, D., \& Clark, L. A. (1984). Negative affectivity: The disposition to experience aversive emotional states. Psychological Bulletin, 96(3), 465490. 


\section{CHAPTER 8}

\section{Summary and concluding remarks}

The present work aimed to explore the role of adversities, of the polymorphism in the promoter region of the human serotonin transporter gene (5-HTTLPR), and of their interactions in the causation of childhood and adolescent depression under a developmental perspective.

The complex role of adversities (i.e. stressful life events) in causing and maintaining depressive symptoms over time in adolescents was investigated in Chapter 2. We used a five-years-follow-up study to assess continuity and discontinuity of adolescent depressive symptoms while taking into account the multiple covariation of internalizing and externalizing psychopathological traits and the complex role of recent stressful life events (SLEs) in a general population sample. Our data suggest that the most reliable predictor of affective problems in late adolescence is the presence of high affective problems in preadolescence, but also that adolescent Affective Problems were significantly predicted by Somatic and Oppositional Defiant Problems in early adolescence thus confirming the constructs of equifinality (i.e. diversity of pathways leading to a common outcome) for developmental affective problems. Further analysis revealed that recent SLEs partially mediated the heterotypic progression of Oppositional Defiant Problems towards the development of Affective Problems. We also found that a higher number of recent SLEs predicted higher Affective Problems longitudinally, confirming the importance of adversities in contributing to the path leading to unfolding of depression in youth. Furthermore, we found that higher early-adolescent Affective Problems predicted a higher number of SLEs in adolescence in a univariate approach. Controlling for other psychopathologies, i.e. the full spectrum of behaviours assessed by $\mathrm{CBCL}$ DSM-Oriented scales, Oppositional Defiant Problems was the only dimension still able to predict a significantly higher number of SLEs. These data are partly in agreement with developmental models of 
psychopathology suggesting a transactional perspective in which stress exposure contributes to depressive symptoms and in turn depressed children and adolescents contribute to negative events through their own behavior (Hammen et al., 2006). In fact our multivariate approach allows us to suggest that externalizing symptoms, often co-morbid with depression in youngster, constitutes a relatively robust predictor of adversities in youth. Mediational analysis revealed that recent SLEs partially accounted for the heterotypic progression of Oppositional Defiant Problems towards the development of Affective Problems. Our data confirmed longitudinally the cross-sectional findings of Rowe et al. (2006), i.e. that adversities support the association between oppositionality and depressed mood in youth. Moreover, our follow-up perspective allowed us to investigate and to confirm the existence of a reciprocal cycle of stress generation in maintaining specific developmental trajectories across externalizing and internalizing domains. These data may be able to enlighten us on the mechanisms underlying the continuity/etiology of both Oppositional Defiant and Depression Problems from early- to lateadolescence: adversities in adolescence concur to the etiology/maintenance of these disturbances in addition to adversities having occurred earlier in life. This chain of risk appears to merit particular attention, although it should not be thought of as deterministic. For instance, if environmental reinforcements are disrupted, recovery and adaptation become likely.

The main role of 5-HTTLPR polymorphism in childhood and adolescent depression was explored in Chapter 3 and Chapter 4. In Chapter 3 we explored the effect of the 5-HTTLPR polymorphism, known to regulate gene expression in vitro, on the serotonin re-uptake in vivo; that is, we looked at possible associations between 5-HTT promoter variants and differential regulation of platelet $5 \mathrm{HTT}$ functionality parameters in drugnaive healthy and depressed children and adolescents. In fact, the platelet serotonin transporter (5-HTT) system is accepted as a less invasive model of the 5-HT nerve terminal since it shares embryological ancestry, biochemistry, transport protein gene sequences and functionality (Owens \& Nemeroff, 1994). Among normal controls, subjects who were homozygous for the L allele of the 5-HTT promoter gene had an uptake 1.4 to 1.9 times higher than that of subjects carrying one or two copies of the $S$ variant, and subjects with the L/S and S/S genotypes were not significantly different from each other. These figures are consistent with the association observed between $\mathrm{L}$ allele and increased 5 -HT uptake in lymphoblast cell lines (Lesch et al.,1996), and in platelets of adult healthy controls (Greenberg et al.,1999), suggesting a dominant- rather than 
codominant- effect for the $S$ allele. We also found a significant decrease of maximum serotonin uptake ( $V \max$ ) in drug-naive depressed children and adolescents for the first time. A comparison between diagnostic groups showed that the L/L genotype determined a substantial difference in serotonin uptake, while the short variants (L/S or S/S) brought about minimal differences in platelet serotonin uptake. These data altogether suggest that during a depressive episode subjects carrying both $L$ alleles may be exposed to epistatic/epigenetic effects specifically affecting serotonin uptake. None of the other platelets serotonin parameters are influenced by the 5-HTT genotype, thus confirming prior findings of platelet studies in adult human subjects (Greenberg et al., 1999).

In Chapter 4 we explored the possible association between child- and early- adolescent-onset major depression and dysthymia and the 5HTTLPR locus, using both the case-control and family-based genetic approaches. The results of the case-control analyses support an association between 5-HTTLPR locus and childhood and adolescent Depressive Disorder with a small but significant effect of the S-allele and a moderately higher risk for Depressive Disorder, as indicated by the odds ratio. The family-based association analyses, which are more persuasive because they are not prone to stratification bias, reveal that the S-allele was preferentially transmitted to children with Depressive Disorder. These results suggest a role of the 5-HTTLPR locus in child negative emotionality as a general construct of liability to anxiety and depression (Auerbach et al., 2001) and they are consistent with some (Collier et al. 1996; Gutierrez et al. 1998), but not all (Clarke et al., 2010), studies of adults with affective disorders.

The hypothesis of a possible effect of the interactions of 5-HTTLPR polymorphism and adversities on childhood and adolescent psychopathology, under a gene-environment, perspective was explored in Chapter 5 and 6.

In Chapter 5, in a relatively unselected general population sample of Northern Italian early adolescents (aged 10-14 years) we found evidence that the 5-HTTLPR polymorphism - alone and in apparent gene-byenvironment interaction with an environmental risk factor (i.e. family structure) - is associated with higher scores at the CBCL/6-18 Affective Problems DSM-Oriented Scale. We found that adolescents belonging to a 'one-parent' family and carrying also the 5-HTTLPR 'S allele' showed a higher risk of developing depressive symptoms; a role for environmental factors in moderating the contribution of this specific genetic polymorphisms to human variability in depressive symptoms is thus suggested. Our finding of a significant interaction between 5-HTTLPR 
genotype and a possible environmental risk factor is broadly consistent with several studies suggesting that the 5-HTTLPR short allele yields greater risk concomitantly with exposure to stressful events (Caspi et al., 2010) especially with those based on objective evidence or detailed interviews to assess environmental adversity (for a review see Uher \& McGuffin, 2008; Karg 2011) as discussed hereinafter.

In Chapter 6 we examined the independent and joint effects of the 5HTTLPR, of the dopamine receptor D4 (DRD4) and of a societal moderator, namely family socio-economic status (SES) upon rule-breaking and aggressive behaviours measured with the Child Behaviour CheckList/6-18 in the same general population sample of Northern Italian early adolescents. We found evidence, based on both one locus and twoloci genotype analyses, that low SES and DRD4 'long' allele and 5 -HTTLPR 'L' allele, both alone and in interaction, are associated with higher aggressive behaviour scores. These findings are compatible with those of other studies investigating the influence and the relationship of the same polymorphisms upon different measures of externally oriented behaviours in childhood (Auerbach et al., 2001; Lakatos et al. 2003) and in adulthood (Benjamin et al., 2002). Specifically, Benjamin et al. (2002) suggested that the long alleles of DRD4 and the short alleles of 5-HTTLPR oppose each other's effects, in that the DRD4 long alleles promote approach and extraverted behaviours, whereas the short alleles of 5HTTLPR promote avoidance behaviours. In other words, these results confirms the specific role of the ' $S$ ' allele of 5-HTTLPR in internalizing behaviour, and inasmuch as our data are in keeping with studies of infancy and adulthood, they add evidence to the hypothesis that this antagonistic interaction mechanism may be present across the whole span of human life. Furthermore, consistent with studies that showed the effects of societal moderators on the heritability of externalized behaviours across different segments of the population, we suggest that diminished social constraints associated with low parental SES may act as enhancers of the genetic influence of specific DRD4 and 5-HTTLPR alleles over aggressive behaviours in early adolescence.

In Chapter 7 we investigated the moderating role of 5-HTTLPR polymorphism on the stability/instability of internalizing problems throughout adolescence, taking also into account the possible interaction with two chronic societal stressors, by using time-sensitive modelling techniques. We analyzed social, behavioural and genetic data from a fiveyear follow-up general population study using Structural Equation Modelling. We found that the pathway between internalizing problems and family structure at the first wave (early-adolescents aged 10-14) was 
positive and significant $(\beta=0.24, p<0.01)$ only for adolescents carrying $S$ allele genotype. Furthermore the two groups (LL vs S-allele carriers genotype) were significantly different in the pathway between internalizing problems at first and second wave (late-adolescents aged 15-19), suggesting that the direct impact of internalizing problems at first wave on internalizing problems at second wave was greater for the S-allele carriers group. Data from this longitudinal study suggest that the 5-HTTLPR polymorphism plays an important role in determining the stability of this psychopathological trait throughout a developmental period (i.e. adolescence) during which internalizing problems increase. A moderating role of 5-HTTLPR on the effect of family status in determining the presence of internalizing problems was found only during early-adolescence.

Overall, we based our investigations upon reasonable nomological network evidence that the environment moderates the behavioural effect of a biological system (serotonergic neurotransmission) involved in the disorder under study (affective symptoms), and that a candidate gene (5HTTLPR) is associated with reactivity to environmental pathogens. Our data are largely in agreement with many studies testing the hypothesis that the 5-HTTLPR moderates the effect of stress on depression phenotypes (for an extensive review see Caspi et al., 2010). Although the first report of this gene-environment interaction was followed by a number of replications enhancing confidence in this GxE interaction as a causal mechanism in depression, recently, several large studies and two metaanalysis (Risch et al., 2009 and Munafò et al., 2009) have shown results inconsistent with the original findings.

Two consecutive reviews of Uher and Mc Guffin (2008; 2010) suggests that the method used to assess environmental adversities could explain most discrepancies in results. Studies using objective evidence or detailed interviews to assess environmental adversity consistently found an interaction in the expected direction. Studies relying on brief self-report measures of adversity often showed negative findings. That is, this interaction is revealed by objective indicators of adversity (for example 'family status') and may be attenuated by inaccuracies of retrospective self-report questionnaires. In a very large quantitative metaanalysis (based on 54 studies), Karg et al. (2011) reported strong evidence of genetic moderation of the relationship between stress and depression by 5 -HTTLPR with the less functional $S$ allele associated with stress sensitivity. They also identified important study characteristics that influence study outcome, i.e. stressor type and stress assessment method. As underlined before, standard of stress assessment is a critical point: the 
evidence of genetic moderation was stronger among studies that used objective measures or interpersonal interviews to assess stress than among studies that used self-report questionnaires.

Another potential reason for the difference in stressor subgroup is the nature of the stressor studied: evidence for moderating effect was stronger for chronic stressors.

In addition, further evidence links the 5-HTTLPR genotypes to a broader range of stress-reactive phenotype (for a review see Caspi et al., 2010) and suggests a more general theory:

5 -HTTLPR carriers are characterized by the stable trait of negative affectivity (or neuroticism) that is converted to psychopathology only under conditions of stress. Negative affectivity represents the potential for excitability of anxiety and fear neural circuits, and is characterized by an attentional bias toward negatively valenced information and a cognitive sensitivity to perceive threat (Watson \& Clark, 1984).

While evidence for the 5HTTLPR stress sensitivity hypothesis is accumulating, many questions still remain unresolved. How does exposure to adverse experience, especially one that is psychosocial in its nature, 'get under the skin', compromising a child's development? How can children experiencing the same environmental adversity develop a very different disorder later in life?

Genetic epidemiology and experimental neuroscience now need to join forces to include a new generation of studies in order to unravel the complex mechanisms that underlie gene-environment interactions:

(i) Studies that compare human genotype groups on their responses to experimentally administered environmental stimuli, using functional neuroimaging measures or other peripheral psychophysiological measures.

Specifically, a new generation of research in experimental psychopathology that exposes individuals with different genotypes to stress-inducing situations or affectively-charged stimuli in order to examine genetic control of sensitivity to the environment by measuring their stress reactivity is emerging. For example, research on fear conditioning-whose neural mechanisms involve the amygdala - also reveals that variation in the 5-HTTLPR is implicated in how people learn to fear new stimuli. Compared to LL homozygotes, S-allele carriers acquire potentiated startle reactions to stimuli associated with an aversive event, and this acquired fear is more resistant to extinction. This research suggests that S-carriers are more likely to pick up and retain fear of stimuli associated with 
threat (Lonsdorf et al., 2009). Research using acute stress-induction paradigms shows that 5 -HTTLPR variation is associated with variations in cortisol response to a psychosocial challenge. Adolescents with two copies of the $S$ allele showed a marked increase in cortisol immediately following exposure to stress and a slow return to baseline (Gotlib et al., 2008). This research not only suggests that genetic susceptibility to HPA-axis dysregulation is detectable in SS carriers as early as adolescence, but also that those individuals have a higher reactivity to stressors than non-SS individuals.

(ii) Epidemiological cohort studies collecting neuroscience measures of individual differences (i.e. neuropsychological tests, heart rate reactivity and immune system markers).

Unfortunately, taking neuroscience measurements in large cohorts can be costly and, for functional imaging paradigms, prohibitive. However, this could be the way to explore not only genetically moderated environment-to-disorder associations but also to cast light on genetically moderated environment-to-brain associations.

(iii) Studies investigating sets of genetic polymorphisms that are active in the pathophisiology of a disorder. For example, in relation to childhood and adolescent depression, information about the biology of psycho-social stress can be used as a first step to characterize a set of genes that define a genotype that is vulnerable as opposed to resilient to environmental adversities. 


\section{REFERENCES}

Caspi, A., Hariri, A. R., Holmes, A., Uher, R., \& Moffitt, T. E. (2010). Genetic sensitivity to the environment: The case of the serotonin transporter gene and its implications for studying complex diseases and traits. The American Journal of Psychiatry, 167(5), 509-527.

Clarke, H., Flint, J., Attwood, A. S., \& Munafo, M. R. (2010). Association of the 5- HTTLPR genotype and unipolar depression: A meta-analysis. Psychological Medicine, 40(11), 1767-1778.

Collier, D. A., Stober, G., Li, T., Heils, A., Catalano, M., Di Bella, D., et al. (1996). A novel functional polymorphism within the promoter of the serotonin transporter gene: Possible role in susceptibility to affective disorders. Molecular Psychiatry, 1(6), 453-460.

Gotlib, I. H., Joormann, J., Minor, K. L., \& Hallmayer, J. (2008). HPA axis reactivity: A mechanism underlying the associations among 5 -HTTLPR, stress, and depression. Biological Psychiatry, 63(9), 847-851.

Gutierrez, B., Pintor, L., Gasto, C., Rosa, A., Bertranpetit, J., Vieta, E., et al. (1998). Variability in the serotonin transporter gene and increased risk for major depression with melancholia. Human Genetics, 103(3), 319-322.

Karg, K., Burmeister, M., Shedden, K., \& Sen, S. (2011). The serotonin transporter promoter variant (5-HTTLPR), stress, and depression metaanalysis revisited: Evidence of genetic moderation. Archives of General Psychiatry, 68(5), 444-454.

Lonsdorf, T. B., Weike, A. I., Nikamo, P., Schalling, M., Hamm, A. O., \& Ohman, A. (2009). Genetic gating of human fear learning and extinction: Possible implications for gene-environment interaction in anxiety disorder. Psychological Science, 20(2), 198-206.

Middeldorp, C. M., de Geus, E. J., Beem, A. L., Lakenberg, N., Hottenga, J. J., Slagboom, P. E., et al. (2007). Family based association analyses between the serotonin transporter gene polymorphism (5-HTTLPR) and neuroticism, anxiety and depression. Behavior Genetics, 37(2), 294-301.

Middeldorp, C. M., Slof-Op 't Landt, M. C., Medland, S. E., van Beijsterveldt, C. E., Bartels, M., Willemsen, G., et al. (2010). Anxiety and depression in children and adults: Influence of serotonergic and neurotrophic genes? Genes, Brain, and Behavior, 9(7), 808-816.

Munafo, M. R., Durrant, C., Lewis, G., \& Flint, J. (2009). Gene X environment interactions at the serotonin transporter locus. Biological 
Psychiatry, 65(3), 211-219.

Risch, N., Herrell, R., Lehner, T., Liang, K. Y., Eaves, L., Hoh, J., et al. (2009). Interaction between the serotonin transporter gene (5-HTTLPR), stressful life events, and risk of depression: A meta-analysis. JAMA : The Journal of the American Medical Association, 301(23), 2462-2471.

Uher, R., \& McGuffin, P. (2008). The moderation by the serotonin transporter gene of environmental adversity in the aetiology of mental illness: Review and methodological analysis. Molecular Psychiatry, 13(2), 131-146.

Uher, R., \& McGuffin, P. (2010). The moderation by the serotonin transporter gene of environmental adversity in the etiology of depression: 2009 update. Molecular Psychiatry, 15(1), 18-22. 
CHAPTER 8 


\section{SAMENVATTING}

Dit onderzoek heeft als doel de rol te verkennen van tegenslagen, van het polymorfisme in de promoter regie van het menselijk serotonine transport gen (5-HTTLPR) en van hun interacties die leiden tot depressie bij kinderen en jongeren in een ontwikkelings perspectief.

De complexe rol van tegenslagen (b.v. stressful life events) bij het veroorzaken en het lang aanhouden van symptomen van depressie bij jongeren is onderzocht in Hoofdstuk 2. We hebben een 5 jaar durende follow-up studie gebruikt om de continuïteit en discontinuïteit te evalueren van symptomen van depressie bij jongeren en tegelijkertijd rekening gehouden met de veelvoudige covariatie van internalisatie en externalisatie van psychopathologische karaktertrekken en de complex rol van recente stressful life events (SLEs) in een algemene bevolkingsgroep. Onze gegevens suggereren dat de meest betrouwbare predictor van affectieve stoornissen in de late puberteit de aanwezigheid is van grote affectieve stoornissen in de vroege puberteit, maar ook dat Affectieve Stoornissen bij jongeren bovenmatig voorspeld worden door Somatische en Oppositioneel-opstandige Problemen in de vroege puberteit, hetgeen het construct bevestigt van de equifinaliteit (i.e. de veelvoudigheid van trajecten die leiden tot een gezamenlijk resultaat) van affectieve stoornissen in de ontwikkeling. Verdere analyse heeft onthuld dat recente SLEs de heterotypische vooruitgang van Oppositioneel-opstandige Problemen gedeeltelijk mediëren ten opzichte van de ontwikkeling van Affectieve Stoornissen. Verder ontdekten we dat hoe meer recente SLEs er zijn des te groter de longitudine is in Affectieve Stoornissen, hetgeen het belang bevestigt van tegenslagen die bijdragen tot het traject dat leidt tot het zich ontvouwen van depressie bij de jeugd. Voorts ontdekten we dat hoe groter de Affectieve Stoornissen in de vroege puberteit zijn des te meer SLEs zich voordoen in de puberteit in een univariate aanpak. Deze gegevens komen gedeeltelijk overeen met de ontwikkelingsmodellen van psychopathologie en suggereren een transactioneel perspectief, waarin het blootstellen aan stress bijdraagt tot depressieve symptomen, en depressieve kinderen en jongeren op hun beurt wegens hun eigen gedrag bijdragen tot negatieve gebeurtenissen (Hammen et al., 2006). Dankzij onze multivariate aanpak mogen we inderdaad suggereren dat het externaliseren van symptomen, vaak comorbide met depressie bij jongeren, een relatief sterke predictor vormt van tegenslagen in de jeugd. Een mediatie analyse heeft onthuld dat recente SLEs gedeeltelijk verantwoordelijk zijn voor de heterotypische voortgang van Oppositioneelopstandige Problemen ten opzichte van de ontwikkeling van Affectieve 
Stoornissen. Onze gegevens bevestigen longitudinaal de cross-sectionele bevindingen van Rowe et al. (2006), i.e. dat tegenslagen de samenhang ondersteunen tussen oppositionaliteit en depressief humeur bij jongeren. Bovendien, dankzij ons follow-up perspectief, konden we het bestaan onderzoeken en bevestigen van een wederzijdse cyclus van stress vorming bij de handhaving van specifieke ontwikkelings trajecten langs externalisatie en internalisatie domeinen.

De voornaamste rol van 5-HTTLPR polymorfisme in depressie bij kinderen en jongeren is onderzocht in Hoofdstukken 3 en 4. In Hoofdstuk 3 hebben we het effect onderzocht van het 5-HTTLPR polymorfisme, dat zoals bekend de gen expressie in vitro regelt, op de heropname van serotonine in vivo; dat wil zeggen, we hebben de mogelijke samenhang waargenomen tussen 5 -HTT promoter varianten en de differentiaal regeling van functionaliteits maatstaven van $5 \mathrm{HTT}$ bloedplaatjes bij medicijn-naïeve gezonde en depressieve kinderen en jongeren. Het serotonine transmitter systeem bloedplaatje (5-HTT) wordt inderdaad geaccepteerd als een minder invasief model van het 5-HT zenuweinde, aangezien het embryologische afkomst, biochemie, proteïne transport gen volgordes en functionaliteit gemeen heeft (Owens \& Nemeroff, 1994). Bij normale controles hadden patiënten met homozygotie voor de $L$ allel van de 5-HTT promoter gen een 1.4 tot 1.9 malen hogere opname dan dat van patiënten die één of twee copieën van de $S$ variant dragen, en de patiënten met L/S en S/S genotypes waren niet beduidend verschillend van elkaar. Deze cijfers komen overeen met het geobserveerde verband tussen de $\mathrm{L}$ allel en de hogere 5-HT opname in lymfoblast cellijnen (Lesch et al.,1996), en in bloedplaatjes van gezondheidscontroles op volwassenen (Greenberg et al.,1999), en suggereren eerder een dominant dan een codominant effect voor de $S$ allel. We hebben ook voor het eerst een beduidende vermindering vastgesteld van de maximale serotonine opname (Vmax) in medicijn-naïeve depressieve kinderen en jongeren. Een vergelijking tussen diagnostische groepen heeft aangegeven dat het L/L genotype een aanmerkelijk verschil vaststelt in de serotonine opname, terwijl de korte varianten (L/S of $S / S$ ) minimale verschillen teweegbrengen in de serotonine opname in bloedplaatjes. Deze gegevens suggereren in totaal dat patiënten die beide $L$ allelen dragen tijdens een depressieve episode blootgesteld kunnen worden aan epistatische/epigenetisce effecten, met invloed op de serotonine opname. Geen van de overige serotonine bloedplaatjes maatstaven wordt beïnvloed door het 5-HTT genotype, en dit bevestigt eerdere bevindingen van bloedplaatjes onderzoek in volwassen menselijke patiënten (Greenberg et al., 1999).

In Hoofdstuk 4 hebben we het mogelijke verband onderzocht tussen de 
aanvang van ernstige depressie en dysthymie bij kinderen en vroege pubers en de 5-HTTLPR locus, zowel met de case-control als de genetische familie gebaseerde aanpak. De resultaten van de case-control analyse onderbouwen het verband tussen de 5-HTTLPR locus en Depressieve Stoornissen bij kinderen en jongeren, met een klein maar betekenisvol effect van de S-allel en een gematigd hoger risico op Depressieve Stoornissen, zoals aangegeven door de odds ratio. De familie gebaseerde verband analyses, die meer overtuigend zijn omdat ze niet neigen tot stratificatie vervorming, onthullen dat de S-allel met voorkeur overgedragen wordt aan kinderen met Depressieve Stoornissen. Deze resultaten suggereren een rol van de 5-HTTLPR locus in negatieve emotionaliteit bij kinderen als een algemeen construct van neiging tot angst en depressie (Auerbach et al., 2001), en komen overeen met enkele (Collier et al. 1996; Gutierrez et al. 1998), maar niet alle (Clarke et al., 2010) onderzoeken op volwassenen met affectieve stoornissen.

De veronderstelling van een mogelijk effect op de interacties van 5HTTLPR polymorfisme en tegenslagen op psychopathologie bij kinderen en jongeren, in een gen-omgeving interactie perspectief, is onderzocht in Hoofdstukken 5 en 6.

In Hoofdstuk 5, in een relatief ongeselecteerde algemene bevolkingssteekproef van Noord-Italiaanse jonge pubers (met een leeftijd tussen 10 en 14 jaar) hebben we bewijs gevonden dat het 5-HTTLPR polymorfisme - afzonderlijk en in een duidelijke gen-door-omgeving interactie met een omgevings-risicofactor (i.e. gezinsstructuur) gecombineerd gaat met een hoger puntenaantal op de CBCL/6-18 Affectieve Stoornissen DSM-Gerichte Schaal. We hebben ontdekt dat pubers die deel uit maken van een 'één-ouder' gezin en tevens de 5HTTLPR 'S allel' dragen, een hoger risiko vertonen op het ontwikkelen van depressieve symptomen; we kunnen dus een rol toebedelen aan omgevingsfactoren die de bijdrage modereren van dit specifieke genetische polymorfisme aan menselijke verscheidenheid in depressieve symptomen. Onze ontdekking van een beduidende interactie tussen het 5-HTTLPR genotype en een mogelijke omgevings-risicofactor komt ruimschoots overeen met verschillende onderzoeken die aantonen dat de korte 5-HTTLPR allel een hoger risico genereert in combinatie met blootstelling aan stressvolle gebeurtenissen (Caspi et al., 2010), vooral met de onderzoeken die gebaseerd zijn op objectief bewijs of gedetaileerde interviews om tegenslagen in de leefomgeving in te schatten (voor een overzicht zie Uher \& McGuffin, 2008; Karg 2011), zoals hierna vermeld.

In Hoofdstuk 6 hebben we de onafhankelijke en gemeenschappelijke 
effecten onderzocht van de 5-HTTLPR, van de dopamine receptor D4 (DRD4) en van een maatschappelijke moderator, namelijk de socioeconomische status (SES) van het gezin op regelbrekend en aggressief gedrag, gemeten met de Child Behaviour CheckList/6-18 in dezelfde algemene bevolkingssteekproef van Noord-Italiaanse jonge pubers. We hebben bewijs gevonden, zowel gebaseerd op één locus als twee-loci genotype analyses, dat een lage SES en een 'lange' DRD4 allel en 5HTTLPR 'L' allel, zowel afzonderlijk als in interactie, samengaan met een hoger puntenaantal in aggressief gedrag. Deze bevindingen sluiten aan bij de uitkomst van andere onderzoeken op de invloed en de verhouding van dezelfde polymorfismen op verschillende maatregelen van naar buiten toe gericht gedrag van kinderen (Auerbach et al., 2001; Lakatos et al. 2003) en van volwassenen (Benjamin et al., 2002). In het bijzonder suggereerde Benjamin et al. (2002) dat de lange allelen van DRD4 en de korte allelen van 5-HTTLPR een tegengesteld effect hebben, in de zin dat de DRD4 lange allelen toenadering en extravert gedrag bevorderen, terwijl de korte allelen van 5-HTTLPR ontwijkend gedrag bevorderen. Met andere woorden, deze resultaten bevestigen de specifieke rol van de ' $S$ ' allel van 5 -HTTLPR in gesloten gedrag, en aangezien onze gegevens in lijn zijn met onderzoeken op jeugd en volwassenheid, voegen ze bewijs toe aan de veronderstelling dat dit antagonistiche interactie mechanisme aanwezig kan zijn tijdens de gehele duur van het menselijk leven. Bovendien, conform onderzoeken die de effecten aantonen van maatschappelijke moderatoren op de erfelijkheid van externaliserend gedrag bij verscheidene segmenten van de bevolking, suggereren we dat een vermindering van sociale beperkingen, in combinatie met een lage SES van de ouders, kan fungeren als versterking van de genetische invloed van specifieke DRD4 en 5-HTTLPR allelen op aggressief gedrag bij jonge pubers.

In Hoofdstuk 7 hebben we de modererende rol onderzocht van 5-HTTLPR polymorfisme bij de stabiliteit/instabiliteit van het internaliseren van problemen tijdens de puberteit, tevens rekening houdend met de mogelijke interactie met twee chronische maatschappelijke stressoren, d.m.v. het gebruik van tijd-sensitieve meettechnieken. We hebben de sociale, gedrags- en genetische gegevens geanalyseerd uit een vijjarig follow-up algemeen bevolkinsonderzoek met gebruik van Structural Equation Modelling. We hebben ontdekt dat het traject tussen het internaliseren van problemen en de gezinsstructuur bij de eerste golf (vroege pubers met een leeftijd tussen 10 en 14 jaar) alleen positief en betekenisvol was $(\beta=0.24$, $p<0.01)$ voor pubers met het $S$-allel genotype. Bovendien gaven de twee groepen (LL vs dragers van het S-allel genotype) grote verschillen aan in 
het traject tussen het internaliseren van problemen bij de eerste en de tweede golf (late pubers met een leeftijd tussen 15 en 19 jaar), hetgeen suggereert dat de onmiddellijke impact van het internaliseren van problemen bij de eerste golf op het internaliseren van problemen bij de tweede golf groter was in de groep van S-allel dragers. De gegevens van dit longitudinale onderzoek suggereren dat het 5-HTTLPR polymorfisme een belangrijke rol speelt in het vaststellen van de stabiliteit van deze psychopathologische karaktertrek gedurende een ontwikkelingsperiode (i.e. puberteit), wanneer het internaliseren van problemen groeit. Een modererende rol van 5-HTTLPR op het effect van de gezinsstatus bij het vaststellen van de aanwezigheid van het internaliseren van problemen is alleen ontdekt tijdens de vroege puberteit. 



\section{ACKNOWLEDGEMENTS}

This book is a summary of a long process developed in the last ten years but that has its roots in what has happend long before.

Thanks to Prof Enrico Smeraldi and to Dr Marco Catalano for giving me the opportunity to discover the biological and genetic side of Psychiatry, teaching me to reflect on biological processes underlying psychological and psychopathological processes. Thanks to Dr Massimo Molteni for giving me the chance to go on my research in the field of developmental psychopathology thus considering a different perspective on adult psychopathological traits: i.e. the evolution of behaviour throughout different developmental stages. Thanks to Prof Marco Battaglia and Dr Cecilia Marino for their precious advices and their willingness to discuss my ideas.

Thanks to all my friends and colleagues (Monica, Paola, Laura, Valentina, Claudio, Margherita, Alessandro, and especially to Sara who accepted to be my paranynph), living with me in the 'bunker', for their precious help and collaborations during all these years. Thanks to Sheila, my English teacher, for taking with a bit of humor the revision of all my manuscripts. A warm thanks to my husband, my sons, my parents and my mother in law for having tolerated me when I was crabbier then usual and for having always been close.

A special thank to Maastricht University and Prof Eric Griez for giving me the opportunity to obtain my doctoral degree, a special dream I have almost abandoned. Thanks also to Leni Noteborn for her help and kindness.

Finally a real special thank to Prof Giampaolo Perna for a sincere friendship that has its roots in the distant past and that has never failed. 



\section{CURRICULUM VITAE}

Maria Nobile was born in Giussano (Milan, Italy) in 1965. She is married and mother of four sons. She took her degree in Medecine and Surgery in 1990 and her residency in Psychiatry in 1994 at the University of Milan (Italy). In 1992 she was at the Vollum Institute for Advanced Biomedical Research, Oregon Health Science University, (Director: Prof. Olivier Civelli) for two months as Research Fellow. From 1992 to 1998 she worked as Clinical Assistant at the Psychiatry Department of the 'San Raffaele' Scientific Institute, University of Milan, Italy (Director: Prof E. Smeraldi). From 1998 to 2003 she worked as Clinical Assistant at the Child Psychiatry Department of the 'Eugenio Medea' Scientific Institute, Bosisio Parini, Italy (Director: Dr M. Molteni). From 2003, she is Clinical Research Consultant at the Child Psychiatry Department of the 'Eugenio Medea' Scientific Institute. She was Principal Investigator in several reserches supported by the Italian Ministry of Health on childhood and adolescence psychopathology, and especially, on the role of environmental pathogens and candidate genes and of their interaction in emotional and behavioral problems (including externalizing disorder, ADHD and depression) in childhood and adolescence. 


\section{PUBLICATIONS}

Nobile M, Colombo P, Bellina M, Molteni M, Simone D, Nardocci F, Carlet $\mathrm{O}$, Battaglia M. Psychopathology and adversities from early- to lateadolescence: a general population follow-up study with the CBCL DSM-Oriented Scales. Epidemiology and Psychiatric Sciences: 2012 Apr 11:1-11. [Epub ahead of print].

Salvaterra M, Giorda R, Bassi MT, Borgatti R, Knudsen LE., Martinuzzi A, Nobile M, Pozzoli U, Ramelli GP, Reni G, Rivolta D, Stazi MA, Strazzer S, Thijs C, Toccaceli V, Trabacca A, Turconi AC, Zanini S, Zucca C, Bresolin N, Lenzi L, Pediatric Biobanking ELSI Working Group (Rossetto MG) (2012); Pediatric biobanking: a pilot qualitative survey of practices, rules, and researcher opinions in ten european countries; Biopreservation and Biobanking, 2012, 10(1):29-36 Doi: 10.1089/bio.2011.0037

Nobile M., Perego P., Piccinini L., Mani E., Rossi A., Bellina M., Molteni M. Further evidence of complex motor dysfunction in drug naïve children with autism using automatic motion analysis of gait. Autism. 2011 May;15(3):263-83

Forti S; Valli A; Perego P; Nobile M; Crippa A; Molteni M. Motor planning and control in autism. A kinematic analysis of preschool children. Research In Autism Spectrum Disorders. 2011 April-June; 5(2), 834-842

Nobile M, Rusconi M, Bellina M, Marino C, Giorda R, Carlet O, Vanzin L, Molteni M, Battaglia M. COMT Val158Met polymorphism and socioeconomic status interact to predict attention deficit/hyperactivity problems in children aged 10-14. European Child and Adolescent Psychiatry. 2010 Jul;19(7):549-57. Epub 2009 Nov 28.

Nobile M, Rusconi M, Bellina M, Marino C, Giorda R, Carlet O, Vanzin $\mathrm{L}$, Molteni M, Battaglia M. The influence of family structure, the TPH2 G703T and the 5-HTTLPR serotonergic genes upon affective problems in children aged 10-14 years. Journal of Child Psychology and Psychiatry. 2009 Mar;50(3):317-25.

Nobile M, Giorda R, Marino C, Carnet O, Pastore V, Vanzin L, Bellina M, Molteni M, Battaglia M. Socioeconomic Status Mediates the Genetic Contribution of the DRD4 and 5-HTTLPR Polymorphisms to Externalization in Pre-adolescence. Development and Psychopathology. 2007 Fall;19(4):1147-60.

Marino C, Citterio A, Giorda R, Facoetti A, Menozzi G, Vanzin L, Lorusso 
ML, Nobile M, Molteni M. Association of short-term memory with a variant within DYX1C1 in developmental dyslexia. Genes Brain and Behaviour. 2007 Sep 20;6(7):640-646.

Battaglia M, Zanoni A, Giorda R, Pozzoli U, Citterio A, Beri S, Ogliari A, Nobile M, Marino C, Molteni M. Effect of the catechol-Omethyltransferase val/met genotype on children's early phases of facial stimuli processing. Genes Brain and Behaviour. 2007 Jun 6(4):364-74

Frigerio A, Vanzin L, Pastore V, Nobile M, Giorda R, Marino C, Molteni M, Rucci P, Ammaniti M, Lucarelli L, Lenti C, Walder M, Martinuzzi A, Carlet O, Muratori F, Milone A, Zuddas A, Cavolina P, Nardocci F, Tullini A, Morosini P, Polidori G, De Girolamo G. The Italian preadolescent mental health project (PrISMA): rationale and methods. International Journal of Methods in Psychiatric Research. 2006. 15(1):22-35.

Cataldo MG, Nobile M, Lorusso ML, Battaglia M, Molteni M. Impulsivity in depressed children and adolescents: a comparison between behavioral and neuropsychological data. Psychiatry Research. 2005 Sep 15;136(23):123-33.

Marino C, Giorda R, Luisa Lorusso M, Vanzin L, Salandi N, Nobile M, Citterio A, Beri S, Crespi V, Battaglia M, Molteni M. A family-based association study does not support DYX1C1 on $15 q 21.3$ as a candidate gene in developmental dyslexia. European Journal of Human Genetic. 2005, 13(4):491-9.

Marino C, Vanzin L, Giorda R, Frigerio A, Lorusso ML, Nobile M, Molteni $M$, Battaglia $M$. An assessment of transmission disequilibrium between quantitative measures of childhood problem behaviors and DRD2/Taql and DRD4/48bp-repeat polymorphisms. Behaviour Genetic. 2004; 34(5):495502.

Nobile M, Cataldo MG, Giorda R, Battaglia M, Baschirotto C, Bellina M, Marino C, Molteni M: A case-control and family-based association study of the 5-HTTLPR in pediatric-onset depressive disorders. Biological Psychiatry. 2004 Aug 15;56(4):292-5

Marino C, Giorda R, Vanzin L, Nobile M, Lorusso ML, Baschirotto C, Riva L, Molteni M, Battaglia M. A locus on 15q15-15qter influences dyslexia: further support from a transmission/disequilibrium study in an Italian speaking population. Journal of Medical Genetic. 2004 Jan;41(1):42-6.

Nobile M, Cataldo GM, Marino C, Molteni M: Diagnosis and treatment of dysthymia in children and adolescents. CNS drugs 2003, 44: 1545-8. 
Marino C, Giorda R, Vanzin L, Molteni M, Lorusso ML, Nobile M, Baschirotto C, Alda M, Battaglia M: No evidence of association and linkage disequilibrium between dyslexia and markers of four dopamine-related genes. European Child and Adolescent Psychiatry 2003, 12: 198-202.

Nobile M, Bellotti B, Marino C, Molteni M, Battaglia M: An open trial of Paroxetine in the treatment of children and adolescents with dysthymic disorder. Journal of Child and Adolescent Psychopharmacology 2000, 10(2): 103-109

Battaglia M, Ogliari A, Maffei C, Marino C, Molteni M, Nobile M.: Cautionary note: complex (dys)function of the serotonin transporter. Biological Psychiatry 2000, 48 (4): 334-335

Nobile M, Marino C, Molteni M, Battaglia M. Some ado about a polymorphism. American Journal of Psychiatry 2000 Nov;157(11):1886-8

Nobile M, Begni B, Giorda R, Frigerio A, Marino C, Molteni M, Ferrarese C, Battaglia M.: Effects of Serotonin Transporter Promoter Genotype on Platelet Serotonin Transporter Functionality in Depressed Children and Adolescents. Journal of American Academy of Child and Adolescent Psychiatry 1999, 38 (11): 1396-402

Serretti A, Lilli R, Di Bella D, Bertelli S, Nobile M, Novelli E, Catalano M, Smeraldi E: "Dopamine receptor D4 gene is not associated with major psychoses" American Journal of Medical Genetic 1999, 88 (5):486-491.

Zenner MT, Nobile M, Henningsen R, Smeraldi E Civelli O, Hartman DS, Catalano M: Expression and characterization of a dopamine D4R variant associated with delusional disorder. FEBS Letters 1998, 422 (2): 146-150

Nobile M., Maffei P., Noethen M.M., Rietchel M., Smeraldi E., Catalano M.: "Association study of Schizophrenia and the histidase gene" Psychiatric Genetics 7: 107-109, 1997.

Maffei P., Nobile M., Di Bella D., Novelli E., Smeraldi E., Catalano M.: "Intragenic tetranucleotide repeat polymorphism at the human histidase (HAL) locus". Clinical Genetics 52: 194-195, 1997.

Novelli E., Nobile M., Diaferia G., Sciuto G., Catalano M.:"A molecular investigation suggests no relationship between obsessive-compulsive disorder and Dopamine D2 receptor". Neuropsychobiology 29: 61-63, 1994.

Di Bella D., Catalano M., Strukel A., Nobile M., Novelli E., Smeraldi E.: "Distribution of the Msc-I polymorphism of the Dopamine D3 receptor in 
an italian psychotic population". Psychiatric Genetics 4: 39-42, 1994.

Catalano M., Sciuto G., Di Bella D., Novelli E., Nobile M., Bellodi L.: "Lack of association between obsessive-compulsive disorder and the dopamine D3 receptor gene: some preliminary considerations". American Journal of Medical Genetics (Neuropsychiatric Genetics) 54: 253-255, 1994.

Catalano M., Nobile M., Novelli E., Nothen M.M., Smeraldi E.: "Distribution of a novel mutation in the first exon of the human dopamine D4 receptor gene in psychotic patients. Biological Psychiatry 34: 459-464, 1993.

Marino C., Nobile M., Smeraldi E.:"Delusional Disorder and Mood Disorders: can they coexist?". Psychopathology 26: 53-61, 1993.

Catalano M., Nobile M., Novelli E., Smeraldi E.: "Use of PCR and DGGE to identify polymorphisms in three exons of Dopamine D2 Receptor Gene in Schizophrenic and Delusional Patients". Neuropsychobiology 26 (1-2): 1-3, 1992. 
